\title{
Revision of Scelio pulchripennis - group species (Hymenoptera, Platygastroidea, Platygastridae)
}

\author{
Matthew J. Yoder ${ }^{1, \dagger}$, Alejandro A. Valerio ${ }^{1, \neq}$, Andrew Polaszek ${ }^{2, \S}$, \\ Lubomír Masner, ${ }^{3,1}$, Norman F. Johnson ${ }^{1, \pi}$
}

I Department of Entomology, The Ohio State University, Columbus, Ohio. U.S.A. 2 Hymenoptera Section, Department of Entomology, Natural History Museum, London, U.K. 3 Agriculture and Agri-Food Canada, Ottawa, Canada

† urn:lsid:zoobank.org:author:1001CB72-70BF-46AC-9E72-A8B0C90814AF

†urn:lsid:zoobank.org:author:E4B936BE-5F7D-4A22-B9E7-D237BBDE45EB

§ urn:lsid:zoobank.org:author:AFDEB328-39B5-4902-A907-26603BCC99D6

| urn:lsid:zoobank.org:author:FA505310-F606-4F6C-A1DF-74B9A0055B2E

I urn:lsid:zoobank.org:author:3508C4FF-F027-445F-8417-90AB4AB8FE0D

Corresponding authors: Michael Sharkey (diapriid@gmail.com), Norman F. Johnson (johnson.2@osu.edu)

Academic editor: Norman Johnson | Received 14 May 2009 | Accepted 16 July 2009 | Published 14 September 2009

urn:lsid:zoobank.org:pub:BC2641F1-498F-48F0-8786-393772FA3B93

Citation: Yoder MJ, Valerio AA, Polaszek A, Masner L, Johnson N (2009) Revision of Scelio pulchripennis - group species (Hymenoptera, Platygastroidea, Platygastridae). In: Johnson N (Ed) Advances in the systematics of Hymenoptera. Festschrift in honour of Lubomír Masner. ZooKeys 20: 53-118. doi: 10.3897/zookeys.20.205

\begin{abstract}
The charismatic pulchripennis-group of Scelio Latreille is revised and 18 species are treated. The species group is described and diagnosed. Eight new species are described: S. clarkei Yoder, sp. n. (India, Sri Lanka); S. ememeye Yoder, sp. n. (Sri Lanka, Nepal); S. leipo Yoder, sp. n. (Madagascar); S. parapulchripennis Yoder, sp. n. (Madagascar); S. masneri Yoder, sp. n. (Botswana, South Africa); S. paranitens Yoder, sp. n. (Botswana, Kenya, South Africa, Zimbabwe); S. tria, Yoder \& Masner, sp. n. (India); and S. turbidus Yoder, sp. n. (Botswana, South Africa, Tanzania). Scelio princeps Nixon is treated as a junior synonym of S. poecilopterus Priesner (syn. n.). Scelio variegatus Kozlov \& Kononova is removed from synonymy with S. poecilopterus Priesner and treated as a valid species (stat. n.). Lectotypes are designated for Scelio baoli Risbec, S. corion Nixon, and S. pulchripennis Brues. Known hosts are eggs of grasshoppers in the family Acrididae (Orthoptera). The electronic version of this paper contains numerous hyperlinks that make use of biodiversity informatics standards to reference supporting data.
\end{abstract}

\section{Keywords}

Scelionidae, key, Orthoptera, egg parasitoid, revision

Copyright M.J. Yoder et al. This is an open access article distributed under the terms of the Creative Commons Attribution License, which permits unrestricted use, distribution, and reproduction in any medium, provided the original author and source are credited. 


\section{Introduction}

This paper is the first in a series from the Platygastroidea Planetary Biodiversity Inventory (PPBI), which seeks to revise a majority of the world's species of Scelio Latreille (Hymenoptera: Platygastridae). Scelio are found worldwide, and available host data suggest that they are exclusively parasitoids of orthopteran eggs (Dangerfield et al. 2001). Some Scelio have been implemented as important biological control agents (e.g., of the genus Oxya Serville); these efforts are most recently summarized in Dangerfield et al. (2001). The genus Scelio is one of the largest within the subfamily Scelioninae, with an estimated total of more than 500 species. The pulchripennis-group was first recognized and diagnosed in a key by Nixon (1958) to African Scelio species, and the group is easily diagnosed against worldwide species. Species recognized here as belonging to the group have also been described from Mongolia and Saudi Arabia (Kozlov and Kononova 1990), and we extend the known distribution further to include new species from India and Sri Lanka.

No work to date has specifically focused on supraspecific relationships within Scelio. Nixon (1958), in a key, referenced several groupings, and Dangerfield et al. (2001) present a phylogeny largely focused on the Australian species. Based on the larger efforts of the PPBI we believe that there are monophyletic groupings within Scelio. The pulchripennis-group is perhaps one of the most well supported morphologically, and as such it was excised and treated independently. The PPBI's future papers on Scelio will be geographically circumscribed (Asia, Afrotropics, South America), and each will treat multiple species groups. The treatment of the African species of Scelio will provide hypotheses for a some of these groups. Supraspecific group hypotheses are being tested in a quantitative framework with ongoing morphological and molecular work.

This paper represents a tribute to our co-author Lubomír Masner for his longtime contributions to Hymenoptera taxonomy. In addition to his many scientific works, Lubo's infectious enthusiasm and juggernaut collecting drive profoundly influenced several generations of hymenopteran systematists, including us. In recognition of his work in his honor we have named perhaps his favorite species in the pulchripennisgroup, at least as judged by the excitement in his voice when he first introduced to the senior author.

This work is a product of the Platygastroidea Planetary Biodiversity Inventory, a project funded by the U.S. National Science Foundation (N.F. Johnson, Ohio State University and A.D. Austin, University of Adelaide, principal investigators). One of the primary objectives of this project is to use biodiversity informatics tools to accelerate the taxonomic process and to make real-time collaboration possible among the narrow community of researchers with appropriate expertise. The contributions of the individual authors are: M.J. Yoder: project coordination, character definition, species concept development, species group concept development; key development, imaging, databasing of specimen data; A. Valerio: character development, species concept development, imaging, databasing of specimen data; A. Polaszek: character develop- 
ment, species concept development, imaging, databasing of specimen data; L. Masner: species group concept development; development of collection; N.F. Johnson: species identity; manuscript preparation. The authorship of the new taxa reflects the contribution of each individual.

\section{Materials and methods}

The following collections provided specimens for this study: BMNH, Natural History Museum, London, $\mathrm{UK}^{1}$; CASC, California Academy of Sciences, San Francisco, $\mathrm{CA}^{2}$; CNCI, Canadian National Collection of Insects, Ottawa, Canada ${ }^{3}$; INHS, Illinois Natural History Survey, Champaign, IL ${ }^{4}$; MCZC, Harvard University Museum of Comparative Zoology, Cambridge, $\mathrm{MA}^{5}$; MNHN, Muséum National d'Histoire Naturelle, Paris, France ${ }^{6}$; OSUC, C.A. Triplehorn Insect Collection, Columbus, $\mathrm{OH}^{7}$; SAMC, Iziko Museums of Cape Town, South Africa ${ }^{8}$; SANC, South African National Collection of Insects, Pretoria, South Africa ${ }^{9}$; TAMU, Texas A\&M University, College Station, TX ${ }^{10}$; USNM, National Museum of Natural History, Washington, DC ${ }^{11}$. The cutoff date for included specimens was November, 2008.

Species descriptions were prepared and generated as in Johnson et al. (2008) and Yoder et al. (2009). A description of how specimen and other data may be electronically accessed, and how hyperlinks are derived is available in Johnson et al. (2008). The Association sections are generated from information tied directly to specimens usually in the form of tags on the pin itself. The vocabulary used there for the biological relationships reflects the information that is found on the label. We strongly encourage users of the key to refer to the Comments section in the descriptions of individual species for information on morphological variability.

Images were taken with a JVC 3 CCD camera (model KY-575U) attached to a Leica Z16 APO with a Planapo $1.0 \times$ objective. Specimens were illuminated with a 4 channel LED dome light from Advanced Illumination, with light levels at maximum output. Figures were produced from stacks of images that vertically transected the specimen. These were combined automatically into a single image using either AutoMontage Pro version 5.1 or Cartograph software packages. For those images produced with Auto-Montage the resulting image was in most cases manually corrected for color balance, contrast, and in some cases introduced artifacts surrounding the specimen. Some images were post-processed for contrast and light levels in Adobe ${ }^{\circledast}$ Photoshop ${ }^{\circledast}$ or similar software.

Abbreviations and morphological terms used in the text follow Johnson et al. (2008). New abbreviations are used in conjunction with some figures, and defined in the respective caption. Sculpture is highly variable and important to species description in some Scelio species groups. The use of several terms may benefit from some clarification: irregular - the pattern of sculpture retains a general form (e.g. reticulate) while changing within a given referenced area (e.g. from elongate polygonal sculpture to narrow polygonal sculpture); obliterated - indicates a loosely delimited patch or 
area wherein the sculpture is variously reduced to absent, as if it were worn away or erased (but implying neither secondary process nor phylogenetic polarity); fine - features are sharply defined and relatively narrow.

Species of the pulchripennis-group have relatively uniform zones of sculpture on the head. To aid in their description, four areas (Figs. 3, 4) are referenced: lwf - lower

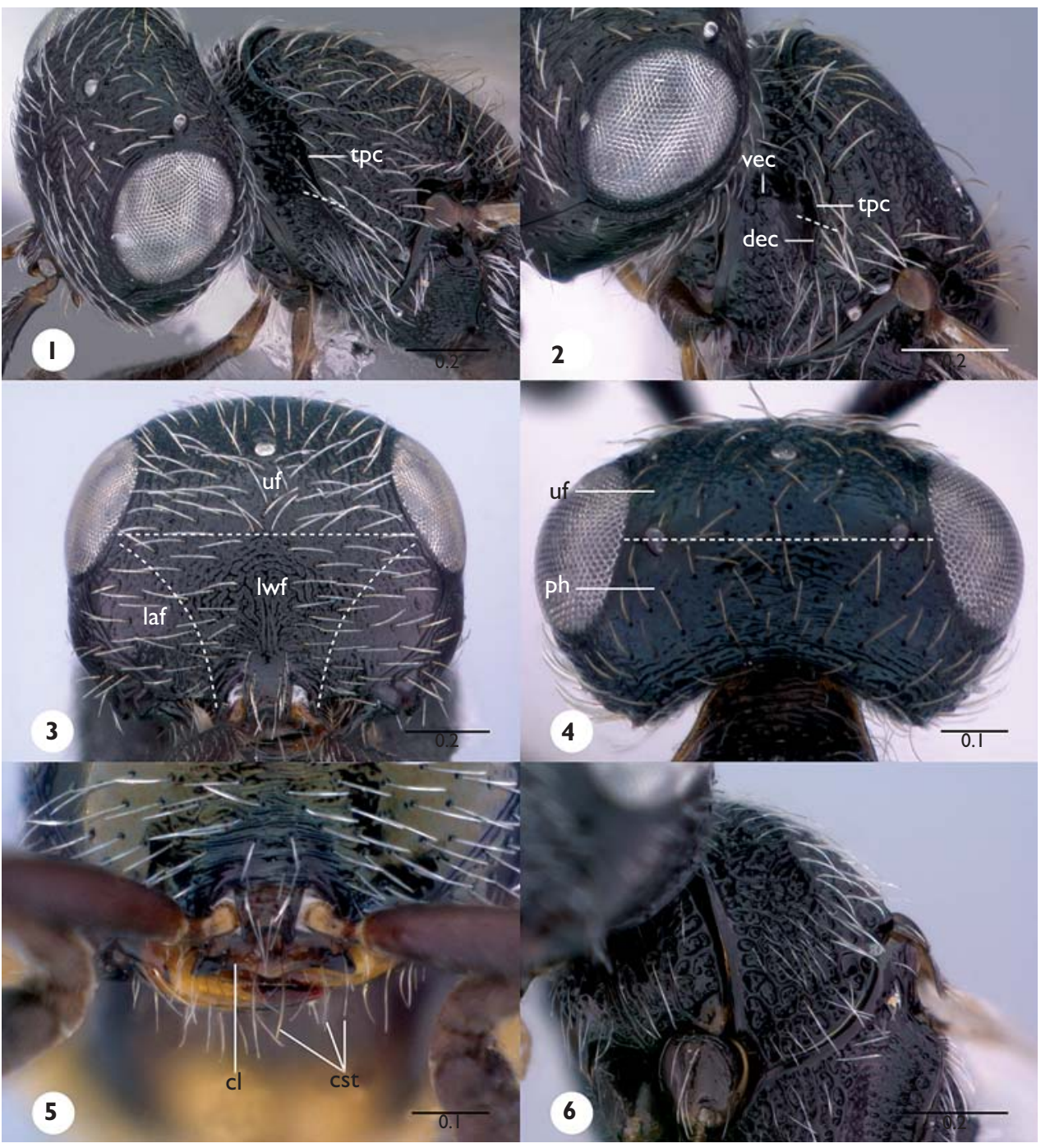

Figures I-6.99 I Scelio parapulchripennis sp. n., pronotum, dorsolateral oblique view, female (CASENT 2042134); 2 S. leipo sp. n., pronotum, dorsolateral oblique view, female (CASENT 2132586) 3 S. turbidus sp. n., head, anterior view, female (OSUC 223095) 4 S. antorides Nixon, head, dorsal view, female (OSUC 212555) 5 S. nitens sp. n., clypeus, anterior view, female (OSUC 212091) 6 S. parapulchripennis sp. n., pronotum, ventrolateral oblique view, female (CASENT 2042134). Abbreviations: $c l$, clypeus; cst, (paired) clypeal setae; $d e c$, dorsal epomial carina; laf, lateral frons; $l w f$, lower frons; $p h$, posterior head; $t p c$, transverse pronotal carina; $u f$, upper frons; vec, vertical epomial carina. Scale bars in millimeters. 
frons; laf - lateral frons, delimited by the malar sulcus laterally, and an arc from the lateral base of the clypeus to a point at around the lower 1/3 of the compound eye; uf - upper frons; and $\mathbf{p h ~ - ~ p o s t e r i o r ~ h e a d , ~ t h e ~ h e a d ~ v i s i b l e ~ i n ~ d o r s a l ~ v i e w ~ p o s t e r i o r ~ t o ~}$ a line connecting the lateral ocelli. All scale bars are in millimeters.

As a contribution to the effort to build an ontology of Hymenoptera anatomy the descriptive terminology was tested against the Hymenoptera Anatomy Ontology ("HAO", Deans et al. 2008, or http://purl.oclc.org/NET/hymontology/wiki). The complete descriptive lexicon was extracted from the character definitions as managed by the vSysLab software (see Johnson et al. 2008). The "proofing" function of the HAO was used to extract all unique single words and paired sequential word combinations that did not match entries already existing in the HAO. These were manually reviewed and selected for entry when appropriate. This process helps to ensure that the descriptive content within the paper is highly compatible with future algorithmic parsing, for example by software which seeks to automatically link gene expression data to phenotypes via an ontological hierarchy.

\section{Results}

\section{Scelio, pulchripennis-group Nixon, 1958}

Description. Predominantly moderately sized relative to other species of Scelio, Length $1.78-4.77 \mathrm{~mm}$; habitus somewhat flattened in lateral view, vertical distance between dorsal extent of mesonotum and propodeum minimal; body variously colored, orange to black, in some with metallic blue to green color on the head, mesosoma and posterodorsal metanotum; fore legs often lighter colored than mid and hind; sculpture often fine, or faintly impressed, often obliterated in patches; macropterous.

Pilosity throughout body of moderate length to elongate, often semi-erect to erect, in most with apices slightly curved, color typically lighter (white to light yellow) on lateral surfaces and on lateral T1-T2 and light golden brown on dorsal surfaces and apical metasoma; pilosity of lower (Fig. 2, lwf) and lateral frons (Fig. 2, laf) sparse to moderate, appressed to semi-decumbent, laterally oriented; pilosity of upper frons (Fig. 3, uf) sparse to moderate, appressed to semi-decumbent, orientation varying, though in nearly all species ventralmost setae laterally oriented, with those near the anterior ocellus and above dorsally oriented (see Comments section in species descriptions for notable exceptions); pilosity of the dorsal head (e.g. Fig. 4) nearly always similar in form and density to that of anterior, with few exceptions (see Comments sections in species descriptions); clypeus (anteclypeus) with three pairs of setae, the medial pair longest (Fig. 5); pilosity immediately adjacent to malar sulcus oriented posteriorly, sharply contrasting with ventrally oriented setae of posterior gena (lateral view); eye glabrous; pilosity of pronotum appressed to semi-decumbent, posterolaterally oriented; netrion always setose; pilosity of the anterior mesoscutum oriented posteriorly, that on the posterior mesoscutum oriented toward midline; pilosity of 
mesoscutellum frequently sparser medially, often slightly more erect than remaining mesonotal and mesoscutal setae, variously oriented; line of setae along anterior mesopleuron sparse (ventrally) to very dense; dorsal surface of propodeum almost glabrous, with only a small patch in anterolateral corner and a sparse line along posterolateral corner; line of setae along anterior line of metapleuron moderate to dense dorsally,

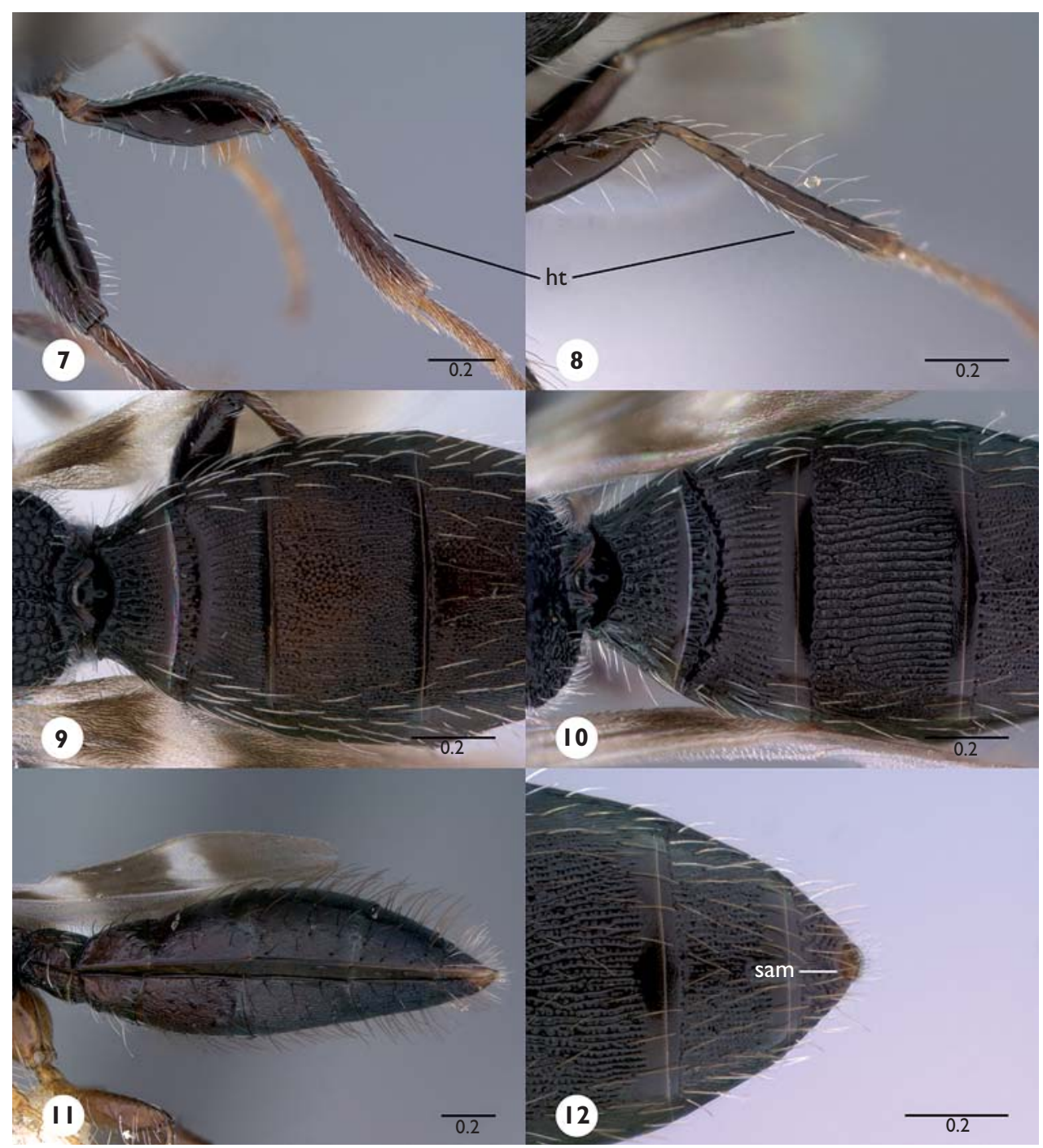

Figures 7-12.50 7 Scelio turbidus sp. n., hind femur, tibia, anterior view, female (OSUC 223095) 8 S. antorides Nixon, hind tibia, anterior oblique view, female (OSUC 214234) 9 S. baoli Risbec, anterior metasoma, dorsal view, female (OSUC 214182) 10 Scelio parapulchripennis sp. n., anterior metasoma, dorsal view, female (CASENT 2042134) II Scelio paranitens sp. n., metasoma, lateral view (OSUC 211472) I 2 Scelio parapulchripennis sp. n., posterior metasoma, dorsal view (CASENT 2042134). Abbreviations: $h t$, hind tibia; sam, subapical margin. Scale bars in millimeters. 
absent to very dense ventrally; T1-T3 more or less glabrous dorsally, sometimes with line of sparse appressed setae along posterior margin of T3; dorsal T4-T6 gradually more densely setose, often with setae gradually more erect posteriorly; T1 laterally with sparse to moderately dense pilosity, line of setae on lateral margin absent to sparsely present, never forming dense linear patch; pilosity of lateral T2-T6 typically somewhat sparse though very dense in a few species, density and form largely following that of remaining body; laterotergites glabrous or with sparse, appressed to semidecumbent short, straight, and narrow light brown setae.

Head somewhat quadrate in anterior view, with gena below eye not strongly curved towards mandible (Nixon 1958), and somewhat sharply reflexed towards mandible, narrow in lateral view; claval formula A12-A7:1-2-2-2-2-2; flagellum relatively compact, A3-A4 not particularly elongate, evenly broadening into base of compact clava; male flagellum compact, flagellomeres typically as wide or wider than long; male A5 unmodified; ocelli very small, lateral ocellus separated from margin of eye by a distance roughly equal to its diameter; ventral orbit of eye often with some minute rugulae; malar sulcus always present, sometimes partially obliterated; sculpture surrounding malar sulcus obliterated to absent, rarely with smoother area reduced to a thin strip, usually with some very fine confused rugulae along anteroventral margin of eye; antennal scrobe not developed, confluent with surrounding surface, nearly always with fine transverse striae, uncommonly with confused rugulae; interantennal process not strongly projecting, uniform in shape, without medial armature, toruli (carina of interantennal process) not forked or extended onto antennal scrobe; mandible with lower tooth reduced in size, often blunt and much shorter than upper tooth, rarely completely absent; upper mandibular node absent; basal tooth absent; lateral head smooth with setigerous punctures to more or less reticulate with margins smooth to obliterated, frequently finely umbilicate, density and distribution of sculpture closely paralleling that of remainder of head; genal carina absent; occipital carina percurrent, a sharp narrow carina, clearly concave (sometimes deeply so) near base of mandible.

Mesosoma with vertical epomia almost horizontal, never percurrent, obliterated anteriorly, typically present only as a slight branch from the junction of the transverse pronotal carina and the lateral epomial carina; antespiracular patch of pronotum present near posterior extension of lateral epomia, slightly anteroventral to pronotal spiracle, patch a verriculelike bump or small group of appressed to semierect setae; pronotal collar thin and smooth, without even microsculpture; anterior margin of netrion generally poorly delimited, somewhat fused throughout; fore wing typically surpassing anterior margin of T5, without percurrent tubular veins; venation in both sexes reduced, fore wing with submarginal vein more or less obliterated near its curve towards costal margin, never tubular; stigmal vein nebulous; fore wing pseudostigma present but poorly differentiated; hind wing submarginal vein spectral except at base where it is nebulous; female fore wing pictate, always with a basal pigmented spot, a basal fascia, and pigmentation in apex beyond pseudostigma, apical pigmentation typically beginning at stigmal vein, with or without an apical fascia, margin glabrous; male wings hyaline to (rarely) slightly infuscate; mesoscutellum broadly separated 
from mesoscutum medially; axillulae (lateral node) weakly developed; mesepipleural margin undefined; metascutellum unarmed; propodeum flat, prominently visible in dorsal view, with longitudinal-sinuate (serpentine) sculpture throughout (species with metallic color, e.g., Fig. 60), or sculpture predominantly reticulate (species without metallic color); propodeal projections not developed, corners of propodeum relatively evenly rounded, not bulging laterally (Fig. 60); propodeal nucha smooth, medially divided by extension of the medial carinae of propodeum, in larger individuals some weak additional longitudinal carinae laterad of medial carinae; upper margin of metapleuron posterior to propodeal spiracle strongly sloped, somewhat curved; metapleural depression more or less absent; legs without spines or other obvious armature; hind femur smooth, sparsely setose, with distinct lines of erect setae along antero- and dorsoventral margins.

Metasoma in lateral view with terga and sterna more or less symmetrical, weakly convex, or terga evenly arcuate (Fig. 11, most metallic individuals); anterior margin of $\mathrm{T} 1$ concave; sculpture of T4-T5 similar in form to that of T3, but typically denser, more compact, finer, less strongly impressed; T6 sculpture variable, degree of impression of sculpture similar to that seen in preceding terga, typically consisting of confused longitudinal striae that curve slightly towards posterolateral margin, number of reticulations variable, interstices more or less smooth to irregularly minutely rough; preapical margin of T6 always semicircular (Fig. 12, sam); sculpture on transition from dorsal to lateral terga often obliterated; felt fields absent, at most with extremely slight differentiation (narrow, as if pinched together) on T2; medial S3-S5, and sometimes S2, with sculpture obliterated to absent, rarely sculpture present; lateral S3-S5 in most species with longitudinal sculpture, in a few this somewhat reticulate; S6 sculpture variable, often irregularly reticulate, with some longitudinal trend, interstices smooth to minutely rough, sculpture fine to coarse.

Diagnosis. Most similar to species in the walkeri group sensu Nixon (1958), both sharing the absence of angular corners of the propodeum, presence of a sharply cascading band of setae behind the propodeal spiracle (lateral view), and the absence of modification of the male A5. Distinguished from species of the walkeri group by the broadly concave clypeus with a slight medial projection, the absence of a basal tooth on the mandible, the strong reduction to absence of the lowermost (posterior/ventral) tooth, the absence of thickened appressed white setae and the relatively flattened habitus with elongate propodeum. Additional diagnostic (but not unique) characters include the presence of pictate wings in females, the evenly rounded, semicircular subapical margin of T6 (Fig. 12, sam), and the more or less completely sculptured lower frons. Around half the known pulchripennis-group species can be further distinguished from Old World species of Scelio by the presence of metallic coloration on the head, mesosoma or dorsal metasoma.

Two other groups warrant mention here. An undescribed group ("S") known from three species from South Africa shares several similar characters. The anteclypeus shares the same general form but is narrower, with the medial point much broader. Species of group " $\mathrm{S}$ " also have somewhat narrow, erect pilosity as seen in many pulchripennis- 
group species, and relatively fine sculpture throughout. However, the setae are more robust (not flattened) than pulchripennis-group species and females do not have pictate fore wings. Scelio fulgidus Crawford, an Australian species, also shares a number of apparent convergences or parallelisms with species of the pulchripennis-group. Specimens of $S$. fulgidus have the lower mandibular tooth reduced, with the mandible relatively sharply pointed, a somewhat flattened habitus, and numerous obliterated or polished areas. Beyond these striking but superficial similarities they can be diagnosed against pulchripennis-group species by the lack of pictate wings, the shape of S6, and the trapezoidal medial anteclypeus.

Distribution. Species of the pulchripennis-group are found throughout Africa (including the Canary Islands), the southern Arabian Peninsula, Turkmenistan, India, Sri Lanka, Nepal and Mongolia.

Comments. Based on the available material, females are more commonly collected than males by a ratio of about 4:1. Males of the different species are quite uniform in sculpture, particularly that of the thorax, and have reduced metallic color in those species that have it. Based on external morphology alone, the association of males with conspecific females is difficult. The absence of modifications of the male release and spread structure (A5) and the interspecific convergence of sculptural characters of the mesonotum (in males) complicates this task. Because of the limited material available, males were not dissected, and diagnoses and descriptions pertain to females alone unless otherwise explicitly noted.

\section{Key to species of the Scelio pulchripennis-group (females)}

1 Body massive ( $4.8 \mathrm{~mm}$ long in the specimen we examined, recorded as 5.5 $\mathrm{mm}$ in Kozlov and Kononova, 1990), black throughout, without metallic coloration; mesoscutum robustly sculptured medially, with two smooth patches in humeral area (Fig. 72); apical fascia of fore wing absent (Figs. 67, 68) (Mongolia) Scelio nisa Kozlov

- $\quad$ Body typically sized (usually around 2.5-4 mm long, never $>4.5 \mathrm{~mm}$ ), body variously colored, if metasoma dark brown to black and concolorous with mesosoma, then with a distinct metallic sheen; mesoscutum variously sculptured, with or without smooth patches; apical fascia of fore wing (Fig. 101, af) absent or (more commonly) present 2

2 Mesoscutum with 2-3 straight longitudinal carinae (Fig. 114, car) that correspond roughly to the notauli and the medial mesoscutal line, length of medial pair reduced in some cases; sculpture of lateral mesoscutum more or less absent; body without orange or metallic coloration (India, Nepal, Sri Lanka)........... 3 Mesoscutum variously sculptured, sometimes with notauli indicated, if appearing to have three carinae as above, then mesosoma orange, mesoscutellum variously sculptured or smooth; lateral mesoscutum with or without sculpture; body with or without metallic coloration 
3 Mesoscutellum sculptured with more or less parallel carinae throughout (Fig. $114)$; notauli typically indicated as a pair of carinae at posterior margin of mesoscutum (Fig. 114) (India). Scelio tria Yoder \& Masner, sp. n.

- Mesoscutellum with sculpture obliterated medially, otherwise rugulose with very slight longitudinal trend (Fig. 42); notauli indicated by single irregular carina with many short transverse extensions (Fig. 42, nt) (Nepal, Sri Lanka). Scelio ememeye Yoder, sp. n.

4 Head and mesosoma black with green metallic sheen; posterodorsal head (Fig. 4, ph) with well-defined transverse striae; base of upper frons (as in Fig. 4, uf) with band of ventrally oriented setae (Fig. 29); fore wing with fuscate patches reduced in size, without a clearly defined apical fascia, margin with more or less transparent band throughout (Fig. 26); pilosity of anterior metapleuron very sparse (India, Sri Lanka)

Scelio clarkei Yoder, sp. n.

Head and mesosoma variously colored, if head metallic then without transverse striae, smooth or densely reticulate; setae of upper frons typically oriented laterally or dorsally; fore wing with well-developed fuscate patches that meet wing margins; pilosity of anterior metapleuron moderate to very dense (Africa, Arabian Peninsula, Madagascar) ............................................5 Mesonotum smooth and shining except for setose punctures and, occasionally, longitudinal carinae along posterior margin adjacent to mesoscutellum (Figs. 75, 81, 96); dorsal head completely smooth Mesonotum predominantly sculptured, at most with some smooth obliterated patches along humeral area, between notauli, or on anterior mesoscutum (e.g., Figs. 18, 24, 42, 126); dorsal head variously sculptured, though usually with at least some fine faint sculpture

6 Head and mesoscutum metallic green to blue; posterior margin of mesoscutum and anterior margin of mesoscutellum smooth (Kenya and south to South Africa) Head black, mesoscutum orange, sometimes brown to dark brown medially, without any trace of metallic coloration; posterior margin of mesoscutum and anterior margin of mesoscutellum with slight grooves (Egypt, Eritrea, India, Saudi Arabia, United Arab Emirates, Spain, Yemen)

Scelio poecilopterus Risbec

Fore wing with apical fascia absent (not to be confused with presence of lighter colored radial cell) (Fig. 78); pilosity of hind tibia strongly appressed, not distinctly elongate (Fig. 7, 74, ht) (Botswana, Namibia, South Africa, Zimbabwe) Scelio nitens Brues

- $\quad$ Fore wing with apical fascia present (Fig. 84, af); pilosity of of hind tibia nearly completely erect, distinctly elongate, and somewhat sparse (Fig. 8, 80, ht) (Botswana, Kenya, South Africa, Zimbabwe) ....... Scelio paranitens Yoder, sp. n. Mesosoma orange, with at most some patches of brown to dark brown color dorsomedially 
Mesosoma brown, nearly black, or with a metallic sheen or coloration, if traces of orange (primarily along sutures) then otherwise completely metallic 10 Head black, without any trace of metallic coloration, sculptured throughout, with sculpture almost granular in appearance (Fig. 125); medial mesoscutum with parallel fine striae all but anteriorly, lateral mesoscutum smooth (Fig. 126); body moderately hairy, pilosity of moderate length, white to golden brown, appressed to semi-erect (Figs. 121, 122); posterodorsal metasoma without metallic coloration (Canary Islands, India, Saudi Arabia, Spain, United Arab Emirates, Yemen) Scelio variegatus Kozlov \& Kononova Head completely metallic, green or blue, with dense fine rugulae throughout (Fig. 65); mesoscutum with fine rugulae throughout (Fig. 63); body densely setose, with long, white and erect setae (Fig. 62); posterodorsal metasoma with metallic blue coloration (Botswana, South Africa) Scelio masneri Yoder, sp. n. Head and mesosoma with metallic sheen to strong metallic coloration, frequently sheen visible on dorsal metasoma as well, degree of metallic coloration variable, bright to almost absent, but always present; metasoma in profile with terga arched, terga and sterna somewhat asymmetrical (cf. Fig. 11) ...........11 Head, mesosoma (and metasoma) without metallic sheen, brown to black; metasoma in profile with terga more or less flat to slightly convex, not arched, terga and sterna more or less symmetrical (e.g., Fig. 54).... Head and mesonotum uniformly sculptured throughout with fine well-developed rugulae (Fig. 57) (South Africa, Zimbabwe) ........ Scelio marbis Nixon Head and mesonotum somewhat irregularly sculptured, frequently with smooth patches, particularly on vertex near lateral ocelli, rugulae somewhat coarse (Figs. 4, 18) (South Africa).... Scelio antorides Nixon Lateral mesoscutum with a distinct smooth patch or completely smooth (Figs. 33, 117)

Lateral mesoscutum sculptured throughout (cf. Figs. 24, 51, 87) 15 Dorsal mesoscutum with 4 smooth or obliterated patches, two medially and 1 laterally in each humeral area (Fig. 33); medial mesoscutum rugulose where sculpture not obliterated; sculpture of lower frons variable; shape of hind femur variable (eastern to southern Africa).

- $\quad$ Dorsal mesonotum with 2 smooth patches, sculptured throughout medially, humeral area with a distinct smooth patch; medial mesoscutal sculpture predominantly longitudinal, parallel-sided, with interstices predominantly smooth, though occasionally with few to moderate number of transverse elements (Fig. 33); lower frons with fine transverse striae (Fig. 35); hind femur narrow, dorsal surface weakly convex (Niger, Mali, Burkina Faso). Scelio corion Nixon Dorsal head nearly completely smooth and shining; transverse pronotal carina incomplete (cf. Fig. 1); hind femur narrow, more or less symmetrical; lower frons striate (South Africa) Scelio habilis Nixon Dorsal head sculptured throughout, though very minutely and faintly in some; transverse pronotal carina complete, meeting mesoscutum or adjacent 
cell (cf. Fig. 2); hind femur broad, dorsal surface distinctly bulging (Fig. 7, hf); lower frons rugulose in most individuals, Fig. 119) (Botswana, Tanzania, South Africa) Scelio turbidus Yoder, sp. n.

15 Apical fascia of fore wing absent (Fig. 54); transverse pronotal carina incomplete (Fig. 1) (Madagascar) Scelio leipo Yoder, sp. n.

- $\quad$ Apical fascia of fore wing present (sometimes only slightly contrasting with lighter surroundings) (as in Fig. 101); transverse pronotal carina complete or incomplete 16

16 Pronotum with transverse pronotal carina incomplete, not meeting mesoscutum or adjacent cell (Fig. 1); apical fascia with a well-developed posterior element (Fig. 101, af) (South Africa) Scelio pulchripennis Brues

- $\quad$ Pronotum with transverse pronotal carina complete, meeting mesoscutum or adjacent cell (Fig. 2); apical fascia present only along anterior margin, if area along posterior margin appearing lighter then whole of apex weakly infuscated and no clear division between fascia and apex delimited

17 Sculpture of T3 predominantly parallel longitudinal with evident gap between longitudinal elements (Fig. 10); mesoscutellar sculpture somewhat rugulose, rugulae often somewhat flattened in appearance, with only slight longitudinal trend (Fig. 87) (Madagascar)

Scelio parapulchripennis Yoder, sp. $\mathrm{n}$.

- $\quad$ Sculpture of T3 finely reticulate, with few prominent longitudinal elements (Fig. 9); sculpture of mesoscutellum predominantly fine parallel striae, in most specimens with few connecting interstices (widespread throughout continental Africa)

Scelio baoli Risbec

\section{Scelio antorides Nixon}

urn:lsid:zoobank.org:act:B99930DE-213B-4ED1-9137-2D3C60206DF1

urn:Isid:biosci.ohio-state.edu:osuc_concepts:5170

Figs 4, 8, 13-18; Morphbank ${ }^{12}$

Scelio antorides Nixon, 1958: 305, 317 (original description. keyed); Masner, 1965a: 92 (type information).

Description. Female body length: $2.61-3.85 \mathrm{~mm}(\mathrm{n}=8)$. Color of antenna in female: concolorous, brown to dark brown throughout. Color of head in female: black with subtle dark blue sheen, or black with subtle dark green sheen. Color of mesosoma in female: brown to dark brown with subtle dark blue to teal sheen, sheen visible dorsally and in some specimens laterally. Color of coxae in female: brown to dark brown. Color of leg past coxa in female: brown to dark brown. Color of metasoma in female: brown to dark brown.

Sculpture of lower frons in female: predominantly transverse to slightly arcuate striae, or predominantly fine irregular rugulae. Sculpture of ventrolateral frons in female: dense fine rugulae. Form of malar sulcus in female: sulcus percurrent, slit, groove 
or carina extremely narrow but course well defined, or not percurrent, with some sections variously obliterated. Sculpture of upper frons of female: rugulose, sculpture between lateral ocelli and immediately below obliterated to varying degrees. Sculpture of dorsal head between and posterior to lateral ocelli in female: rugulose, obliterated in spots or not. Mandible of female: upper tooth typically developed, lower tooth very short but clearly present, truncate to pointed.

Transverse pronotal carina in female: well developed, linear or with extremely slight deviations, contiguous with mesoscutum or interrupted by a single subpolygo-

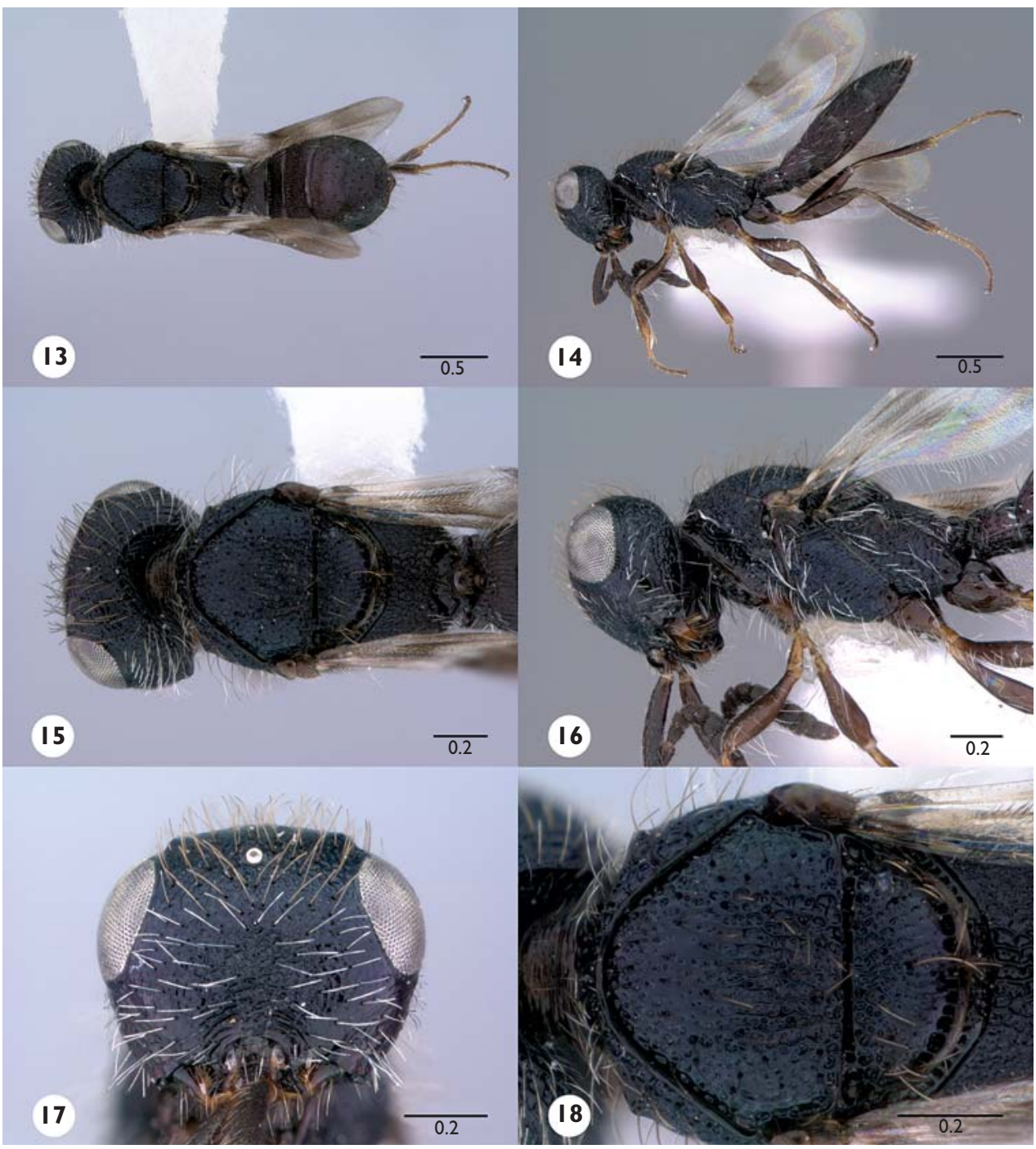

Figures 13-18. ${ }^{51}$ Scelio antorides Nixon, female (OSUC 214234). 13 Habitus, dorsal view 14 Habitus, lateral view $\mathbf{1 5} \mathrm{Head}$ and mesosoma, dorsal view $\mathbf{1 6} \mathrm{Head}$ and mesosoma, lateral view $\mathbf{1 7} \mathrm{Head}$, anterior view 18 Mesonotum, dorsal view. Scale bars in millimeters. 
nal cell, anterior shoulder relatively abruptly transitioned to anterior pronotum, or absent mesad, transition from dorsal shoulder to anterior pronotum not sharply delimited but rather slightly curved, if appearing slightly present then either obliterated medially or composed of adjacent subpolygonal sculpture. Sculpture of medial mesoscutum in female: rugulose to roundly reticulate, rugulae rarely fine, typically slightly flattened, a longitudinal trend visible in some specimens, within anterior half some obliteration or at least slight polish. Sculpture of notaular course in female: more or less undifferentiated to slightly more robust and coarse relative to medial sculpture. Sculpture of lateral mesoscutum in female: present. Sculpture of mesoscutellum in female: rugulose, rugulae obliterated and flattened in some specimens, particularly posteriorly, therein appearing roundly reticulate to punctulate. Sculpture of lateral pronotum in female (excluding interstitial sculpture): reticulate sculpture throughout (smooth patch below lateral epomial carina absent). Pronotal verricule in female: small bump with 1-2 very short setae at center. Pronotal setal patch posteroventral to end of lateral epomial carina in female: very sparse (around 1-3), long, erect setae. Sculpture of mesopleural depression in female: predominantly longitudinally striate. Pilosity of anteroventral metapleuron in female: dense patch of semi-decumbent to erect setae. Dorsal surface of hind tibia in female: sparse, elongate, erect and slightly curved. Shape of hind femur in female: narrow, dorsal and ventral surfaces relatively symmetrical. Basal pigmented spot of fore wing in female: percurrent from submarginal vein to posterior margin, striplike (a band), divided only by hyaline course of $\mathrm{M}+\mathrm{Cu}$. Basal fascia of fore wing in female: subrectangular, striplike, percurrent from anterior to posterior margin. Apical fascia of fore wing in female: broad, hyaline, percurrent from anterior to posterior fore wing margin, apex of fore wing past fascia concolorous with distal patch.

Sculpture of dorsal T1 in female: longitudinally striate, with few to no transverse divisions or reticulations, interstices smooth or with very slight irregular microsculpture. Sculpture of dorsal T2 in female: fine parallel to slightly reticulate striae with minutely colliculate to transverse sculpture within interstices. Sculpture of anterior T2 through anterior depression in female: percurrent. Sculpture of dorsal T3 in female: fine parallel to irregular longitudinal striae, with reticulation absent to moderately present. Medial sculpture of T4 in female: present, obliterated to smooth. Medial sculpture of T5 in female: obliterated to smooth. Sculpture of T2-T5 curved transition from dorsal to lateral terga in female: sculptured. Profile of female metasoma in lateral view: ventral surface more or less flat, dorsal surface weakly to strongly arched from T2-T6 highest point between T4-T5, evenly curved to T6. Sculpture of lateral T2-T6 in female: T2 striate-obliterated, T3-T6 with dense striae throughout. Pilosity of laterotergites in female: glabrous, or apparently so.

Diagnosis. Scelio antorides can be distinguished from most species by the presence of metallic coloration on the mesosoma, a state it shares with $S$. ememeye and $S$. marbis. The species is diagnosable from $S$. ememeye by the completely sculptured lateral mesoscutum (largely smooth in $S$. ememeye), and from $S$. marbis by the obliterated smooth patches on the dorsal head (finely reticulate-rugulose throughout in S. marbis). 
Link to distribution map. [http://osuc.biosci.ohio-state.edu/HymOnline/maplarge.html?id=5170]

Material examined. Holotype female: SOUTH AFRICA: South Africa, Western Cape Prov., Mossel Bay, V.1921, R.E. Turner, OSUC 254459 (deposited in BMNH). Other material: SOUTH AFRICA: 16 females, 17 males, OSUC 254460-254465, 254467-254484 (BMNH); OSUC 211458, 211510, 211517, 211550, 212555 (CNCI); OSUC 214234, 223241-223242 (SAMC); OSUC 250705 (SANC).

Comments. Several character states in $S$. antorides are relatively variable. The sculpture of the head is predominantly rugulose, though the regularity, and to a lesser degree thickness, varies somewhat. In some specimens the sculpture forms somewhat regular and more elongate channels that tend to arch around the orbit of the eye. The degree of obliteration of sculpture on the head and mesonotum is also variable, though there is an overall trend to have some obliteration present, particularly surrounding the lateral ocelli. The intensity and color of the metallic sheen varies: most species exhibit a dark blue sheen, with a few species having a brighter, more green to teal tint. The pilosity surrounding the pronotal verricule in $S$. antorides is more or less absent, which is notable for pulchripennis-group species. Three specimens are included here tentatively (OSUC 212555, 211458, 211510); they differ slightly in tint, size and sculpture of the mesoscutum and in future revisions should be compared with newly collected material.

\section{Scelio baoli Risbec}

urn:lsid:zoobank.org:act:894ADEA5-47EF-4E2B-B2CB-12B72795384F

urn:Isid:biosci.ohio-state.edu:osuc_concepts:5180

Figs 9,19-24; Morphbank ${ }^{13}$

Scelio baoli Risbec, 1950: 589 (original description); Masner, 1976: 17 (type information).

Description. Female body length: $2.76-3.77 \mathrm{~mm}(\mathrm{n}=24)$. Male body length: 3.02 $\mathrm{mm}(\mathrm{n}=1)$. Color of antenna in female: A1 brown to dark brown, tip of A2 and A3 slightly lighter (to yellow), remaining brown to dark brown. Color of head in female: black. Color of mesosoma in female: dark brown to black. Color of coxae in female: brown to dark brown. Color of leg past coxa in female: brown to dark brown. Color of metasoma in female: brown to dark brown.

Sculpture of lower frons in female: predominantly transverse to slightly arcuate striae. Sculpture of ventrolateral frons in female: minutely rugulose to obliterated, sculpture appearing slightly rough, without fine umbilicate sculpture. Form of malar sulcus in female: sulcus percurrent, slit, groove or carina extremely narrow but course well defined. Sculpture of upper frons of female: rugulose, with dorsoventral trend. Sculpture of dorsal head between and posterior to lateral ocelli in female: rugulose, obliterated in spots or not. Mandible of female: upper tooth typically developed, lower tooth very short but clearly present, truncate to pointed. 
Transverse pronotal carina in female: well developed, linear or with extremely slight deviations, contiguous with mesoscutum or interrupted by a single subpolygonal cell, anterior shoulder relatively abruptly transitioned to anterior pronotum. Sculpture of medial mesoscutum in female: fine reticulate to irregularly rugulose. Sculpture of notaular course in female: more or less undifferentiated to slightly more robust and coarse relative to medial sculpture. Sculpture of lateral mesoscutum in female: present. Sculpture of mesoscutellum in female: irregularly longitudinally striate, sparsely to moderately reticulate. Sculpture of lateral pronotum in female (excluding interstitial

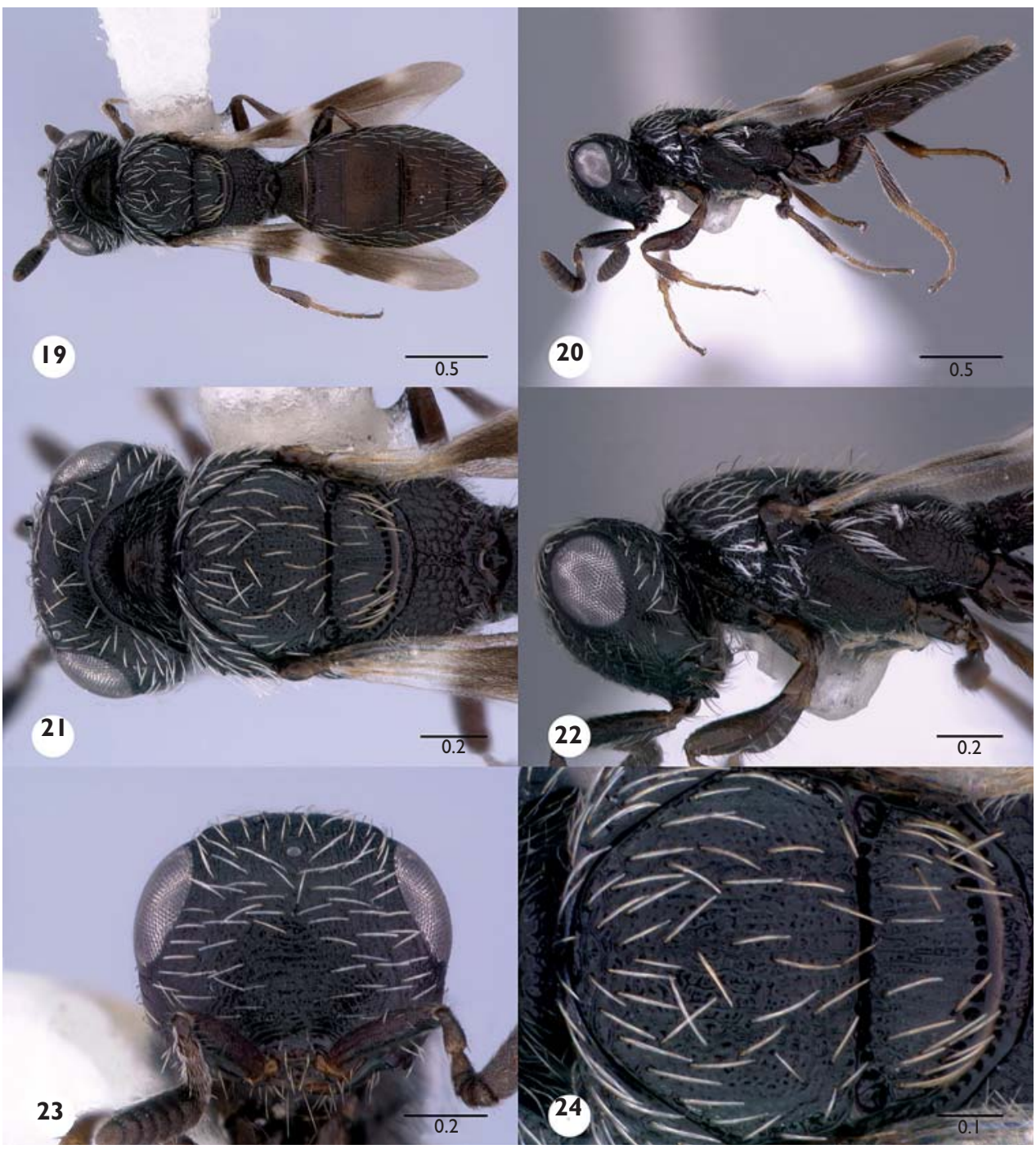

Figures 19-24.52 Scelio baoli Risbec, female (OSUC 214182). 19 Habitus, dorsal view 20 Habitus, lateral view $\mathbf{2} \mathbf{I}$ Head and mesosoma, dorsal view $\mathbf{2 2} \mathrm{Head}$ and mesosoma, lateral view $\mathbf{2} 3 \mathrm{Head}$, anterior view 24 Mesonotum, dorsal view. Scale bars in millimeters. 
sculpture): with smooth to obliterated patch immediately below lateral epomial carina, otherwise reticulate with few to moderate longitudinal elements. Pronotal verricule in female: apparently absent. Pronotal setal patch posteroventral to end of lateral epomial carina in female: dense (around 5 to many) small patch of appressed to slightly semidecumbent setae. Sculpture of mesopleural depression in female: predominantly irregularly reticulate. Pilosity of anteroventral metapleuron in female: glabrous, or sparsely setose. Dorsal surface of hind tibia in female: typical distribution and moderate length, setae appressed to loosely appressed, more or less straight. Shape of hind femur in female: narrow, dorsal and ventral surfaces relatively symmetrical. Basal pigmented spot of fore wing in female: percurrent from submarginal vein to posterior margin, striplike (a band), divided only by hyaline course of $\mathrm{M}+\mathrm{Cu}$. Basal fascia of fore wing in female: subrectangular, striplike, percurrent from anterior to posterior margin. Apical fascia of fore wing in female: broad, more or less semicircular, only slightly lightened, without lighter patch posteriorly, gradually lighter to apex of fore wing.

Sculpture of dorsal T1 in female: longitudinally striate, with moderate to dense reticulation, intersticies rough throughout. Sculpture of dorsal T2 in female: fine parallel to slightly reticulate striae with minutely colliculate to transverse sculpture within interstices. Sculpture of anterior T2 through anterior depression in female: interrupted with by a smooth strip, majority of sculpture not contiguous with that of posterior T2. Sculpture of dorsal T3 in female: dense minute reticulations, with slight longitudinal elements absent to very sparse. Medial sculpture of T4 in female: present, obliterated to smooth. Medial sculpture of T5 in female: obliterated to smooth. Sculpture of T2T5 curved transition from dorsal to lateral terga in female: sculptured. Profile of female metasoma in lateral view: dorsal and ventral surfaces more or less evenly convex. Sculpture of lateral T2-T6 in female: fine irregular longitudinal striae throughout. Pilosity of laterotergites in female: present on T1-T5, present on T1-T4.

Diagnosis. Similar to other nonmetallic species with the mesoscutum completely sculptured. Differing from these by the combination of the uninterrupted transverse pronotal carina, the presence of an apical fascia on the fore wing and the fine reticulate sculpture of T3.

Link to distribution map. [http://osuc.biosci.ohio-state.edu/HymOnline/maplarge.html?id=5180]

Associations. Emerged from eggs of Zacompsa festa Karsch (Orthoptera: Acrididae, Acridinae).

Material examined. Lectotype female (present designation): SENEGAL: M'Bambey, OSUC 234732 (deposited in MNHN). Other material (46 females, 1 male): BENIN: 1 female, OSUC 254437 (BMNH). BOTSWANA: 10 females, OSUC 211498, 211527, 211530, 211555, 211583 (CNCI); OSUC 164199, 212087 (OSUC); OSUC 171362-171363, 171370 (USNM). MOZAMBIQUE: 1 female, OSUC 211540 (CNCI). SENEGAL: 1 female, OSUC 234731 (MNHN). SOUTH AFRICA: 27 females, 1 male, OSUC 254436 (BMNH); OSUC 211453, 211499, 211518, 211520, 211531-211532, 211576, 211578-211580, 211587, 235073 (CNCI); OSUC 142600 (OSUC); OSUC 213542, 213678, 213684, 213928, 214182, 
223326 (SAMC); OSUC 167010, 167017-167018, 213328, 213482, 250707250708, 250710 (SANC). TANZANIA: 1 female, OSUC 211516 (CNCI). YEMEN: 2 females, OSUC 211514-211515 (CNCI). ZAMBIA: 1 female, OSUC 254434 (BMNH). ZIMBABWE: 3 females, OSUC 211456-211457, 211588 (CNCI).

Comments. It is likely that the concept of Nixon (1958) and other past workers of S. pulchripennis is the concept presented here for S. baoli. Nixon (1958) noted "Sculpture of the scutellum very variable...", and while there are general trends, the sculpture of the mesoscutellum and mesoscutum does indeed vary in the relative prominence of longitudinal versus transverse elements. Nixon's (1958) figure of the wing seems to match more closely the wing of $S$. leipo, but interpretation of the presence or absence of the apical fascia is difficult. In the past Malagasy specimens in the pulchripennis-group were identified as $S$. pulchripennis. All material from Madagascar is here excluded from S. baoli; see S. parapulchripennis and S. leipo for material from Madagascar.

Scelio baoli is the most widespread species within Africa. While the majority of specimens are known from eastern Africa, the type series was collected in Senegal. In West Africa $S$. baoli can only be confused with $S$. corion. In some specimens of $S$. baoli the lateral mesoscutum is slightly polished or flattened, which would seem to represent an intermediate state between the absence of sculpture observed in S. corion and its presence in $S$. baoli. The unique sculpture of the medial mesoscutum in S. corion (relatively uninterrupted longitudinal grooves, cf. Fig. 10) together with the obliterated patches on the lateral metasoma (sculptured throughout in $S$. baoli), however, clearly distinguishes S. corion from S. baoli. The particularly dense, fine reticulate to near granulate sculpture of the metasoma is most common, though weakly striate sculpture is also possible.

Risbec (1950) did not designate a holotype, but listed three specimens as the material he examined. We were only able to locate two of these three in the MNHN. We have designated one of these as the lectotype in order anchor the concept of $S$. baoli.

Three potentially extralimital specimens are here included in S. baoli. Two individuals from Yemen match well with smaller individuals from South Africa with the wing banding pattern being slightly more highly contrasting, the apical fascia appearing percurrent from anterior to posterior. At present this difference does not seem to warrant description of an additional species. A single specimen from Nigeria (OSUC 211518) has the sculpture of the metasoma and face less dense than typically observed, but otherwise matches well. See also Comments section for S. pulchripennis.

\section{Scelio clarkei Yoder, sp. n.}

urn:lsid:zoobank.org:act:886F90AB-C5B2-41F7-9CF3-C981FE1726CE urn:Isid:biosci.ohio-state.edu:osuc_concepts:238050

Figs 25-30; Morphbank ${ }^{14}$

Description. Female body length: 3.13-3.35 mm ( $\mathrm{n}=6)$. Male body length: 3.13$3.16 \mathrm{~mm}(\mathrm{n}=2)$. Color of antenna in female: A1-A5 or A6 yellow to light brown, remaining brown. Color of head in female: black with subtle dark green sheen. Color 
of mesosoma in female: dark brown, dorsally with subtle dark green sheen. Color of coxae in female: brown to dark brown. Color of leg past coxa in female: brown to dark brown. Color of metasoma in female: brown to dark brown.

Sculpture of lower frons in female: predominantly transverse to slightly arcuate striae. Sculpture of ventrolateral frons in female: smooth, with some clearly defined fine umbilicate sculpture. Form of malar sulcus in female: not percurrent, with some sections variously obliterated. Sculpture of upper frons of female: rugulose, with dorsoventral trend. Sculpture of dorsal head between and posterior to lateral ocelli in

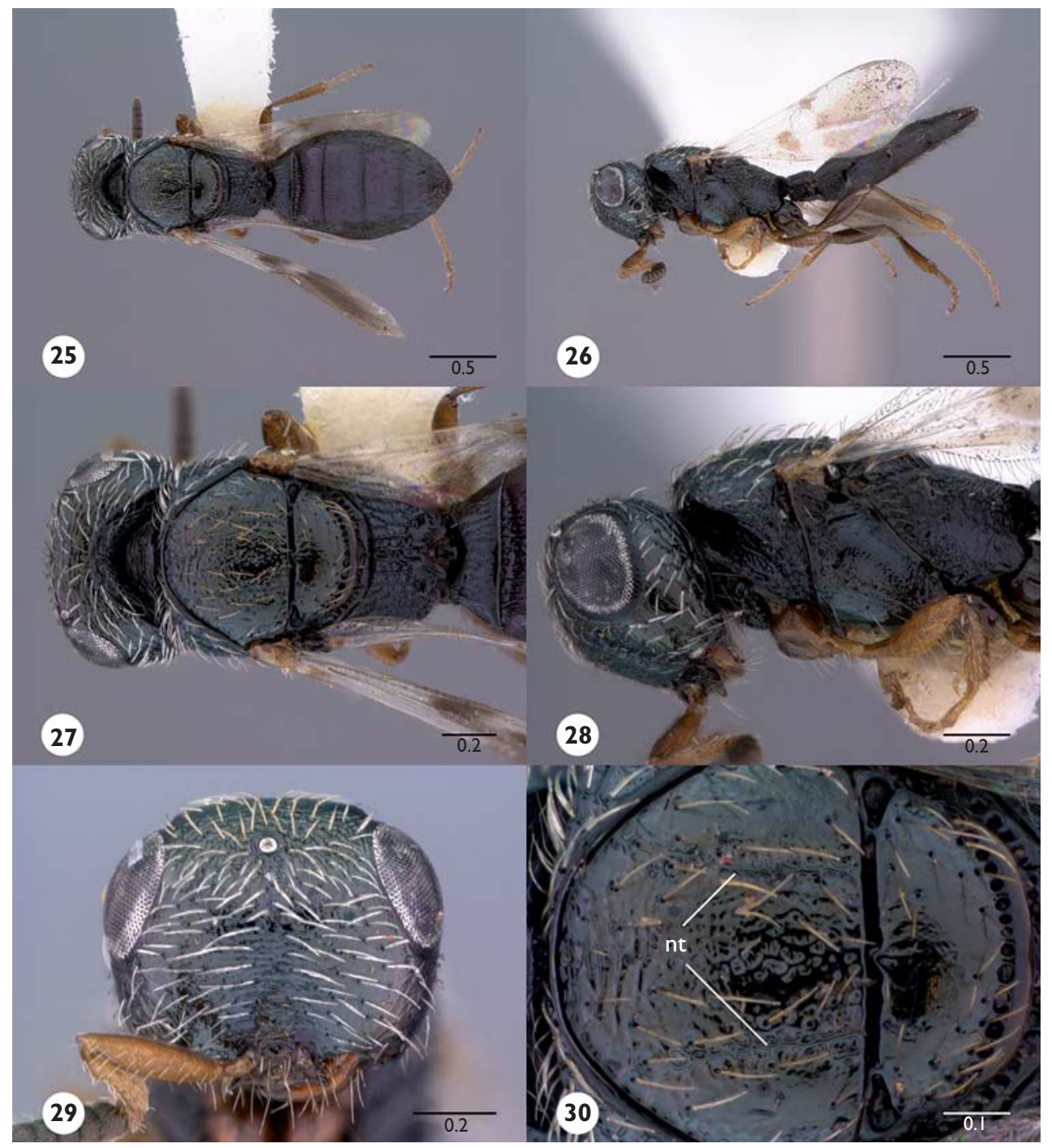

Figures 25-30.53 Scelio clarkei sp. n. (OSUC 211565). 25 Habitus, dorsal view 26 Habitus, lateral view 27 Mesosoma, dorsal view 28 Mesosoma, lateral view 29 Head, anterior view 30 Mesonotum, dorsal view. Abbreviation: $n t$, notauli. Scale bars in millimeters. 
female: fine irregular transverse striae. Mandible of female: upper tooth typically developed, lower tooth very short but clearly present, truncate to pointed.

Transverse pronotal carina in female: well developed, linear or with extremely slight deviations, contiguous with mesoscutum or interrupted by a single subpolygonal cell, anterior shoulder relatively abruptly transitioned to anterior pronotum. Sculpture of medial mesoscutum in female: anterior patch of transverse striae, remainder rugulose-reticulate, in some specimens this sculpture more or less obliterated throughout. Sculpture of notaular course in female: medial irregular longitudinal carina that is scrobiculate (with transverse branches) to each side. Sculpture of lateral mesoscutum in female: absent, or with obliterated patch that covers at least $1 / 2$ of area. Sculpture of mesoscutellum in female: predominantly smooth, with only scattered setigerous punctures. Sculpture of lateral pronotum in female (excluding interstitial sculpture): with smooth to obliterated patch immediately below lateral epomial carina, otherwise reticulate with few to moderate longitudinal elements. Pronotal verricule in female: base more or less unmodified, with tightly clumped clump of extremely short setae. Pronotal setal patch posteroventral to end of lateral epomial carina in female: sparse (around 2-5) scattered, shorter semidecumbent to erect setae. Sculpture of mesopleural depression in female: surface smooth or with very faint coriaceous (obliterated) sheen, with minute foveae or grooves along posterior margin. Pilosity of anteroventral metapleuron in female: glabrous, or sparsely setose. Dorsal surface of hind tibia in female: typical distribution and moderate length, setae appressed to loosely appressed, more or less straight. Shape of hind femur in female: narrow, dorsal and ventral surfaces relatively symmetrical. Basal pigmented spot of fore wing in female: medially situated, not reaching submarginal vein, faintly reaching hind margin. Basal fascia of fore wing in female: subrectangular, striplike, percurrent from anterior to posterior margin. Apical fascia of fore wing in female: absent, fore wing past marginal vein gradually lighter.

Sculpture of dorsal T1 in female: longitudinally striate, with few to no transverse divisions or reticulations, interstices smooth or with very slight irregular microsculpture. Sculpture of dorsal T2 in female: fine parallel to slightly reticulate striae with minutely colliculate to transverse sculpture within interstices. Sculpture of anterior T2 through anterior depression in female: percurrent. Sculpture of dorsal T3 in female: fine parallel to irregular longitudinal striae, with reticulation absent to moderately present. Medial sculpture of T4 in female: present. Medial sculpture of T5 in female: obliterated to smooth. Sculpture of T2-T5 curved transition from dorsal to lateral terga in female: obliterated to smooth. Profile of female metasoma in lateral view: dorsal and ventral surfaces more or less evenly convex. Sculpture of lateral T2-T6 in female: fine irregular striae ventrally, faint coriaceous to obliterated sculpture dorsally. Pilosity of laterotergites in female: present on T1-T2.

Diagnosis. Most similar to S. ememeye which shares similarly formed notauli (a single carina, Fig. 30, nt) and a relatively short T1 medially. Diagnosed against all species by the unique pattern of infuscation on the fore wing in which the coloration throughout is more 
or less absent along the margins. Further diagnosed against all species with metallic coloration by the form of the notauli (Fig. 30, nt) and the transverse striae of the dorsal head.

Etymology. First discovered in material from Sri Lanka, the long-time residence of the recently deceased Arthur C. Clarke, a noted science fiction writer.

Link to distribution map. [http://osuc.biosci.ohio-state.edu/HymOnline/maplarge.html?id=238050]

Material examined. Holotype female: INDIA: Tamil Nadu St., Coimbatore, 25.IX-1.X.1979, J. S. Noyes, OSUC 238948 (deposited in BMNH). Paratypes: (5 females, 2 males) INDIA: 3 females, 2 males, OSUC 238949-238951 (BMNH); OSUC 59152, 59154 (OSUC). SRI LANKA: 2 females, OSUC 211565-211566 (CNCI).

Comments. Remarkable for the pattern of infuscation on the fore wing. The pilosity of the lateral mesosoma is highly reduced relative to most species. T1 is particularly narrow medially. If the ventrally oriented strip of setae of the upper frons (Fig. 29) is not an artifact then this state is unique for all species in the group.

\section{Scelio corion Nixon}

urn:1sid:zoobank.org:act:7500884A-B732-430C-BDD1-EAB910CC9D87 urn:lsid:biosci.ohio-state.edu:osuc_concepts:5207

Figs 31-36; Morphbank ${ }^{15}$

Scelio corion Nixon, 1958: 305, 316 (original description. keyed); Masner, 1965a: 92 (type information).

Description. Female body length: $2.60-3.32 \mathrm{~mm}(\mathrm{n}=16)$. Male body length: 3.00 $\mathrm{mm}(\mathrm{n}=1)$. Color of antenna in female: A1 brown to dark brown, tip of A2 and A3 slightly lighter (to yellow), remaining brown to dark brown. Color of head in female: black. Color of mesosoma in female: dark brown to black. Color of coxae in female: brown to dark brown. Color of leg past coxa in female: brown to dark brown. Color of metasoma in female: brown to dark brown.

Sculpture of lower frons in female: predominantly transverse to slightly arcuate striae. Sculpture of ventrolateral frons in female: minutely rugulose to obliterated, sculpture appearing slightly rough, without fine umbilicate sculpture. Form of malar sulcus in female: sulcus percurrent, slit, groove or carina extremely narrow but course well defined. Sculpture of upper frons of female: rugulose, with dorsoventral trend. Sculpture of dorsal head between and posterior to lateral ocelli in female: rugulose, obliterated in spots or not. Mandible of female: upper tooth slightly elongate, elongate-triangular, lower tooth absent to almost imperceptible, a slight extension of the inner-ventral margin, or upper tooth typically developed, lower tooth very short but clearly present, truncate to pointed.

Transverse pronotal carina in female: well developed, linear or with extremely slight deviations, contiguous with mesoscutum or interrupted by a single subpolygonal cell, anterior shoulder relatively abruptly transitioned to anterior pronotum. 
Sculpture of medial mesoscutum in female: reticulate-rugulose in anterior $1 / 4-1 / 3$, otherwise parallel-striate with no to very few reticulations, striae broadly separated, interstices with little to no sculpture. Sculpture of notaular course in female: more or less undifferentiated to slightly more robust and coarse relative to medial sculpture. Sculpture of lateral mesoscutum in female: absent, or with obliterated patch that covers at least $1 / 2$ of area. Sculpture of mesoscutellum in female: longitudinally striate, with few to no reticulations. Sculpture of lateral pronotum in female (excluding interstitial sculpture): reticulate sculpture throughout (smooth patch below lateral

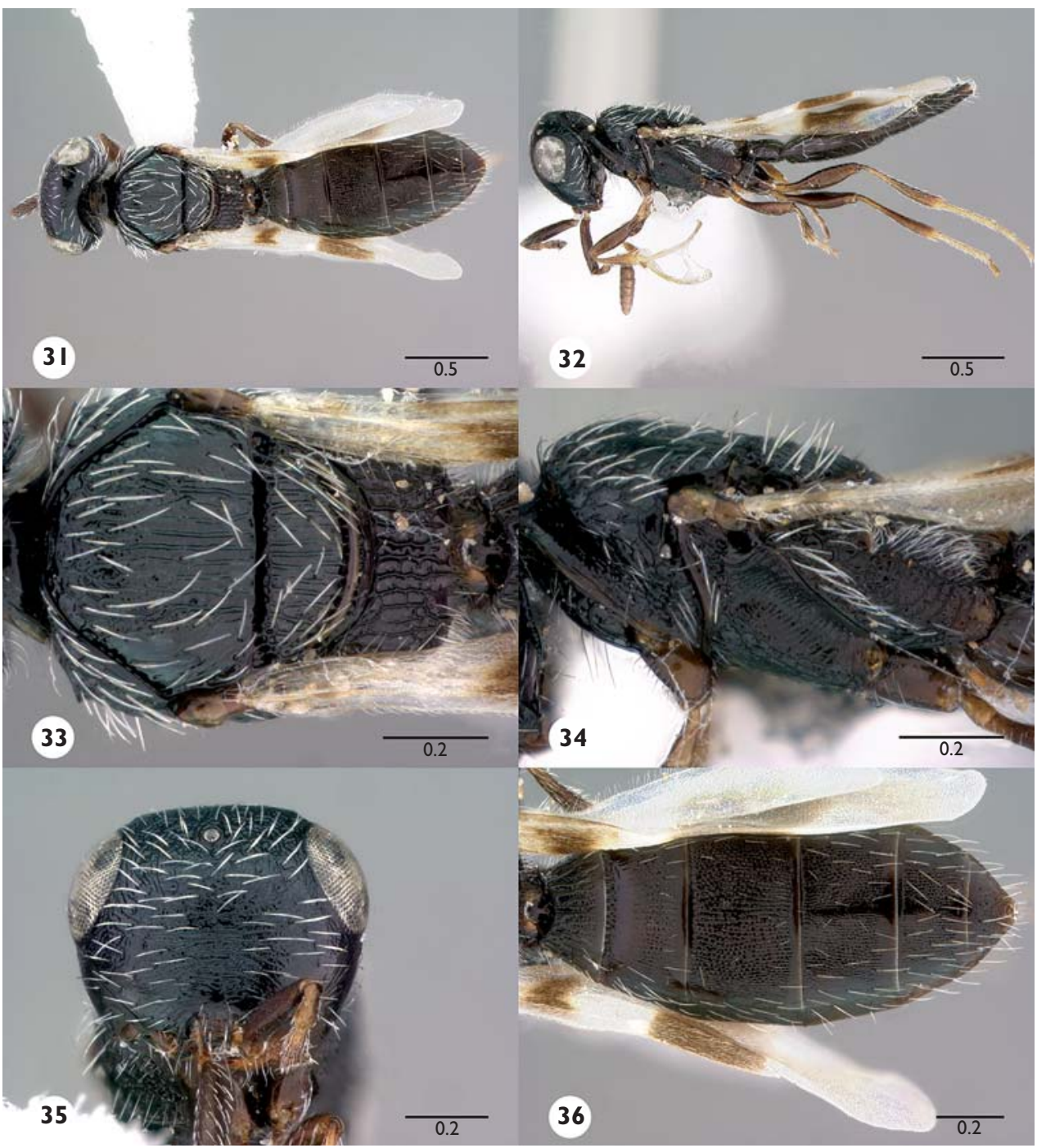

Figures 3 I-36. ${ }^{54}$ Scelio corion Nixon (OSUC 142617). 3 I Habitus, dorsal view; 32 Habitus, lateral view; 33 Mesosoma, dorsal view; 34 Mesosoma, lateral view; 35 Head, anterior view; 36 Metasoma, dorsal view. Scale bars in millimeters. 
epomial carina absent). Pronotal verricule in female: base more or less unmodified, with tightly clumped clump of short to moderately elongate setae. Pronotal setal patch posteroventral to end of lateral epomial carina in female: dense (around 5 to many) small patch of appressed to slightly semi-decumbent setae. Sculpture of mesopleural depression in female: predominantly longitudinally striate. Pilosity of anteroventral metapleuron in female: glabrous, or sparsely setose. Dorsal surface of hind tibia in female: typical distribution and moderate length, setae appressed to loosely appressed, more or less straight. Shape of hind femur in female: narrow, dorsal and ventral surfaces relatively symmetrical. Basal pigmented spot of fore wing in female: percurrent from submarginal vein to posterior margin, striplike (a band), divided only by hyaline course of $\mathrm{M}+\mathrm{Cu}$. Basal fascia of fore wing in female: subrectangular, striplike, percurrent from anterior to posterior margin. Apical fascia of fore wing in female: anterior margin with slightly lighter smaller patch, posterior margin even fainter (less contrasting), broadly divided medially by coloration that gradually fades to apex of fore wing.

Sculpture of dorsal T1 in female: polygonal-reticulate, interstices more or less smooth, longitudinally striate, with few to no transverse divisions or reticulations, interstices smooth or with very slight irregular microsculpture. Sculpture of dorsal T2 in female: fine parallel to slightly reticulate striae with minutely colliculate to transverse sculpture within interstices. Sculpture of anterior T2 through anterior depression in female: interrupted with by a smooth strip, majority of sculpture not contiguous with that of posterior T2. Sculpture of dorsal T3 in female: fine parallel to irregular longitudinal striae, with reticulation absent to moderately present. Medial sculpture of T4 in female: obliterated to smooth. Medial sculpture of T5 in female: obliterated to smooth. Sculpture of T2-T5 curved transition from dorsal to lateral terga in female: obliterated to smooth. Profile of female metasoma in lateral view: dorsal and ventral surfaces more or less evenly convex. Sculpture of lateral T2-T6 in female: fine irregular longitudinal striae throughout. Pilosity of laterotergites in female: present on T1-T5, present on T1-T4, present on T1-T3.

Diagnosis. Most similar to $S$. turbidus which shares the combination of absence of metallic coloration, presence of smooth patches on the lateral mesoscutum, and a percurrent transverse pronotal carina. Differing from $S$. turbidus by the sculpture of the lower frons face (striate, not rugulose), the shape of the hind femur (relatively narrow, not bulging), and the regular parallel striae of the medial mesoscutum (reticulate or obliterated in S. turbidus).

Link to distribution map. [http://osuc.biosci.ohio-state.edu/HymOnline/maplarge.html?id=5207]

Associations. Emerged from eggs of Acrididae; (Orthoptera); emerged from eggs of Hieroglyphus daganensis Krauss (Orthoptera: Acrididae, Hemiacridinae); emerged from eggs of Kraussaria Uvarov (Orthoptera: Acrididae, Cyrtacanthacridinae); emerged from eggs of Orthoptera; emerged from eggs of Sherifuria haningtoni Uvarov (Orthoptera: Acrididae, Acridinae); solitary egg parasitoid of Sherifuria haningtoni Uvarov. 
Material examined. Lectotype female (present designation): MALI: [French Sudan] central flood plain of Niger River, I.1956-III.1956, G. Popov, ex eggs of Sherifuria haningtoni Uvarov, OSUC 254515 (deposited in BMNH). Other material (33 females, 5 males): BURKINA FASO: 1 female, OSUC 211444 (CNCI). MALI: 16 females, 4 males, OSUC 254516-254525, 254529-254533 (BMNH); OSUC 211439-211443 (CNCI). NIGER: 14 females, 1 male, OSUC 254526-254528, 254534-254535 (BMNH); OSUC 213710-213712, 244208-244211, 251068-251070 (TAMU). NIGERIA: 2 females, OSUC 211584 (CNCI); OSUC 142617 (OSUC).

Comments. The sculpture of the interstices within the parallel longitudinal striae of the mesoscutum varies somewhat, with few to moderate transverse elements present in some individuals.

\section{Scelio ememeye Yoder, sp. n.}

urn:lsid:zoobank.org:act:5DBB647C-559E-4A11-B7DE-9528AE7291E0 urn:lsid:biosci.ohio-state.edu:osuc_concepts:238051

Figs 37-42; Morphbank ${ }^{16}$

Description. Female body length: 3.16-3.61 mm $(\mathrm{n}=3)$. Male body length: 3.06$3.32 \mathrm{~mm}(\mathrm{n}=3)$. Color of antenna in female: A1-A3 yellow to light brown, remaining brown. Color of head in female: black. Color of mesosoma in female: dark brown to black. Color of coxae in female: amber-orange. Color of leg past coxa in female: amber-orange. Color of metasoma in female: brown to dark brown.

Sculpture of lower frons in female: predominantly transverse to slightly arcuate striae. Sculpture of ventrolateral frons in female: smooth, with some clearly defined fine umbilicate sculpture. Form of malar sulcus in female: not percurrent, with some sections variously obliterated. Sculpture of upper frons of female: rugulose, with dorsoventral trend. Sculpture of dorsal head between and posterior to lateral ocelli in female: rugulose, obliterated in spots or not. Mandible of female: upper tooth typically developed, lower tooth very short but clearly present, truncate to pointed.

Transverse pronotal carina in female: well developed, linear or with extremely slight deviations, contiguous with mesoscutum or interrupted by a single subpolygonal cell, anterior shoulder relatively abruptly transitioned to anterior pronotum. Sculpture of medial mesoscutum in female: anterior patch of transverse striae, otherwise with a medial band of irregular rugluae/foveas bounded by thin more or less smooth strips. Sculpture of notaular course in female: broad band of confused minute foveae. Sculpture of lateral mesoscutum in female: absent, or with obliterated patch that covers at least $1 / 2$ of area. Sculpture of mesoscutellum in female: minute round reticulations, patch immediately laterad median slightly obliterated. Sculpture of lateral pronotum in female (excluding interstitial sculpture): with smooth to obliterated patch immediately below lateral epomial carina, otherwise reticulate with few to moderate longitudinal elements. Pronotal verricule in female: base more or less unmodified, with tightly clumped clump of short to moderately elongate setae. Pronotal setal patch posteroven- 
tral to end of lateral epomial carina in female: dense (around 5 to many) small patch of appressed to slightly semi-decumbent setae. Sculpture of mesopleural depression in female: reticulate, with a smooth band in anterior half. Pilosity of anteroventral metapleuron in female: glabrous, or sparsely setose. Dorsal surface of hind tibia in female: typical distribution and moderate length, setae appressed to loosely appressed, more or less straight. Shape of hind femur in female: narrow, dorsal and ventral surfaces relatively symmetrical. Basal pigmented spot of fore wing in female: medially situated, not reaching fore or hind margin, not fusing with apical pigmented area, or percurrent

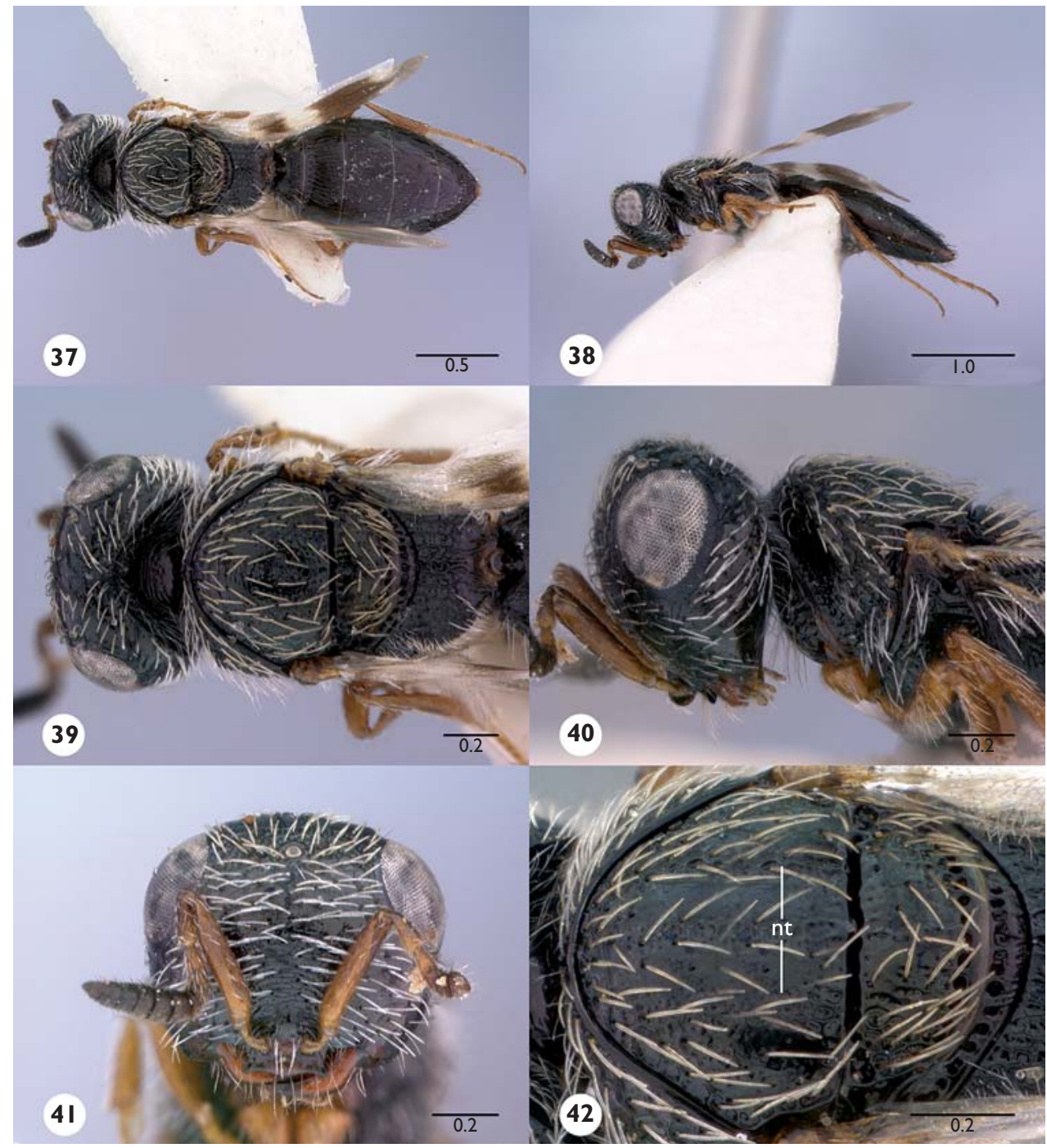

Figures 37-42.55 Scelio ememeye sp. n. (OSUC 211567) 37 Habitus, dorsal view 38 Habitus, lateral view 39 Mesosoma, dorsal view 40 Mesosoma, lateral view 4 I Head, anterior view 42 Mesonotum, dorsolateral view. Abbreviation: $n t$, notauli. Scale bars in millimeters. 
from submarginal vein to posterior margin, striplike (a band), divided only by hyaline course of $\mathrm{M}+\mathrm{Cu}$. Basal fascia of fore wing in female: subrectangular, striplike, percurrent from anterior to posterior margin. Apical fascia of fore wing in female: anterior margin with slightly lighter smaller patch, posterior margin even fainter (less contrasting), broadly divided medially by coloration that gradually fades to apex of fore wing.

Sculpture of dorsal T1 in female: polygonal-reticulate, interstices more or less smooth. Sculpture of dorsal T2 in female: fine parallel to slightly reticulate striae with minutely colliculate to transverse sculpture within interstices. Sculpture of anterior T2 through anterior depression in female: percurrent, interrupted with by a smooth strip, majority of sculpture not contiguous with that of posterior T2. Sculpture of dorsal T3 in female: fine parallel to irregular longitudinal striae, with reticulation absent to moderately present. Medial sculpture of T4 in female: present. Medial sculpture of T5 in female: present. Sculpture of T2-T5 curved transition from dorsal to lateral terga in female: obliterated to smooth. Profile of female metasoma in lateral view: dorsal and ventral surfaces more or less evenly convex. Sculpture of lateral T2-T6 in female: with some fine striae ventrally, particularly medially, dorsally smooth. Pilosity of laterotergites in female: present on T1-T2.

Diagnosis. Most similar to $S$. tria which shares the presence of notauli and a medial mesoscutal division in the form of longitudinal carinae (Fig. 42, nt). Differing from $S$. tria by the sculpture of the mesoscutellum (longitudinally striate in $S$. tria, obliterate or reticulate in S. ememeye).

Etymology. Phonetically MMI, or 2001, in reference to one of the most famous novels of Arthur C. Clarke.

Link to distribution map. [http://osuc.biosci.ohio-state.edu/HymOnline/maplarge.html?id=238051]

Material examined. Holotype female: SRI LANKA: Western Prov., Colombo Dist., seashore, Pamunugama, 16.III.1981, K.-V. Krombein, T. Wijesinhe \& L. Weeratunge, OSUC 211567 (deposited in CNCI). Paratypes (2 females, 3 males): NEPAL: 2 males, OSUC 234823, 234825 (CNCI). SRI LANKA: 2 females, 1 male, OSUC 211568 (CNCI); OSUC 244200-244201 (USNM).

Comments. The patch of transverse striae of the lower frons is relatively small for species of the pulchripennis-group.

\section{Scelio habilis Nixon}

urn:lsid:zoobank.org:act:E7ED88F0-7864-4F60-B388-DEF887FCC3E7

urn:Isid:biosci.ohio-state.edu:osuc_concepts:5247

Figs 43-48; Morphbank ${ }^{17}$

Scelio habilis Nixon, 1958: 306, 316 (original description. keyed); Masner, 1965a: 94 (type information).

Description. Female body length: $3.66-3.81 \mathrm{~mm}(\mathrm{n}=2)$. Color of antenna in female: concolorous, brown to dark brown throughout. Color of head in female: black. Color 
of mesosoma in female: dark brown to black. Color of coxae in female: brown to dark brown. Color of leg past coxa in female: brown to dark brown. Color of metasoma in female: brown to dark brown.

Sculpture of lower frons in female: predominantly transverse to slightly arcuate striae. Sculpture of ventrolateral frons in female: smooth, with some clearly defined fine umbilicate sculpture. Form of malar sulcus in female: sulcus percurrent, slit, groove or carina extremely narrow but course well defined. Sculpture of upper frons of female: irregular dorsoventral striae and fine umbilications, sculpture variously

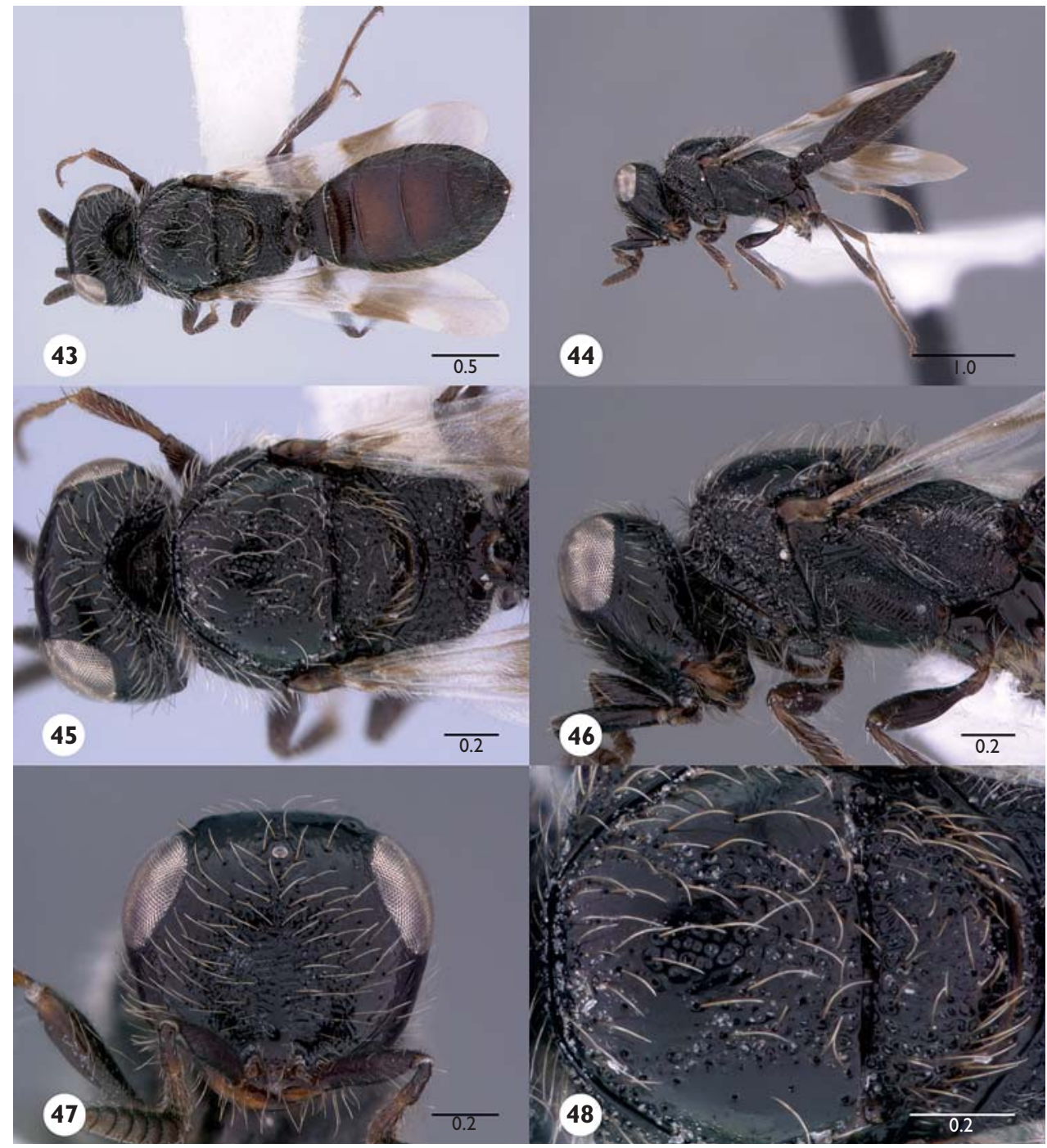

Figures 43-48. ${ }^{56}$ Scelio habilis Nixon, female (OSUC 180778). 43 Habitus, dorsal view 44 Habitus, lateral view $45 \mathrm{Head}$ and mesosoma, dorsal view $\mathbf{4 6} \mathrm{Head}$ and mesosoma, lateral view $\mathbf{4 7} \mathrm{Head}$, anterior view 48 Mesonotum, dorsal view. Scale bars in millimeters. 
obliterated above anterior ocellus. Sculpture of dorsal head between and posterior to lateral ocelli in female: smooth, with only setigerous punctures, or predominantly obliterated, in some specimens with traces of rugulae medially. Mandible of female: upper tooth typically developed, lower tooth very short but clearly present, truncate to pointed.

Transverse pronotal carina in female: absent mesad, transition from dorsal shoulder to anterior pronotum not sharply delimited but rather slightly curved, if appearing slightly present then either obliterated medially or composed of adjacent subpolygonal sculpture. Sculpture of medial mesoscutum in female: slightly flattened reticulate-punctulate sculpture, with two elongate smooth bands anterolaterally. Sculpture of notaular course in female: more or less undifferentiated to slightly more robust and coarse relative to medial sculpture. Sculpture of lateral mesoscutum in female: absent, or with obliterated patch that covers at least $1 / 2$ of area. Sculpture of mesoscutellum in female: predominantly irregular reticulate to rugulose, carinae slightly to strongly flattened, with or without slight longitudinal trend. Sculpture of lateral pronotum in female (excluding interstitial sculpture): with smooth to obliterated patch immediately below lateral epomial carina, otherwise reticulate with few to moderate longitudinal elements. Pronotal verricule in female: weakly developed ridge-like bump with 1-2 short appressed white setae arising from small pit at apex. Pronotal setal patch posteroventral to end of lateral epomial carina in female: sparse (around 2-5) scattered, shorter semidecumbent to erect setae. Sculpture of mesopleural depression in female: predominantly longitudinally striate. Pilosity of anteroventral metapleuron in female: glabrous, or sparsely setose. Dorsal surface of hind tibia in female: typical distribution and moderate length, setae appressed to loosely appressed, more or less straight. Shape of hind femur in female: narrow, dorsal and ventral surfaces relatively symmetrical. Basal pigmented spot of fore wing in female: percurrent from submarginal vein to posterior margin, striplike (a band), divided only by hyaline course of $\mathrm{M}+\mathrm{Cu}$. Basal fascia of fore wing in female: subrectangular, striplike, percurrent from anterior to posterior margin. Apical fascia of fore wing in female: anterior margin with slightly lighter smaller patch, posterior margin even fainter (less contrasting), broadly divided medially by coloration that gradually fades to apex of fore wing.

Sculpture of dorsal T1 in female: polygonal-reticulate, interstices more or less smooth, longitudinally striate, with few to no transverse divisions or reticulations, interstices smooth or with very slight irregular microsculpture. Sculpture of dorsal T2 in female: reticulate, with some longitudinal elements, interstices irregularly rough, fine parallel to slightly reticulate striae with minutely colliculate to transverse sculpture within interstices. Sculpture of anterior T2 through anterior depression in female: interrupted with by a smooth strip, majority of sculpture not contiguous with that of posterior T2. Sculpture of dorsal T3 in female: fine parallel to irregular longitudinal striae, with reticulation absent to moderately present. Medial sculpture of T4 in female: present. Medial sculpture of T5 in female: present. Sculpture of T2-T5 curved transition from dorsal to lateral terga in female: sculptured. Profile of female metasoma 
in lateral view: dorsal and ventral surfaces more or less evenly convex. Sculpture of lateral T2-T6 in female: scattered variously obliterated faint fine irregular rugulae. Pilosity of laterotergites in female: present on T1-T4.

Diagnosis. Scelio habilis differs from all species in the group by the combination of the smooth dorsal head, absence of metallic coloration, and incomplete transverse pronotal carina.

Link to distribution map. [http://osuc.biosci.ohio-state.edu/HymOnline/maplarge.html?id=5247]

Material examined. Holotype female: SOUTH AFRICA: Western Cape Prov., Mossel Bay, II.1922, R.E. Turner, OSUC 254446 (deposited in BMNH). Other material: SOUTH AFRICA: 5 females, 1 male, OSUC 254447-254450 (BMNH); OSUC 211501 (CNCI); OSUC 180778 (SAMC).

Comments. There is some variation in sculpture within S. habilis. For example, sculpture on a specimen from the Eastern Cape is more reticulated, while that on another from the Western Cape is more linear. This is particularly noticeable on the dorsomedial terga and lateral sterna. Given the relative similarity of sculpture of the head and mesoscutum we elected to not divide these morphs into separate species.

\section{Scelio leipo Yoder, sp. n.}

urn:Isid:zoobank.org:act:37E658AC-FA83-4FDA-AF88-C6C57328F028

urn:lsid:biosci.ohio-state.edu:osuc_concepts:238055

Figs 2, 49-54; Morphbank ${ }^{18}$

Description. Female body length: $2.72-3.25 \mathrm{~mm}(\mathrm{n}=10)$. Color of antenna in female: A1 brown to dark brown, tip of A2 and A3 slightly lighter (to yellow), remaining brown to dark brown. Color of head in female: black. Color of mesosoma in female: light brown to brown. Color of coxae in female: brown to dark brown. Color of leg past coxa in female: brown to dark brown. Color of metasoma in female: brown to dark brown.

Sculpture of lower frons in female: predominantly transverse to slightly arcuate striae. Sculpture of ventrolateral frons in female: smooth, with some clearly defined fine umbilicate sculpture. Form of malar sulcus in female: sulcus percurrent, slit, groove or carina extremely narrow but course well defined. Sculpture of upper frons of female: rugulose, with dorsoventral trend. Sculpture of dorsal head between and posterior to lateral ocelli in female: rugulose, obliterated in spots or not. Mandible of female: upper tooth typically developed, lower tooth very short but clearly present, truncate to pointed.

Transverse pronotal carina in female: absent mesad, transition from dorsal shoulder to anterior pronotum not sharply delimited but rather slightly curved, if appearing slightly present then either obliterated medially or composed of adjacent subpolygonal sculpture. Sculpture of medial mesoscutum in female: slightly flattened and rounded reticulations, sometimes few reticulations broken result- 
ing in irregular rugulae. Sculpture of notaular course in female: more or less undifferentiated to slightly more robust and coarse relative to medial sculpture. Sculpture of lateral mesoscutum in female: present. Sculpture of mesoscutellum in female: predominantly irregular reticulate to rugulose, carinae slightly to strongly flattened, with or without slight longitudinal trend. Sculpture of lateral pronotum in female (excluding interstitial sculpture): with smooth to obliterated patch immediately below lateral epomial carina, otherwise reticulate with few to moderate longitudinal elements. Pronotal verricule in female: apparently absent.

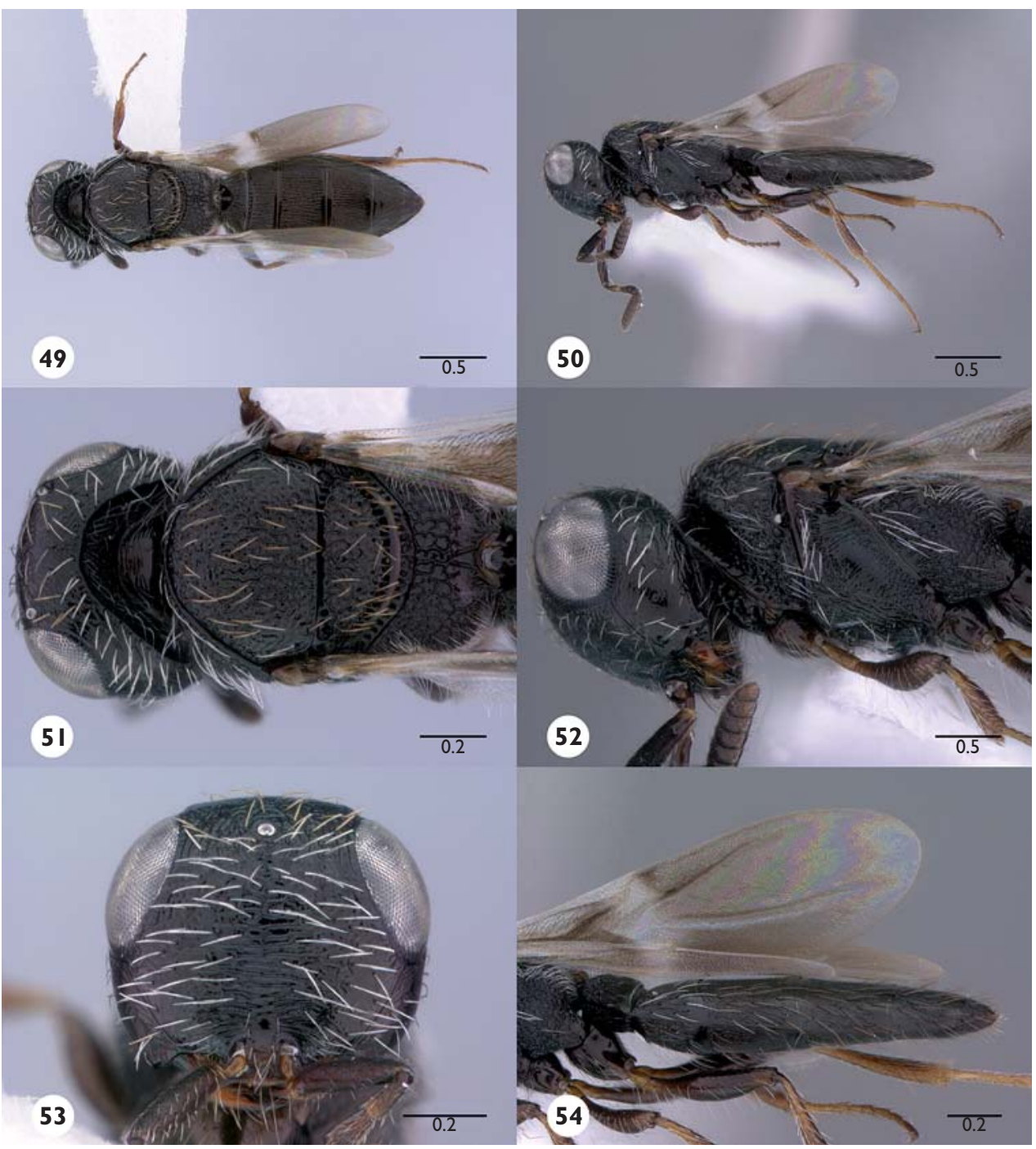

Figures 49-54. ${ }^{\mathbf{5}}$ Scelio leipo sp. n. female (CASENT 2043931) $\mathbf{4 9}$ Habitus, dorsal view $\mathbf{5 0}$ Habitus, lateral view $\mathbf{5}$ I Head and mesosoma, dorsal view $\mathbf{5 2} \mathrm{Head}$ and mesosoma, lateral view $\mathbf{5 3} \mathrm{Head}$, anterior view 54 Metasoma, lateral view. Scale bars in millimeters. 
Pronotal setal patch posteroventral to end of lateral epomial carina in female: dense (around 5 to many) small patch of appressed to slightly semi-decumbent setae. Sculpture of mesopleural depression in female: predominantly irregularly reticulate. Pilosity of anteroventral metapleuron in female: glabrous, or sparsely setose. Dorsal surface of hind tibia in female: typical distribution and moderate length, setae appressed to loosely appressed, more or less straight. Shape of hind femur in female: narrow, dorsal and ventral surfaces relatively symmetrical. Basal pigmented spot of fore wing in female: percurrent from submarginal vein to posterior margin, striplike (a band), divided only by hyaline course of $\mathrm{M}+\mathrm{Cu}$. Basal fascia of fore wing in female: subrectangular, striplike, percurrent from anterior to posterior margin. Apical fascia of fore wing in female: absent, fore wing past marginal vein gradually lightening.

Sculpture of dorsal T1 in female: longitudinally striate, with few to no transverse divisions or reticulations, interstices smooth or with very slight irregular microsculpture. Sculpture of dorsal T2 in female: fine parallel to slightly reticulate striae with minutely colliculate to transverse sculpture within interstices. Sculpture of anterior T2 through anterior depression in female: interrupted with by a smooth strip, majority of sculpture not contiguous with that of posterior T2. Sculpture of dorsal T3 in female: fine parallel to irregular longitudinal striae, with reticulation absent to moderately present. Medial sculpture of T4 in female: present. Medial sculpture of T5 in female: obliterated to smooth. Sculpture of T2-T5 curved transition from dorsal to lateral terga in female: sculptured. Profile of female metasoma in lateral view: dorsal and ventral surfaces more or less evenly convex. Sculpture of lateral T2-T6 in female: fine irregular longitudinal striae throughout. Pilosity of laterotergites in female: present on T1-T3, present on T1-T2, or present on T2.

Diagnosis. Diagnosable from all other species by the combination of the absence of an apical fascia on the fore wing and the incomplete transverse pronotal carina.

Etymology. From the Greek meaning wanting or without, also eclipse. In reference to the "eclipsed" or absent apical fascia and the incomplete transverse pronotal carina.

Link to distribution map. [http://osuc.biosci.ohio-state.edu/HymOnline/maplarge.html?id=238055]

Material examined. Holotype female: MADAGASCAR: Toliara Auto. Prov., Andohahela N.P., parcel II, transitional forest, MA-02-20-30, Tsimelahy, $24^{\circ} 56.21^{\prime} \mathrm{S}$ 463․60'E, 180 m, 22.VI-29.VI.2003, Malaise trap, M. Irwin, F. Parker \& R. Harin'Hala, CASENT 2043551 (deposited in CASC). Paratypes: MADAGASCAR: 9 females, CASENT 2043353, 2043552, 2043930-2043931, 2132586, 21333032133304, 8106500 (CASC); OSUC 214170 (OSUC).

Comments. The sculpture of the mesoscutum, while at first glance appearing similar to that of $S$. parapulchripennis, is fairly consistently different. There are distinctly fewer closed reticulations in S. leipo, and the overall pattern is somewhat more random. The sculpture of the tergites laterally is finer and more confused than that in S. parapulchripennis. The sculpture of the anterior mesopleural depression is consistently slightly obliterated. 


\section{Scelio marbis Nixon}

urn:lsid:zoobank.org:act:2DD44263-3800-4E7F-A774-ED4711F78647

urn:lsid:biosci.ohio-state.edu:osuc_concepts:5270

Figs 55-60; Morphbank ${ }^{19}$

Scelio marbis Nixon, 1958: 306, 317 (original description. keyed); Masner, 1965a: 94 (type information).

Description. Female body length: $3.48-3.59 \mathrm{~mm}(\mathrm{n}=3)$. Color of antenna in female: A1-A2 yellow to light brown, remaining brown, or A1-A5 or A6 yellow to light brown, remaining brown. Color of head in female: metallic green to dark teal. Color of mesosoma in female: brown to near black except for yellow to light brown anterior pronotum and propleuron, with metallic green to dark teal sheen throughout. Color of coxae in female: yellow to light brown. Color of leg past coxa in female: yellow to light brown. Color of metasoma in female: amber-orange to brown at base, darkening to near black at apex, T2 or T3 onwards with metallic blue green sheen.

Sculpture of lower frons in female: predominantly fine irregular rugulae. Sculpture of ventrolateral frons in female: dense fine rugulae. Form of malar sulcus in female: sulcus percurrent, slit, groove or carina extremely narrow but course well defined, or not percurrent, with some sections variously obliterated. Sculpture of upper frons of female: fine rugulae. Sculpture of dorsal head between and posterior to lateral ocelli in female: fine rugulae. Mandible of female: upper tooth typically developed, lower tooth very short but clearly present, truncate to pointed.

Transverse pronotal carina in female: well developed, linear or with extremely slight deviations, contiguous with mesoscutum or interrupted by a single subpolygonal cell, anterior shoulder relatively abruptly transitioned to anterior pronotum. Sculpture of medial mesoscutum in female: serpentine, sharply defined, rugulae relatively dense. Sculpture of notaular course in female: more or less undifferentiated to slightly more robust and coarse relative to medial sculpture. Sculpture of lateral mesoscutum in female: present. Sculpture of mesoscutellum in female: serpentine-rugulose, sculpture narrow, sharply defined. Sculpture of lateral pronotum in female (excluding interstitial sculpture): reticulate sculpture throughout (smooth patch below lateral epomial carina absent). Pronotal verricule in female: small bump with 1-2 very short setae at center. Pronotal setal patch posteroventral to end of lateral epomial carina in female: very sparse (around 1-3), long, erect setae. Sculpture of mesopleural depression in female: predominantly longitudinally striate, or predominantly irregularly reticulate. Pilosity of anteroventral metapleuron in female: dense patch of semi-decumbent to erect setae. Dorsal surface of hind tibia in female: sparse, elongate, erect and slightly curved. Shape of hind femur in female: narrow, dorsal and ventral surfaces relatively symmetrical. Basal pigmented spot of fore wing in female: percurrent from submarginal vein to posterior margin, striplike (a band), divided only by hyaline course of $\mathrm{M}+\mathrm{Cu}$. Basal fascia of fore wing in female: broadly semi-circular, interrupted from posterior margin by 
extension of basal pigmented spot. Apical fascia of fore wing in female: broad, hyaline, percurrent from anterior to posterior fore wing margin, apex of fore wing past fascia concolorous with distal patch.

Sculpture of dorsal T1 in female: longitudinally striate, with moderate to dense reticulation, intersticies rough throughout. Sculpture of dorsal T2 in female: fine parallel to slightly reticulate striae with minutely colliculate to transverse sculpture within interstices. Sculpture of anterior T2 through anterior depression in female: interrupted with by a smooth strip, majority of sculpture not contiguous with that of posterior T2.

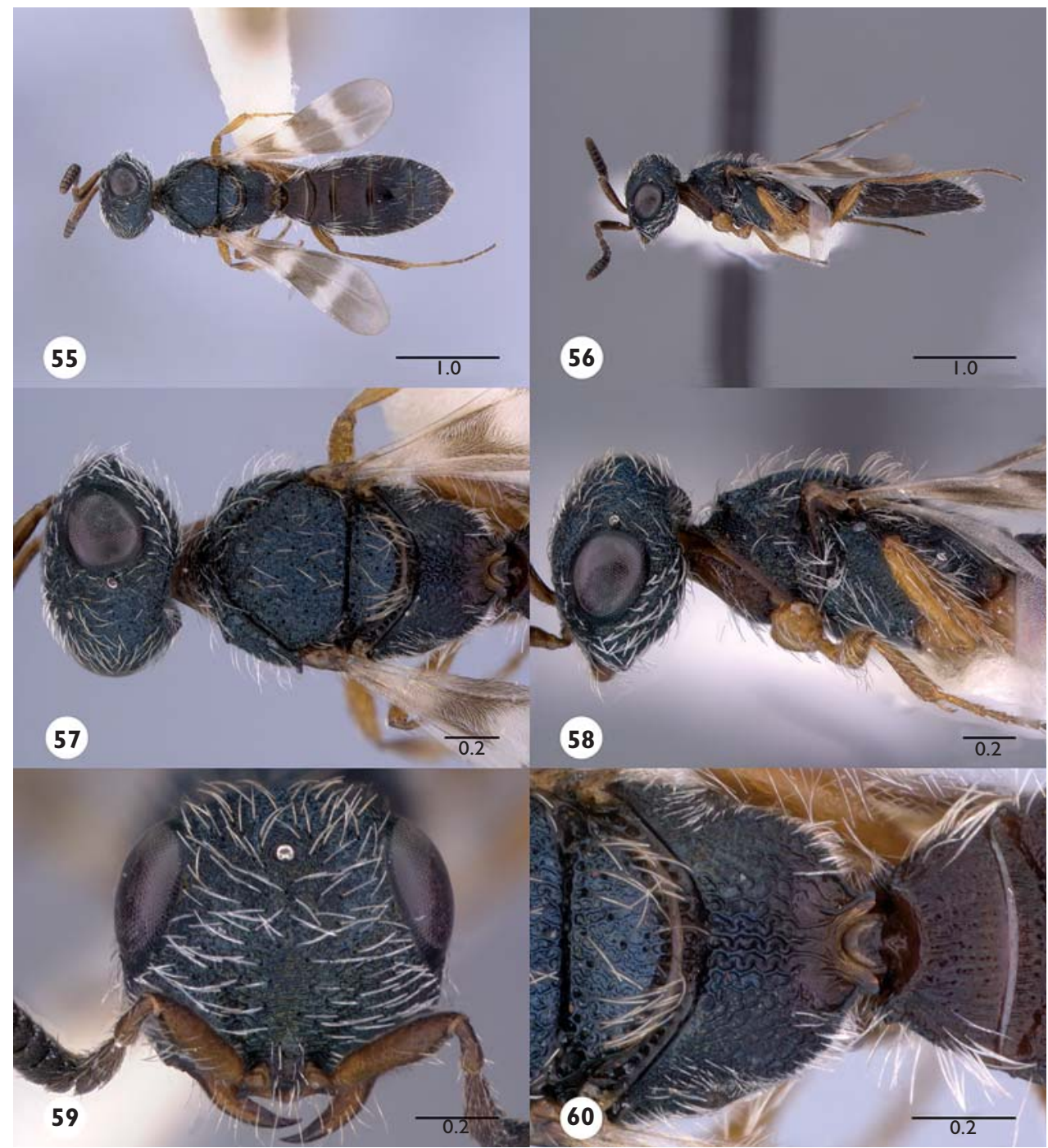

Figures 55-60. ${ }^{\mathbf{5 8}}$ Scelio marbis Nixon (OSUC 235078). $\mathbf{5 5}$ Habitus, dorsal view $\mathbf{5 6}$ Habitus, lateral view 57 Mesosoma, dorsal view 58 Mesosoma, lateral view 59 Head, anterior view $\mathbf{6 0}$ Mesoscutellum, propodeum, T1, dorsal view. Scale bars in millimeters. 
Sculpture of dorsal T3 in female: fine parallel to irregular longitudinal striae, with reticulation absent to moderately present. Medial sculpture of T4 in female: present, obliterated to smooth. Medial sculpture of T5 in female: present, obliterated to smooth. Sculpture of T2-T5 curved transition from dorsal to lateral terga in female: sculptured. Profile of female metasoma in lateral view: ventral surface more or less flat, dorsal surface weakly to strongly arched from T2-T6 highest point between T4-T5, evenly curved to T6. Sculpture of lateral T2-T6 in female: T2 reticulate-rugulose, T3-T6 with dense striae throughout. Pilosity of laterotergites in female: present on T1-T3.

Diagnosis. The strong metallic coloration of the head and mesoscutum in combination with the dense, fine, rugulose-reticulate sculpture is unique to $S$. marbis. A very similar pattern of sculpture and overall form of the body is seen in S. masneri. However, $S$. masneri has an orange mesosoma with no trace of metallic coloration and a distinctly different pattern of pilosity (very dense, white, erect, Fig. 62). See also diagnosis for $S$. antorides.

Link to distribution map. [http://osuc.biosci.ohio-state.edu/HymOnline/maplarge.html?id=5270]

Material examined. Holotype female: SOUTH AFRICA: Eastern Cape Prov., Queenstown, 5500 ft [1676 m], 16.I-10.II.1923, R.E. Turner, OSUC 254438 (deposited in BMNH). Other material: ( 3 females, 7 males) SOUTH AFRICA: 1 female, 7 males, OSUC 254439-254445 (BMNH); OSUC 211459 (CNCI). ZIMBABWE: 2 females, OSUC 211460, 235078 (CNCI).

\section{Scelio masneri Yoder, sp. n.}

urn:Isid:zoobank.org:act:9CB8FEB6-2DAA-40AA-95EA-18492ACC7EA3 urn:lsid:biosci.ohio-state.edu:osuc_concepts:238056

Figs 61-66; Morphbank ${ }^{20}$

Description. Female body length: $3.18-3.78 \mathrm{~mm}(\mathrm{n}=2)$. Color of antenna in female: A1-2 yellow to light brown, remaining brown. Color of head in female: metallic green to dark teal. Color of mesosoma in female: yellow orange. Color of coxae in female: yellow to light brown. Color of leg past coxa in female: yellow to light brown. Color of metasoma in female: amber-orange at base (T1-T3), darkening to near black at apex, T4-T6 with metallic blue-green sheen.

Sculpture of lower frons in female: predominantly fine irregular rugulae. Sculpture of ventrolateral frons in female: dense fine rugulae. Form of malar sulcus in female: sulcus percurrent, slit, groove or carina extremely narrow but course well defined. Sculpture of upper frons of female: fine rugulae. Sculpture of dorsal head between and posterior to lateral ocelli in female: fine rugulae. Mandible of female: upper tooth slightly elongate, elongate-triangular, lower tooth absent to almost imperceptible, a slight extension of the inner-ventral margin.

Transverse pronotal carina in female: absent mesad, transition from dorsal shoulder to anterior pronotum not sharply delimited but rather slightly curved, 
if appearing slightly present then either obliterated medially or composed of adjacent subpolygonal sculpture. Sculpture of medial mesoscutum in female: serpentine, sharply defined, rugulae relatively dense. Sculpture of notaular course in female: more or less undifferentiated to slightly more robust and coarse relative to medial sculpture. Sculpture of lateral mesoscutum in female: present. Sculpture of mesoscutellum in female: serpentine-rugulose, sculpture narrow, sharply defined. Sculpture of lateral pronotum in female (excluding interstitial sculpture): reticulate sculpture throughout (smooth patch below lateral epomial carina ab-

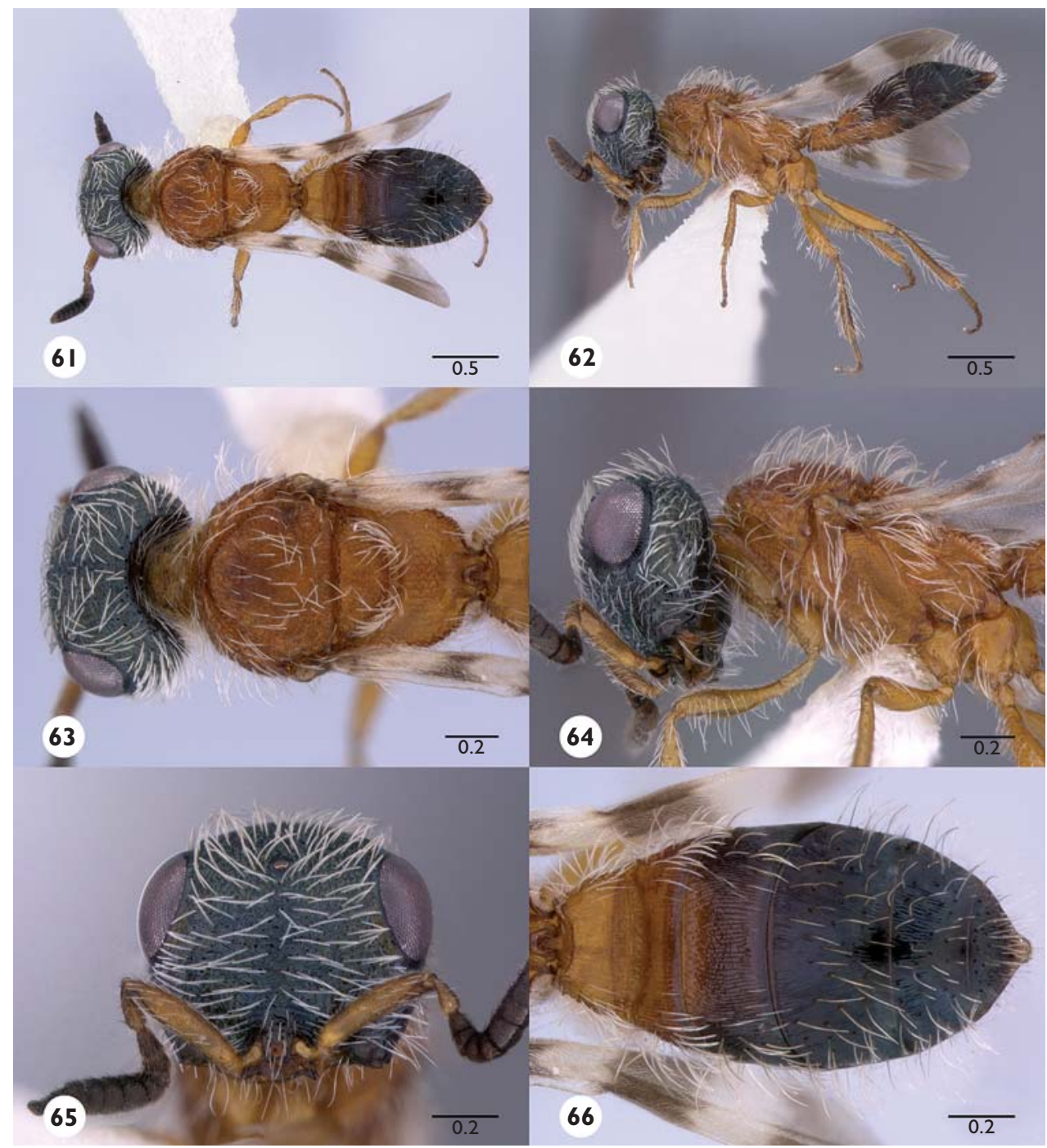

Figures 6I-66.59 Scelio masneri sp. n. (OSUC 235076). 6 I Habitus, dorsal view 62 Habitus, lateral view 63 Mesosoma, dorsal view 64 Mesosoma, lateral view 65 Head, anterior view 66 Metasoma, dorsal view. Scale bars in millimeters. 
sent). Pronotal verricule in female: small bump with 1-2 very short setae at center. Pronotal setal patch posteroventral to end of lateral epomial carina in female: very sparse (around 1-3), long, erect setae. Sculpture of mesopleural depression in female: predominantly longitudinally striate. Pilosity of anteroventral metapleuron in female: dense patch of semi-decumbent to erect setae. Dorsal surface of hind tibia in female: sparse, elongate, erect and slightly curved. Shape of hind femur in female: narrow, dorsal and ventral surfaces relatively symmetrical. Basal pigmented spot of fore wing in female: percurrent from submarginal vein to posterior margin, striplike (a band), divided only by hyaline course of $\mathrm{M}+\mathrm{Cu}$. Basal fascia of fore wing in female: subrectangular, striplike, percurrent from anterior to posterior margin. Apical fascia of fore wing in female: broad, hyaline, percurrent from anterior to posterior fore wing margin, apex of fore wing past fascia concolorous with distal patch.

Sculpture of dorsal T1 in female: longitudinally striate, with few to no transverse divisions or reticulations, interstices smooth or with very slight irregular microsculpture. Sculpture of dorsal T2 in female: fine longitudinal striae with interstices smooth. Sculpture of anterior T2 through anterior depression in female: interrupted with by a smooth strip, majority of sculpture not contiguous with that of posterior T2. Sculpture of dorsal T3 in female: fine parallel to irregular longitudinal striae, with reticulation absent to moderately present. Medial sculpture of T4 in female: present. Medial sculpture of T5 in female: present, obliterated to smooth. Sculpture of T2-T5 curved transition from dorsal to lateral terga in female: sculptured. Profile of female metasoma in lateral view: ventral surface more or less flat, dorsal surface weakly to strongly arched from T2-T6 highest point between T4-T5, evenly curved to T6. Sculpture of lateral T2-T6 in female: T2 reticulate-rugulose, T3-T6 with dense striae throughout. Pilosity of laterotergites in female: present on $\mathrm{T} 1-\mathrm{T} 4$.

Diagnosis. Easily diagnosed from all other species by the metallic green head in combination with bright orange mesosoma that bears dense, erect, long white pilosity.

Etymology. In honor of Lubomír Masner as recognition of his contributions to Hymenoptera taxonomy.

Link to distribution map. [http://osuc.biosci.ohio-state.edu/HymOnline/maplarge.html?id=238056]

Material examined. Holotype female: SOUTH AFRICA: South Africa, Limpopo Prov., $30 \mathrm{~km}$ E Nylstroom, 15.XI-17.XII.1984, flight intercept trap, H. Howden \& A. Howden, OSUC 235076 (deposited in CNCI). Paratype: BOTSWANA: 1 female, OSUC 235079 (CNCI).

Comments. Scelio masneri is the most aberrant member of the pulchripennisgroup. The very long and dense white pilosity, highly domed metasoma, and metallic head and orange body are all potential apomorpohies. The upper lateral pronotum is notable for the complete absence of a smoother patch. It is hard to discern the setae on the laterotergite of T1 in the two specimens observed: in both it appears that some setae have been lost. Additional specimens are required to confirm the coding of this state. 


\section{Scelio nisa Kozlov}

urn:Isid:zoobank.org:act:015A5CE0-C6E8-4F35-AAFD-FDF5743B006C urn:lsid:biosci.ohio-state.edu:osuc_concepts:5284

Figs 67-72; Morphbank ${ }^{21}$

Scelio nisa Kozlov, 1972: 648 (original description); Kozlov \& Kononova, 1990: 220, 223 (description, keyed); Kononova, 1995: 73 (keyed); Kononova \& Kozlov, 2008: 141, 166 (description, keyed).

Description. Female body length: $4.77 \mathrm{~mm}(\mathrm{n}=1)$. Color of antenna in female: A1 brown to dark brown, A2-A3 yellow-brown, remaining brown to dark brown. Color of head in female: black. Color of mesosoma in female: dark brown to black. Color of coxae in female: brown to dark brown. Color of leg past coxa in female: brown to dark brown. Color of metasoma in female: black.

Sculpture of lower frons in female: transverse striae, obliterated and smooth throughout. Sculpture of ventrolateral frons in female: smooth, with only setigerous punctures. Form of malar sulcus in female: sulcus percurrent, slit, groove or carina extremely narrow but course well defined. Sculpture of upper frons of female: more or less obliterated, with sparse irregular reticulation and depression at setal bases. Sculpture of dorsal head between and posterior to lateral ocelli in female: coarse irregular transverse striae. Mandible of female: upper tooth typically developed, lower tooth very short but clearly present, truncate to pointed.

Transverse pronotal carina in female: well developed, linear or with extremely slight deviations, contiguous with mesoscutum or interrupted by a single subpolygonal cell, anterior shoulder relatively abruptly transitioned to anterior pronotum. Sculpture of medial mesoscutum in female: irregular flattened to obliterated longitudinal-reticulate sculpture. Sculpture of notaular course in female: obscured single row of coarse irregular foveae. Sculpture of lateral mesoscutum in female: absent, or with obliterated patch that covers at least 1/2 of area. Sculpture of mesoscutellum in female: irregularly longitudinally striate, sparsely to moderately reticulate, or predominantly irregular reticulate to rugulose, carinae slightly to strongly flattened, with or without slight longitudinal trend. Sculpture of lateral pronotum in female (excluding interstitial sculpture): with smooth to obliterated patch immediately below lateral epomial carina, otherwise reticulate with few to moderate longitudinal elements. Pronotal verricule in female: apparently absent. Pronotal setal patch posteroventral to end of lateral epomial carina in female: dense (around 5 to many) small patch of appressed to slightly semi-decumbent setae. Sculpture of mesopleural depression in female: obliterated flattened reticulations, with some longitudinal trend. Pilosity of anteroventral metapleuron in female: glabrous, or sparsely setose. Dorsal surface of hind tibia in female: typical distribution and moderate length, setae appressed to loosely appressed, more or less straight. Shape of hind femur in female: narrow, dorsal and ventral surfaces relatively symmetrical. Basal pigmented spot of fore wing in female: medially situated, not reaching fore or hind margin, posteriorly fused with apical pigmented area. Basal fascia of fore wing in 
female: broadly semi-circular, interrupted from posterior margin by extension of basal pigmented spot. Apical fascia of fore wing in female: absent, fore wing past marginal vein gradually lightening.

Sculpture of dorsal T1 in female: longitudinally striate, with few to no transverse divisions or reticulations, interstices smooth or with very slight irregular microsculpture. Sculpture of dorsal T2 in female: fine parallel to slightly reticulate striae with minutely colliculate to transverse sculpture within interstices. Sculpture of anterior T2

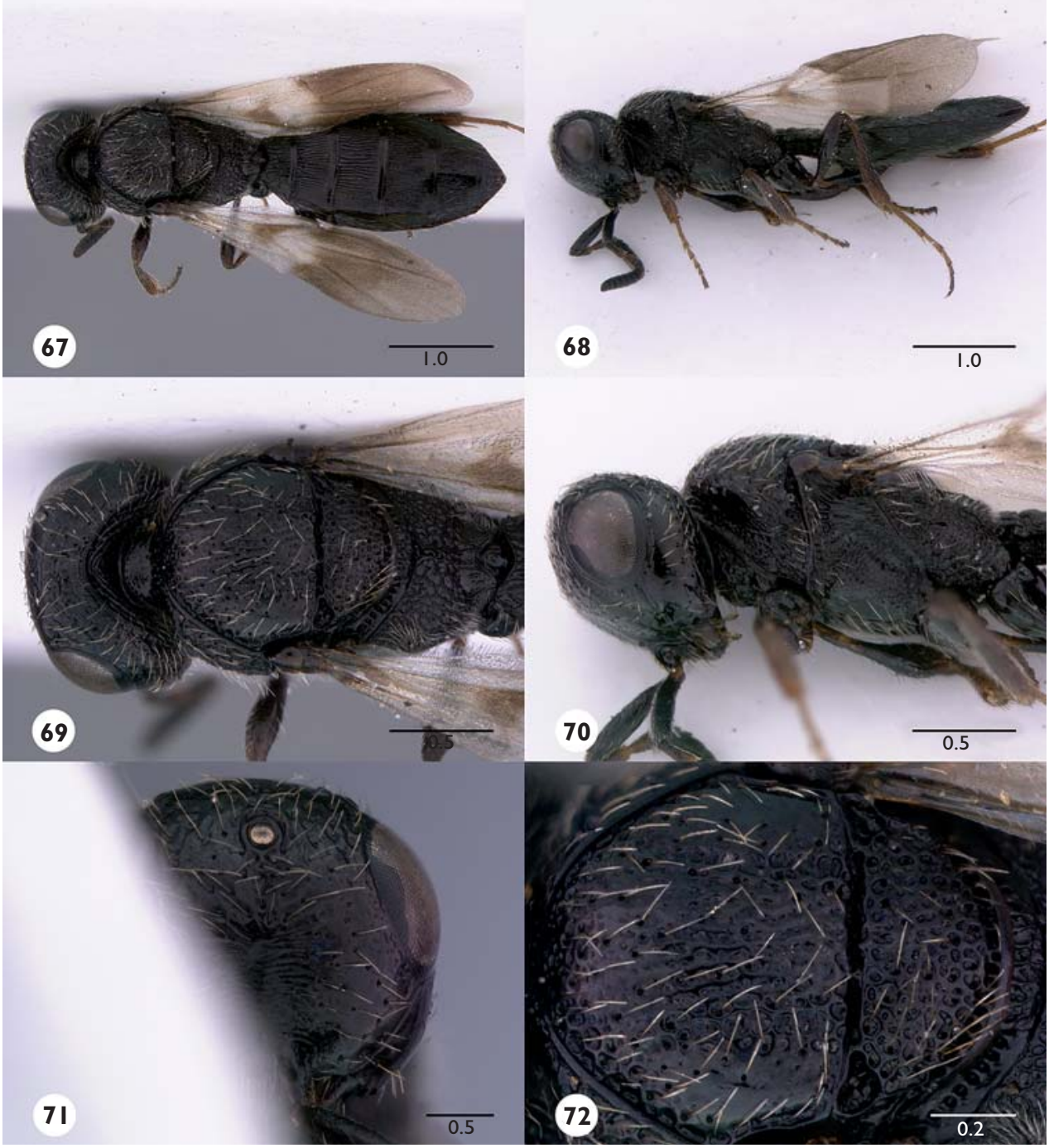

Figures 67-72. ${ }^{60}$ Scelio nisa Kozlov (OSUC 235081). 67 Habitus, dorsal view 68 Habitus, lateral view 69 Mesosoma, dorsal view 70 Mesosoma, lateral view 71 Head, anterior view 72 Mesonotum, dorsal view. Scale bars in millimeters. 
through anterior depression in female: percurrent. Sculpture of dorsal T3 in female: fine parallel to irregular longitudinal striae, with reticulation absent to moderately present. Medial sculpture of T4 in female: present. Medial sculpture of T5 in female: obliterated to smooth. Sculpture of T2-T5 curved transition from dorsal to lateral terga in female: obliterated to smooth. Profile of female metasoma in lateral view: dorsal and ventral surfaces more or less evenly convex. Sculpture of lateral T2-T6 in female: with some fine striae ventrally, particularly medially, dorsally smooth. Pilosity of laterotergites in female: glabrous, or apparently so.

Diagnosis. Easily diagnosed from all other species by its large size, black body, and predominantly obliterated or flattened sculpture.

Link to distribution map. [http://osuc.biosci.ohio-state.edu/HymOnline/maplarge.html?id=5284]

Material examined. Other material: MONGOLIA: 1 female, OSUC 235081 (CNCI).

Comments. The holotype was observed early in this study and could not be examined later. The descriptions published by M.A. Kozlov and S.V. Kononova match well with the specimen in hand from Mongolia, and the species is very distinct from other members of the pulchripennis group. Thus, we feel reasonably confident that we have correctly interpreted this concept.

\section{Scelio nitens Brues}

urn:lsid:zoobank.org:act:A600DB0C-21E3-4CA5-86CE-E38953FBBCA2 urn:lsid:biosci.ohio-state.edu:osuc_concepts:5285

Figs 73-78; Morphbank ${ }^{22}$

Scelio nitens Brues, 1906: 110 (original description); Kieffer, 1926: 310, 324 (description, keyed); Ferrière, 1952: 118 (diagnosis); Nixon, 1958: 304 (keyed); Masner, 1965b: 300 (lectotype designation); Noonan, 1984: 6 (type information). Scelio (Scelio) nitens Brues, 1910: 74 (subgeneric assignment).

Description. Female body length: $2.90-4.00 \mathrm{~mm}(\mathrm{n}=20)$. Male body length: 2.99 $\mathrm{mm}(\mathrm{n}=1)$. Color of antenna in female: concolorous, brown to dark brown throughout. Color of head in female: metallic green to dark teal. Color of mesosoma in female: brown to near black except for yellow to light brown anterior pronotum and propleuron, with metallic green to dark teal sheen throughout. Color of coxae in female: brown to dark brown. Color of leg past coxa in female: brown to dark brown. Color of metasoma in female: brown at base (T1-T3), darkening to apex, T4-T6 with slight metallic blue-green sheen.

Sculpture of lower frons in female: predominantly transverse to slightly arcuate striae. Sculpture of ventrolateral frons in female: smooth, with only setigerous punctures. Form of malar sulcus in female: sulcus percurrent, slit, groove or carina extremely narrow but course well defined. Sculpture of upper frons of female: fine ru- 
gulae to slightly transverse sculpture, above ocellus very smooth, with only setigerous punctures. Sculpture of dorsal head between and posterior to lateral ocelli in female: smooth, with only setigerous punctures. Mandible of female: upper tooth typically developed, lower tooth very short but clearly present, truncate to pointed.

Transverse pronotal carina in female: well developed, linear or with extremely slight deviations, contiguous with mesoscutum or interrupted by a single subpolygonal cell, anterior shoulder relatively abruptly transitioned to anterior pronotum. Sculpture of medial mesoscutum in female: very smooth, with only setigerous punctures. Sculpture

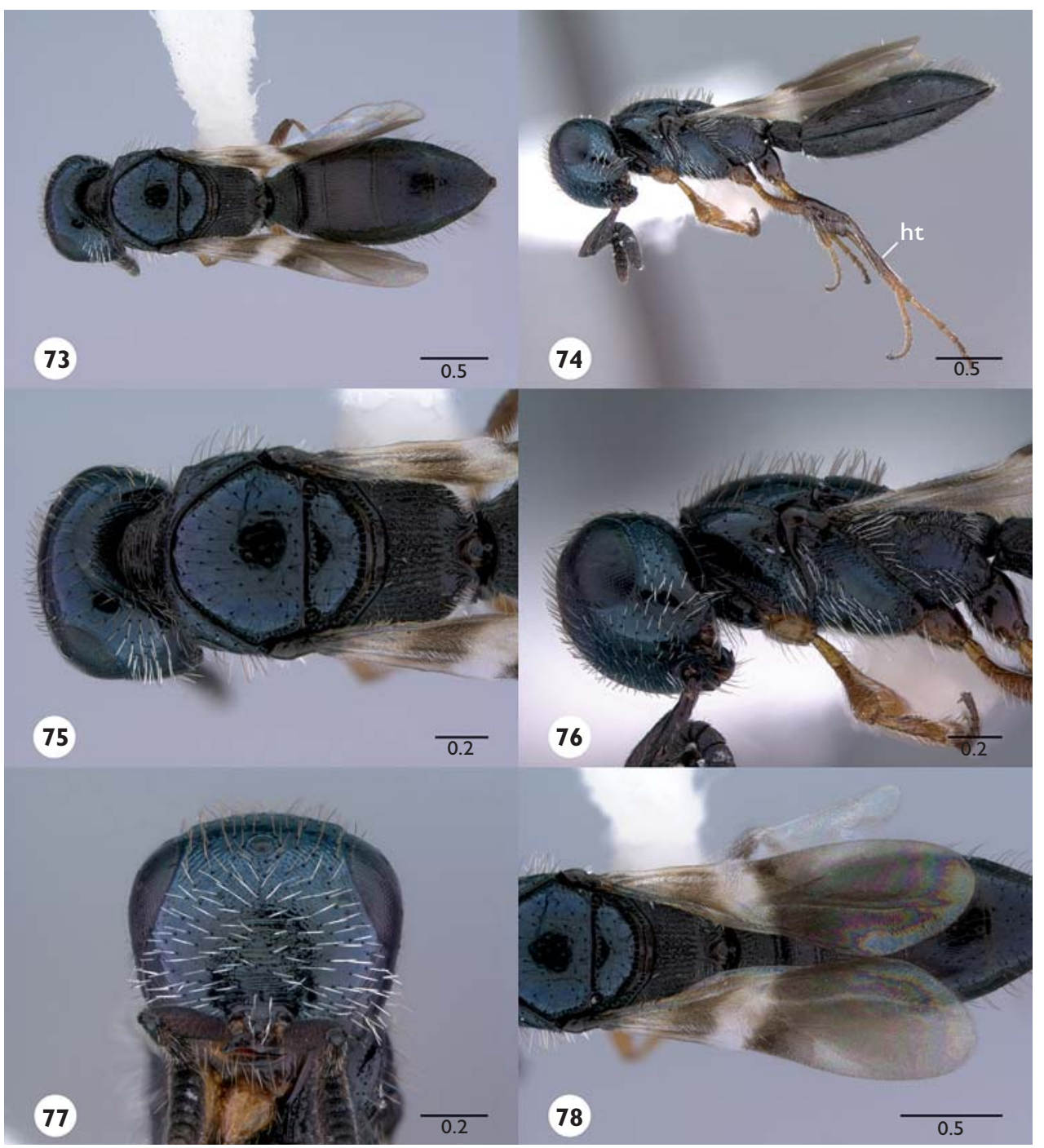

Figures 73-78. ${ }^{61}$ Scelio nitens Brues (OSUC 211500). 73 Habitus, dorsal view 74 Habitus, lateral view 75 Mesosoma, dorsal view 76 Mesosoma, lateral view 77 Head, anterior view 78 Medial habitus, dorsal view. Abbreviation: $h t$, hind tibia. Scale bars in millimeters. 
of notaular course in female: smooth, with only a few micropunctures, or more or less undifferentiated to slightly more robust and coarse relative to medial sculpture. Sculpture of lateral mesoscutum in female: absent, or with obliterated patch that covers at least $1 / 2$ of area. Sculpture of mesoscutellum in female: predominantly smooth,with only scattered setigerous punctures. Sculpture of lateral pronotum in female (excluding interstitial sculpture): predominantly smooth, with slight reticulations along ventral and posterior margin. Pronotal verricule in female: small bump with 1-2 very short setae at center. Pronotal setal patch posteroventral to end of lateral epomial carina in female: very sparse (around 1-3), long, erect setae. Sculpture of mesopleural depression in female: surface smooth or with very faint coriaceous (obliterated) sheen, with minute foveae or grooves along posterior margin. Pilosity of anteroventral metapleuron in female: dense patch of semi-decumbent to erect setae. Dorsal surface of hind tibia in female: typical distribution and moderate length, setae appressed to loosely appressed, more or less straight. Shape of hind femur in female: narrow, dorsal and ventral surfaces relatively symmetrical. Basal pigmented spot of fore wing in female: percurrent from submarginal vein to posterior margin, striplike (a band), divided only by hyaline course of $\mathrm{M}+\mathrm{Cu}$. Basal fascia of fore wing in female: subrectangular, striplike, percurrent from anterior to posterior margin. Apical fascia of fore wing in female: absent, fore wing past marginal vein gradually lightening.

Sculpture of dorsal T1 in female: polygonal-reticulate, interstices more or less smooth. Sculpture of dorsal T2 in female: fine parallel to slightly reticulate striae with minutely colliculate to transverse sculpture within interstices. Sculpture of anterior T2 through anterior depression in female: percurrent. Sculpture of dorsal T3 in female: fine parallel to irregular longitudinal striae, with reticulation absent to moderately present. Medial sculpture of T4 in female: obliterated to smooth. Medial sculpture of T5 in female: obliterated to smooth. Sculpture of T2-T5 curved transition from dorsal to lateral terga in female: obliterated to smooth. Profile of female metasoma in lateral view: ventral surface more or less flat, dorsal surface weakly to strongly arched from T2-T6 highest point between T4-T5, evenly curved to T6. Sculpture of lateral T2-T6 in female: scattered variously obliterated faint fine irregular rugulae. Pilosity of laterotergites in female: glabrous, or apparently so.

Diagnosis. This species is most similar to $S$. paranitens, which shares the smooth mesoscutum and highly metallic coloration throughout. It differs from $S$. paranitens by the absence of the fore wing apical fascia and the appressed pilosity of the hind tibia (fascia present, setae erect in $S$. paranitens).

Link to distribution map. [http://osuc.biosci.ohio-state.edu/HymOnline/maplarge.html?id=5285]

Material examined. Lectotype female: SOUTH AFRICA: Eastern Cape Prov., Algoa Bay, 29.XI.1896, H. Brauns, MCZ 31019 (deposited in MCZC). Paralectotypes: SOUTH AFRICA: 2 females, OSUC 244168-244169 (MCZC). Other material: (44 females, 1 male) BOTSWANA: 33 females, 1 male, OSUC 211451, 211482, 211495, 211523, 211560 (CNCI); OSUC 164233-164236, 164238-164240, 164258-164259, 164261, 164263, 164371-164374, 212085-212086, 212091, 
212095, 234737-234738 (OSUC); OSUC 171138-171140, 207575-207577, 211814, 211820 (USNM). NAMIBIA: 1 female, OSUC 254455 (BMNH). SOUTH AFRICA: 9 females, OSUC 254456 (BMNH); OSUC 211500, 211502-211503, 211511-211512, 211521-211522, 211534 (CNCI). ZIMBABWE: 1 female, OSUC 254457 (BMNH).

Comments. The syntype series of Brues consisted of two species, as hinted at by an annotation in Masner (1965b). Masner (1965b) designated the lectotype of S. nitens which is conspecific with one of the paralectotypes. A third specimen (OSUC 244169) belongs in Scelio paranitens. The fore coxa is frequently lighter in color than the mid and hind coxae. See also Comments section for $S$. paranitens.

\section{Scelio paranitens Yoder, sp. n.}

urn:lsid:zoobank.org:act:25E69EF1-3799-421E-8C05-8D48AB487684

urn:Isid:biosci.ohio-state.edu:osuc_concepts:238057

Figs 5, 11, 79-84; Morphbank ${ }^{23}$

Description. Female body length: $1.78-3.90 \mathrm{~mm}(\mathrm{n}=21)$. Color of antenna in female: concolorous, brown to dark brown throughout. Color of head in female: metallic green to dark teal. Color of mesosoma in female: brown to near black except for yellow to light brown anterior pronotum and propleuron, with metallic green to dark teal sheen throughout. Color of coxae in female: yellow to light brown. Color of leg past coxa in female: yellow to light brown. Color of metasoma in female: brown at base (T1-T3), darkening to apex, T4-T6 with slight metallic blue-green sheen.

Sculpture of lower frons in female: predominantly transverse to slightly arcuate striae, or predominantly fine irregular rugulae. Sculpture of ventrolateral frons in female: smooth, with only setigerous punctures. Form of malar sulcus in female: sulcus percurrent, slit, groove or carina extremely narrow but course well defined, or not percurrent, with some sections variously obliterated. Sculpture of upper frons of female: fine rugulae to slightly transverse sculpture, above ocellus very smooth, with only setigerous punctures. Sculpture of dorsal head between and posterior to lateral ocelli in female: smooth, with only setigerous punctures. Mandible of female: upper tooth typically developed, lower tooth very short but clearly present, truncate to pointed.

Transverse pronotal carina in female: well developed, linear or with extremely slight deviations, contiguous with mesoscutum or interrupted by a single subpolygonal cell, anterior shoulder relatively abruptly transitioned to anterior pronotum. Sculpture of medial mesoscutum in female: very smooth, with only setigerous punctures. Sculpture of notaular course in female: more or less undifferentiated to slightly more robust and coarse relative to medial sculpture. Sculpture of lateral mesoscutum in female: absent, or with obliterated patch that covers at least $1 / 2$ of area. Sculpture of mesoscutellum in female: predominantly smooth,with only scattered setigerous punctures. Sculpture of lateral pronotum in female (excluding 
interstitial sculpture): predominantly smooth, with slight reticulations along ventral and posterior margin. Pronotal verricule in female: small bump with 1-2 very short setae at center. Pronotal setal patch posteroventral to end of lateral epomial carina in female: very sparse (around 1-3), long, erect setae. Sculpture of mesopleural depression in female: surface smooth or with very faint coriaceous (obliterated) sheen, with minute foveae or grooves along posterior margin. Pilosity of anteroventral metapleuron in female: dense patch of semi-decumbent to erect setae. Dorsal surface of hind tibia in female: sparse, elongate, erect and slightly curved. Shape of

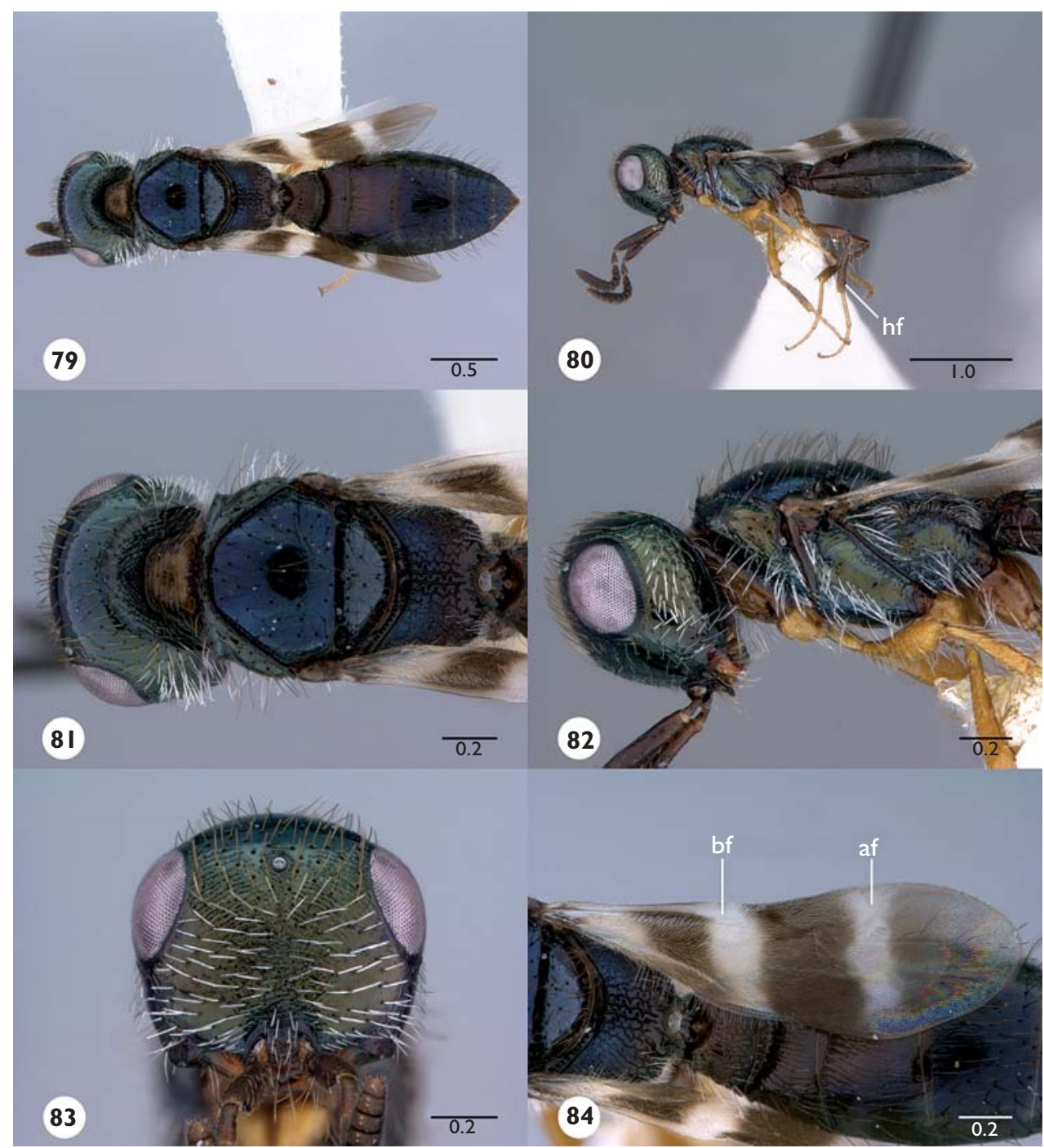

Figures 79-84.62 Scelio paranitens sp. n. (OSUC 211472). $\mathbf{7 9}$ Habitus, dorsal view 80 Habitus, lateral view 8 I Mesosoma, dorsal view 82 Mesosoma, lateral view 83 Head, anterior view 84 Fore wing, lateral view. Abbreviations: $b f$, basal fascia; $a f$, apical fascia. Scale bars in millimeters. 
hind femur in female: narrow, dorsal and ventral surfaces relatively symmetrical. Basal pigmented spot of fore wing in female: percurrent from submarginal vein to posterior margin, strip-like (a band), divided only by hyaline course of $\mathrm{M}+\mathrm{Cu}$. Basal fascia of fore wing in female: subrectangular, strip-like, percurrent from anterior to posterior margin. Apical fascia of fore wing in female: broad, hyaline, percurrent from anterior to posterior fore wing margin, apex of fore wing past fascia concolorous with distal patch.

Sculpture of dorsal T1 in female: polygonal-reticulate, interstices more or less smooth. Sculpture of dorsal T2 in female: fine parallel to slightly reticulate striae with minutely colliculate to transverse sculpture within interstices. Sculpture of anterior T2 through anterior depression in female: percurrent. Sculpture of dorsal T3 in female: fine parallel to irregular longitudinal striae, with reticulation absent to moderately present. Medial sculpture of T4 in female: obliterated to smooth. Medial sculpture of T5 in female: obliterated to smooth. Sculpture of T2-T5 curved transition from dorsal to lateral terga in female: obliterated to smooth. Profile of female metasoma in lateral view: ventral surface more or less flat, dorsal surface weakly to strongly arched from T2-T6 highest point between T4-5, evenly curved to T6. Sculpture of lateral T2-T6 in female: scattered variously obliterated faint fine irregular rugulae. Pilosity of laterotergites in female: present on T2.

Diagnosis. Most similar to $S$. nitens with which it shares the smooth mesoscutum and strong metallic coloration, differing by presence of the apical fore wing fascia and the sparse erect setae on the dorsal surface of the hind tibia.

Etymology. In reference to the high degree of similarity to $S$. nitens.

Link to distribution map. [http://osuc.biosci.ohio-state.edu/HymOnline/maplarge.html?id=238057]

Material examined. Holotype female: SOUTH AFRICA: KwaZulu-Natal Prov., Ngome State Forest, 14.IV-17.IV.1993, pan trap, J. Klimaszewski, OSUC 211496 (deposited in CNCI). Paratypes: (52 females) BOTSWANA: 7 females, OSUC 211449 , 211493, 211526 (CNCI); OSUC 164237, 164260, 164262 (OSUC); OSUC 207578 (USNM). KENYA: 7 females, CASENT 2042598-2042599, 2042601-2042602 (CASC); OSUC 211497, 211541-211542 (CNCI). SOUTH AFRICA: 34 females, OSUC 211293, 211295, 211452, 211454, 211461-211469, 211472-211474, 211476-211478, 211481, 211484-211485, 211487, 211491, 211494 (CNCI); OSUC 244169 (MCZC); OSUC 142599, 171684, 171689, 171691, 234733 (OSUC); OSUC 167019, 174665, 213486 (SANC). ZIMBABWE: 4 females, OSUC 211471, 211479, 211483, 211492 (CNCI). Other material: SOUTH AFRICA: 1 female, OSUC 254458 (BMNH).

Comments. The pilosity of the head (Fig. 83) shows a strong transition from white ventrally to brown dorsally. The specimens from Botswana may represent a new species but are presently included in $S$. paranitens. While this series is atypical for its slightly narrower metasoma, lighter color (more green), and somewhat more gracile habitus, there appear to be no other consistent differences between the Botswana specimens and the South African material. 


\section{Scelio parapulchripennis Yoder, sp. n.}

urn:Isid:zoobank.org:act:E079E393-E95B-4B68-80FB-9AD8BCFED4BA urn:Isid:biosci.ohio-state.edu:osuc_concepts:238053

Figs 1, 6, 10, 12, 85-90; Morphbank ${ }^{24}$

Description. Female body length: $2.92-3.60 \mathrm{~mm}(\mathrm{n}=21)$. Male body length: $2.52-$ $3.20 \mathrm{~mm}(\mathrm{n}=20)$. Color of antenna in female: A1 brown to dark brown, tip of A2 and A3 slightly lighter (to yellow), remaining brown to dark brown. Color of head in female: black. Color of mesosoma in female: dark brown to black. Color of coxae in female: brown to dark brown. Color of leg past coxa in female: brown to dark brown. Color of metasoma in female: brown to dark brown.

Sculpture of lower frons in female: predominantly fine irregular rugulae. Sculpture of ventrolateral frons in female: minutely rugulose to obliterated, sculpture appearing slightly rough, without fine umbilicate sculpture. Form of malar sulcus in female: sulcus percurrent, slit, groove or carina extremely narrow but course well defined. Sculpture of upper frons of female: rugulose, with dorsoventral trend. Sculpture of dorsal head between and posterior to lateral ocelli in female: rugulose, obliterated in spots or not. Mandible of female: upper tooth typically developed, lower tooth very short but clearly present, truncate to pointed.

Transverse pronotal carina in female: well developed, linear or with extremely slight deviations, contiguous with mesoscutum or interrupted by a single subpolygonal cell, anterior shoulder relatively abruptly transitioned to anterior pronotum. Sculpture of medial mesoscutum in female: slightly flattened and rounded reticulations, sometimes few reticulations broken resulting in irregular rugulae. Sculpture of notaular course in female: more or less undifferentiated to slightly more robust and coarse relative to medial sculpture. Sculpture of lateral mesoscutum in female: present. Sculpture of mesoscutellum in female: predominantly irregular reticulate to rugulose, carinae slightly to strongly flattened, with or without slight longitudinal trend. Sculpture of lateral pronotum in female (excluding interstitial sculpture): with smooth to obliterated patch immediately below lateral epomial carina, otherwise reticulate with few to moderate longitudinal elements. Pronotal verricule in female: apparently absent. Pronotal setal patch posteroventral to end of lateral epomial carina in female: dense (around 5 to many) small patch of appressed to slightly semi-decumbent setae. Sculpture of mesopleural depression in female: predominantly irregularly reticulate. Pilosity of anteroventral metapleuron in female: glabrous, or sparsely setose. Dorsal surface of hind tibia in female: typical distribution and moderate length, setae appressed to loosely appressed, more or less straight. Shape of hind femur in female: narrow, dorsal and ventral surfaces relatively symmetrical. Basal pigmented spot of fore wing in female: percurrent from submarginal vein to posterior margin, striplike (a band), divided only by hyaline course of $\mathrm{M}+\mathrm{Cu}$. Basal fascia of fore wing in female: subrectangular, striplike, percurrent from anterior to posterior margin. Apical fascia of fore wing in female: broad, more or less semi- 
circular, only slightly lightened, without lighter patch posteriorly, gradually lighter to apex of fore wing.

Sculpture of dorsal T1 in female: longitudinally striate, with moderate to dense reticulation, intersticies rough throughout. Sculpture of dorsal T2 in female: fine parallel to slightly reticulate striae with minutely colliculate to transverse sculpture within interstices. Sculpture of anterior T2 through anterior depression in female: interrupted with by a smooth strip, majority of sculpture not contiguous with that of posterior T2. Sculpture of dorsal T3 in female: fine parallel to irregular longitudinal striae, with

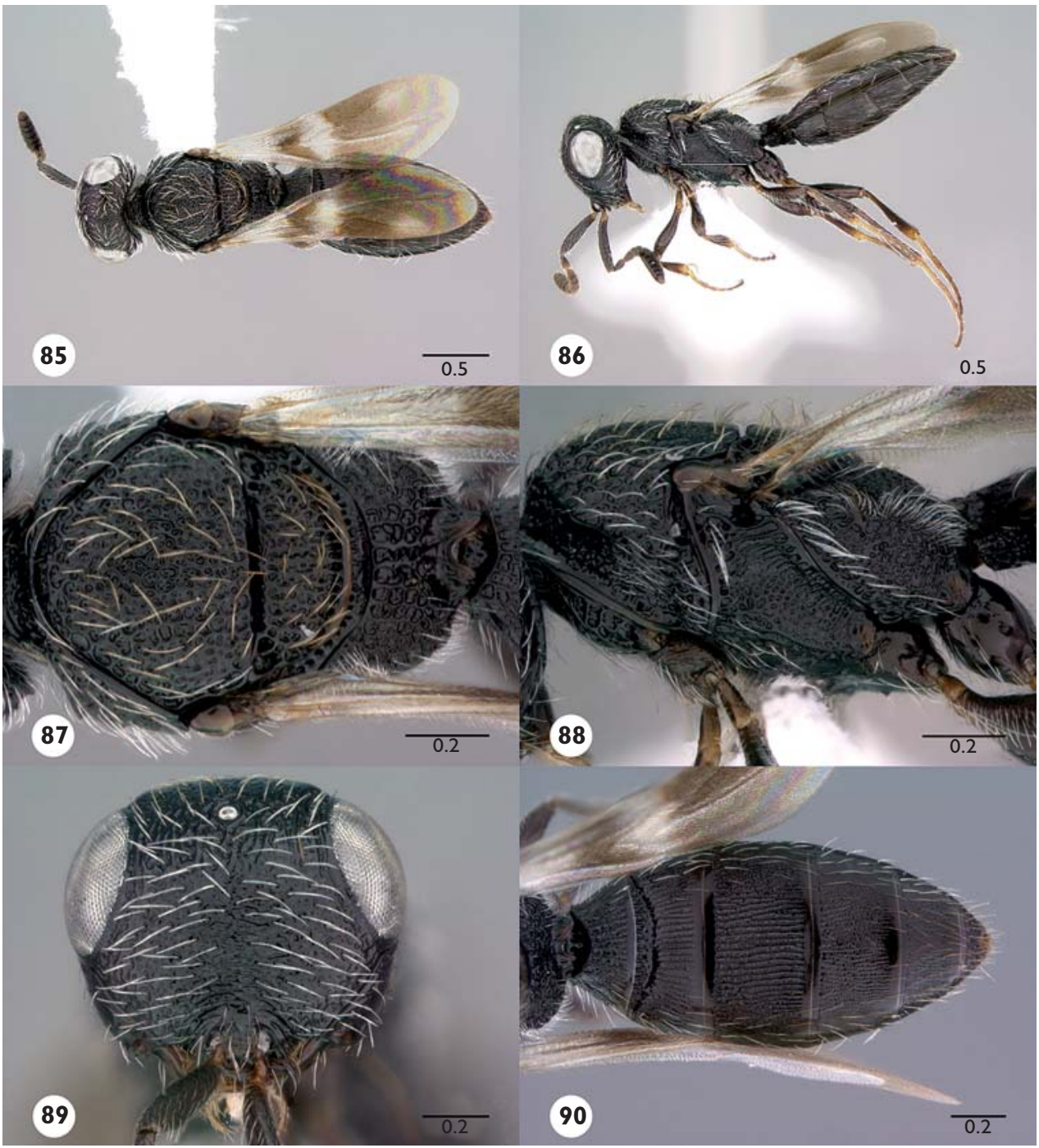

Figures 85-90.63 Scelio parapulchripennis sp. n. female (CASENT 2042134). 85 Habitus, dorsal view 86 Habitus, lateral view $\mathbf{8 7}$ Head and mesosoma, dorsal view $\mathbf{8 8} \mathrm{Head}$ and mesosoma, lateral view 89 Head, anterior view $\mathbf{9 0}$ Metasoma, dorsal view. Scale bars in millimeters. 
reticulation absent to moderately present. Medial sculpture of T4 in female: present. Medial sculpture of T5 in female: present, obliterated to smooth. Sculpture of T2-T5 curved transition from dorsal to lateral terga in female: sculptured. Profile of female metasoma in lateral view: dorsal and ventral surfaces more or less evenly convex. Sculpture of lateral T2-T6 in female: fine irregular longitudinal striae throughout. Pilosity of laterotergites in female: present on T1-T3.

Diagnosis. Most similar to $S$. baoli, sharing the absence of metallic color, completely sculptured mesoscutum and percurrent transverse pronotal carina. Scelio parapulchripennis differs in the parallel longitudinal sculpture of T3 (Fig. 10), contrasting with the fine and reticulate sculpture in S. baoli (Fig. 9).

Etymology. In reference to the general similarity and past confusion with $S$. pulchripennis.

Link to distribution map. [http://osuc.biosci.ohio-state.edu/HymOnline/maplarge.html?id=238053]

Associations. Emerged from ootheca of Acrotylus patruelis (Herrich-Schäffer) (Orthoptera: Acrididae, Oedipodinae); emerged from Oedaleus virgula (Snellen van Vollenhoven) (Orthoptera: Acrididae, Oedipodinae).

Material examined. Holotype female: MADAGASCAR: Toliara Auto. Prov., Andohahela N.P., parcel II, transitional forest, MA-02-20-30, Tsimelahy, $24^{\circ} 56.21^{\prime}$ S 46⒊60'E, 180m, 22.VI-29.VI.2003, Malaise trap, M. Irwin, F. Parker \& R. Harin'Hala, CASENT 2043553 (deposited in CASC). Paratypes: MADAGASCAR: 78 females, 36 males, CASENT 2042131-2042145, 2042628, 2043324, 2043350, 2043389-2043390, 2043554, 2043561, 2043567, 2043591, 2043627, 2043629, 2043634-2043635, 2043689, 2043926, 2132005, 2132091, 2132613, 2132662, 2132682, 2132831, 2132891, 2133085, 2133097, 2133185, 2133203, 2133205, 2133216-2133218, 2133220-2133221, 2133223-2133224, 2133308, 21333682133369, 2133467-2133468, 2133534-2133537, 2133676, 2133697, 2133766, 2134001-2134003, 2134047, 2134136-2134137, 2134196, 2134214, 2134238, 2134279, 2134321, 2134533, 2134583-2134584, 2134641, 8030236-8030237, 8106004, 8106006-8106009, 8106011-8106012, 8106178-8106180, 8106242, $8106454,8106512,8106537,8106748,8106885,8106975$, OSUC 211628 (CASC); OSUC 211504-211509, 211528-211529, 211574 (CNCI); OSUC 173949-173950, 244170-244172, 244196-244199 (MNHN).

Comments. Four specimens (OSUC 244196-244199), most of which (excluding 244199) were previously determined as $S$. pulchripennis, were reared from ootheca of Oedaleus virgula, an oedipodine acridid. Several specimens are variously misshapen, perhaps due to handling pre-emergence. A second series (OSUC 173949, 173950, 244170-244172) is labeled ex Acrotylus patruelis, another oedipodine acridid. In both series the state of the fore wing apical fascia is difficult to interpret due to fading of the apex or the mount, but it appears to be present and the transverse pronotal carina is well developed, confirming the specimens as $S$. parapulchripennis. Males are notable for their slightly infuscate wings, a state not observed in other species. See also comments section for S. baoli. 


\section{Scelio poecilopterus Priesner}

urn:lsid:zoobank.org:act:E98D304A-51B8-4742-8723-688D63B7DB69

urn:lsid:biosci.ohio-state.edu:osuc_concepts:5307

Figs 91-96; Morphbank ${ }^{25}$

Scelio poecilopterus Priesner, 1951: 147 (original description, keyed); Kononova \& Kozlov, 2008: 138, 143 (description, keyed, synonymy).

Scelio princeps Nixon, 1958 new synonymy: 305 (original description, keyed); Nixon:

Masner, 1965a: 94 (type information). urn:lsid:zoobank.org:act:76903862-699C-

438B-9339-07D88C0F5F4B; urn:lsid:biosci.ohio-state.edu:osuc_concepts:5309

Description. Female body length: 3.22-4.17 mm ( $\mathrm{n}=14)$. Male body length: 2.99$3.42 \mathrm{~mm}(\mathrm{n}=2)$. Color of antenna in female: A1 brown to dark brown, A2-A3 yellowbrown, remaining brown to dark brown. Color of head in female: black. Color of mesosoma in female: orange brown with medial dark brown patch on posteromedial mesoscutum, very rarely dark patch more or less absent. Color of coxae in female: orange-brown to dark brown. Color of leg past coxa in female: orange-brown to dark brown. Color of metasoma in female: amber-orange to orange at base (typically T1T3) to brown to dark brown at apex.

Sculpture of lower frons in female: predominantly transverse to slightly arcuate striae. Sculpture of ventrolateral frons in female: smooth, with only setigerous punctures. Form of malar sulcus in female: not percurrent, with some sections variously obliterated. Sculpture of upper frons of female: smooth, with only setigerous punctures, or fine rugulae to slightly transverse sculpture, above ocellus very smooth, with only setigerous punctures. Sculpture of dorsal head between and posterior to lateral ocelli in female: smooth, with only setigerous punctures. Mandible of female: upper tooth slightly elongate, elongate-triangular, lower tooth absent to almost imperceptible, a slight extension of the inner-ventral margin.

Transverse pronotal carina in female: absent mesad, transition from dorsal shoulder to anterior pronotum not sharply delimited but rather slightly curved, if appearing slightly present then either obliterated medially or composed of adjacent subpolygonal sculpture. Sculpture of medial mesoscutum in female: predominantly smooth with scattered setigerous punctures, posterior margin adjacent mesoscutellum with short parallel grooves of varying length, rarely partially obliterated grooves present further towards anterior. Sculpture of notaular course in female: more or less undifferentiated to slightly more robust and coarse relative to medial sculpture. Sculpture of lateral mesoscutum in female: absent, or with obliterated patch that covers at least $1 / 2$ of area. Sculpture of mesoscutellum in female: predominantly smooth, with only scattered setigerous punctures, anterior margin adjacent mesoscutum with short parallel grooves of varying length. Sculpture of lateral pronotum in female (excluding interstitial sculpture): with or without slight smooth patch below lateral epomial carina, otherwise loosely longitudinally carinate, with very few to no reticulate elements. Pronotal verricule in female: base more or less unmodified, with tightly clumped clump of 
short to moderately elongate setae. Pronotal setal patch posteroventral to end of lateral epomial carina in female: dense (around 5 to many) small patch of appressed to slightly semi-decumbent setae, or sparse (around 2-5) scattered, shorter semidecumbent to erect setae. Sculpture of mesopleural depression in female: anterior $1 / 3$ to $1 / 2$ smooth, posterior longitudinally striate, with few to no reticulations. Pilosity of anteroventral metapleuron in female: glabrous, or sparsely setose. Dorsal surface of hind tibia in female: typical distribution and moderate length, setae appressed to loosely appressed, more or less straight. Shape of hind femur in female: narrow, dorsal and ventral sur-

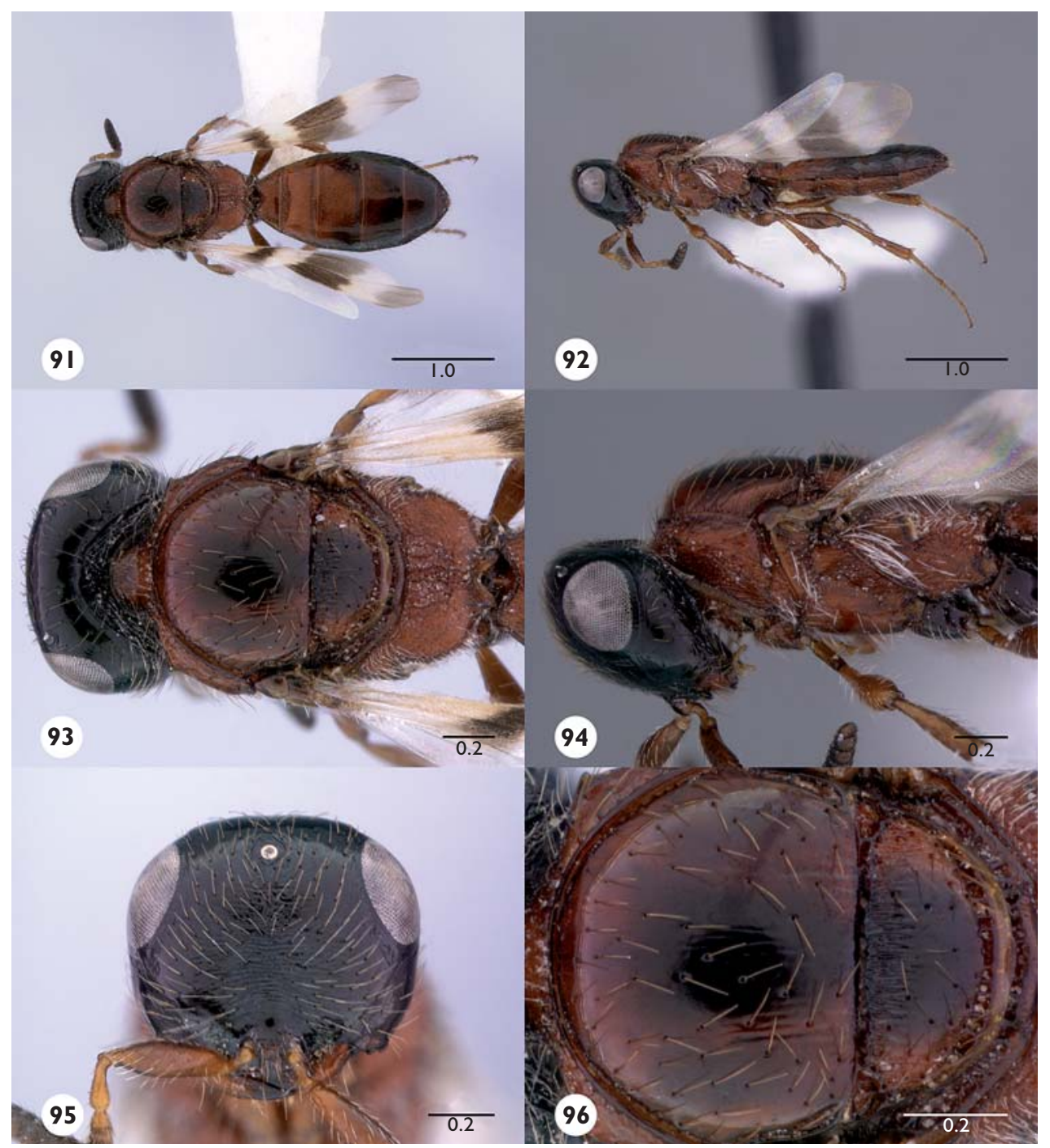

Figures 91-96. ${ }^{64}$ Scelio poecilopterus Priesner (OSUC 235088). 9 I Habitus, dorsal view 92 Habitus, lateral view 93 Mesosoma, dorsal view 94 Mesosoma, lateral view 95 Head, anterior view 96 Mesonotum, dorsal view. Scale bars in millimeters. 
faces relatively symmetrical. Basal pigmented spot of fore wing in female: percurrent from submarginal vein to posterior margin, striplike (a band), divided only by hyaline course of $\mathrm{M}+\mathrm{Cu}$. Basal fascia of fore wing in female: subrectangular, striplike, percurrent from anterior to posterior margin. Apical fascia of fore wing in female: broad, hyaline, percurrent from anterior to posterior fore wing margin, apex of fore wing past fascia only slightly darker.

Sculpture of dorsal T1 in female: longitudinally striate, with few to no transverse divisions or reticulations, interstices smooth or with very slight irregular microsculpture. Sculpture of dorsal T2 in female: appearing smooth, with extremely slight sculpture (shagreen) visible at oblique angles. Sculpture of anterior T2 through anterior depression in female: interrupted with by a smooth strip, majority of sculpture not contiguous with that of posterior T2. Sculpture of dorsal T3 in female: more or less smooth, with extremely slight sculpture (shagreen) visible at oblique angles. Medial sculpture of T4 in female: obliterated to smooth. Medial sculpture of T5 in female: obliterated to smooth. Sculpture of T2-T5 curved transition from dorsal to lateral terga in female: obliterated to smooth. Profile of female metasoma in lateral view: dorsal and ventral surfaces more or less evenly convex. Sculpture of lateral T2-T6 in female: predominantly smooth, in some specimens with very small patch of striae to obliterated grooves ventrally. Pilosity of laterotergites in female: present on T1-T4, present on T1-T3.

Diagnosis. Diagnosable from all non-metallic species by the black head and orange-brown mesosoma and base of mesosoma, and the relative lack of sculpture throughout. Differing from the smaller $S$. variegatus in the absence of fine striae on the medial mesoscutum and mesoscutellum and the smooth upper frons and dorsal head which has dense, very fine minute reticulations in $S$. variegatus.

Link to distribution map. [http://osuc.biosci.ohio-state.edu/HymOnline/maplarge.html?id=5307]

Associations. Emerged from eggs of Acrotylus longipes (Charpentier) (Orthoptera: Acrididae, Oedipodinae); emerged from eggs of Diabolocatantops axillaris (Thunberg) (Orthoptera: Acrididae, Catantopinae; cited as Catantops axillaris); emerged from eggs of Ochrilidia gracilis (Krauss) (Orthoptera: Acrididae, Gomphocerinae); emerged from Heteracris littoralis (Rambur) (Orthoptera: Acrididae, Eyprepocnemidinae; cited as Thisoicetrus littoralis).

Material examined. Holotype female of Scelio princeps Nixon: ERITREA: Wekiro (Wakhiro), 8.XI.1956, D.J. Greathead, OSUC 254485 (deposited in BMNH). Other material (50 females, 3 males): EGYPT: 1 female, OSUC 244167 (USNM, paratype of Scelio poecilopterus Priesner). ERITREA: 12 females, 1 male, OSUC 254486-254497 (BMNH); OSUC 235080 (CNCI). INDIA: 1 female, OSUC 235082 (CNCI). OMAN: 1 female, OSUC 211571 (CNCI). SAUDI ARABIA: 2 females, OSUC 211570, 235077 (CNCI). SPAIN: 3 females, OSUC 254451-254453 (BMNH). UNITED ARAB EMIRATES: 29 females, 2 males, OSUC 254454, 254498-254506, 254508-254514 (BMNH); OSUC 211535-211539, 211572-211573, 235085235091 (CNCI). YEMEN: 1 female, OSUC 211569 (CNCI). 
Comments. We observed several smaller individuals (e.g., OSUC 211571) that were less robustly sculptured and more melanic than seen in a majority of specimens. The metasoma is remarkable for its relative absence of sculpture both dorsally and ventrally.

We have been unable to locate many of the primary types described by Priesner (1951), including the holotype of $S$. poecilopterus. Our interpretation of this name is based on a specimen in the USNM (OSUC 244167) that is labelled as a paratype. We can find no evidence that the use of the name by Kononova and Kozlov (2008) is based on anything other than the printed description.

\section{Scelio pulchripennis Brues}

urn:Isid:zoobank.org:act:AFB58BB5-D2EB-4FE0-BD7A-8280749B331B

urn:lsid:biosci.ohio-state.edu:osuc_concepts:5311

Figs 97-108; Morphbank ${ }^{26}$

Scelio pulchripennis Brues, 1906: 109 (original description); Kieffer, 1926: 310, 323

(description, keyed); Ferrière, 1952: 118 (diagnosis); Nixon, 1958: 306 (description, keyed); Masner, 1965: 300 (type information); Noonan, 1984: 6 (type information).

Scelio (Scelio) pulchripennis Brues, 1910: 74 (subgeneric assignment).

Description. Female body length: $3.60-3.98 \mathrm{~mm}(\mathrm{n}=3)$. Color of antenna in female: concolorous, brown to dark brown throughout. Color of head in female: black. Color of mesosoma in female: dark brown to black. Color of coxae in female: brown to dark brown. Color of leg past coxa in female: brown to dark brown. Color of metasoma in female: yellow brown to light brown.

Sculpture of lower frons in female: predominantly transverse to slightly arcuate striae. Sculpture of ventrolateral frons in female: irregular rugulae with some distinct fine umbilicae. Form of malar sulcus in female: sulcus percurrent, slit, groove or carina extremely narrow but course well defined. Sculpture of upper frons of female: irregular dorsoventral striae and fine umbilications. Sculpture of dorsal head between and posterior to lateral ocelli in female: rugulose, obliterated in spots or not. Mandible of female: upper tooth slightly elongate, elongate-triangular, lower tooth absent to almost imperceptible, a slight extension of the inner-ventral margin.

Transverse pronotal carina in female: absent mesad, transition from dorsal shoulder to anterior pronotum not sharply delimited but rather slightly curved, if appearing slightly present then either obliterated medially or composed of adjacent subpolygonal sculpture. Sculpture of medial mesoscutum in female: fine reticulate to irregularly rugulose. Sculpture of notaular course in female: more or less undifferentiated to slightly more robust and coarse relative to medial sculpture, or broad band of confused minute foveae. Sculpture of lateral mesoscutum in female: present. Sculpture of mesoscutellum in female: irregularly longitudinally 
striate, sparsely to moderately reticulate. Sculpture of lateral pronotum in female (excluding interstitial sculpture): with smooth to obliterated patch immediately below lateral epomial carina, otherwise reticulate with few to moderate longitudinal elements. Pronotal verricule in female: weakly developed ridge-like bump with 1-2 short appressed white setae arising from small pit at apex. Pronotal setal patch posteroventral to end of lateral epomial carina in female: sparse (around 2-5) scattered, shorter semidecumbent to erect setae. Sculpture of mesopleural depression in female: fine reticulations with very slight longitudinal trend, slightly

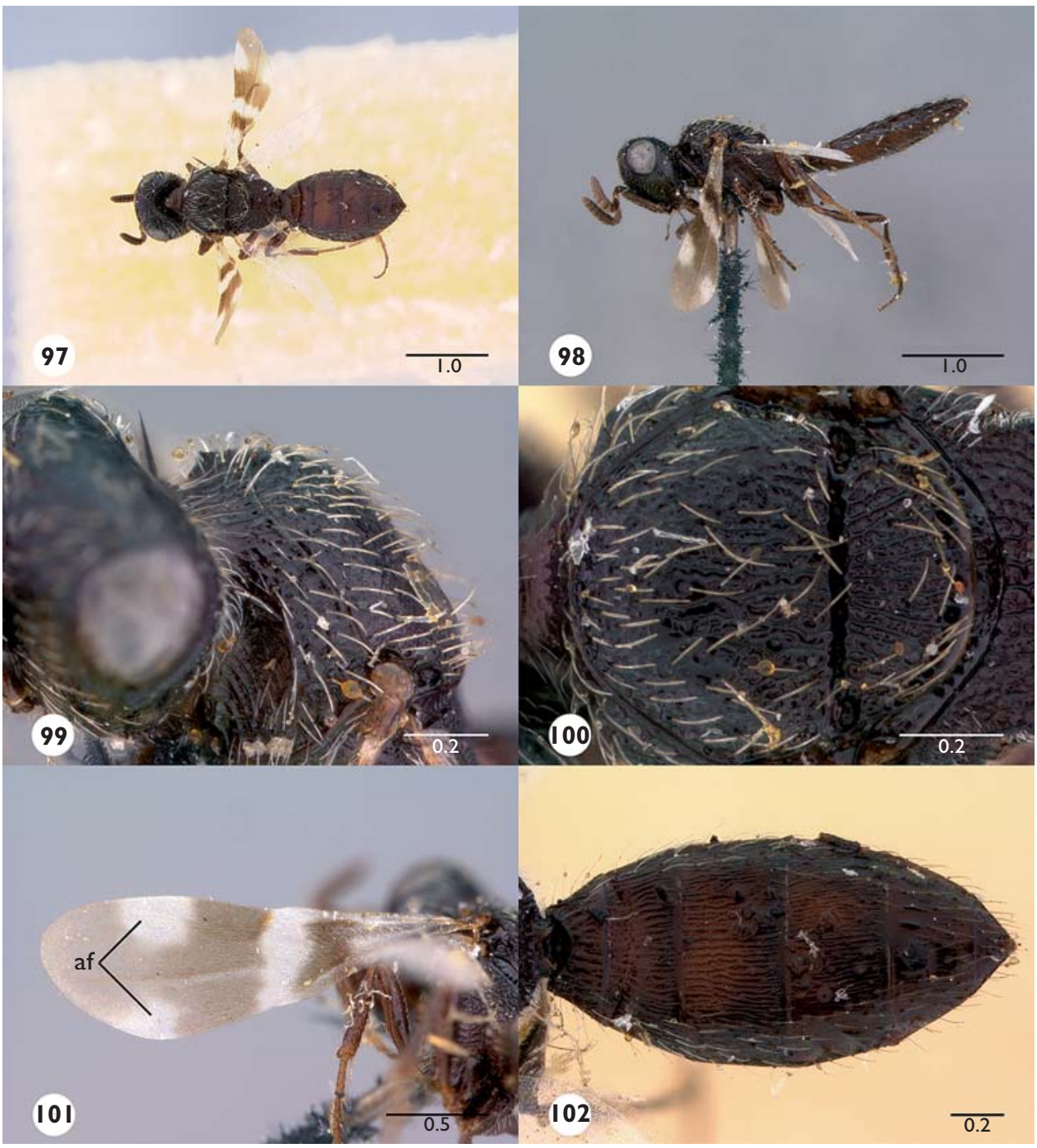

Figures 97-102. ${ }^{65}$ Scelio pulchripennis Brues, lectotype female. 97 Habitus, dorsal view 98 Habitus, lateral view 99 Pronotum, anterolateral oblique view $\mathbf{1 0 0}$ Mesonotum, dorsal view $\mathbf{I} 0 \mathbf{I}$ Fore wing, posterior view 102 Metasoma, dorsal view. Abbreviation: $a f$, apical fascia. Scale bars in millimeters. 
obliterated medially. Pilosity of anteroventral metapleuron in female: glabrous, or sparsely setose. Dorsal surface of hind tibia in female: sparse, elongate, erect and slightly curved. Shape of hind femur in female: narrow, dorsal and ventral surfaces relatively symmetrical. Basal pigmented spot of fore wing in female: percurrent from submarginal vein to posterior margin, striplike (a band), divided only by hyaline course of $\mathrm{M}+\mathrm{Cu}$. Basal fascia of fore wing in female: subrectangular, striplike, percurrent from anterior to posterior margin. Apical fascia of fore wing in female:

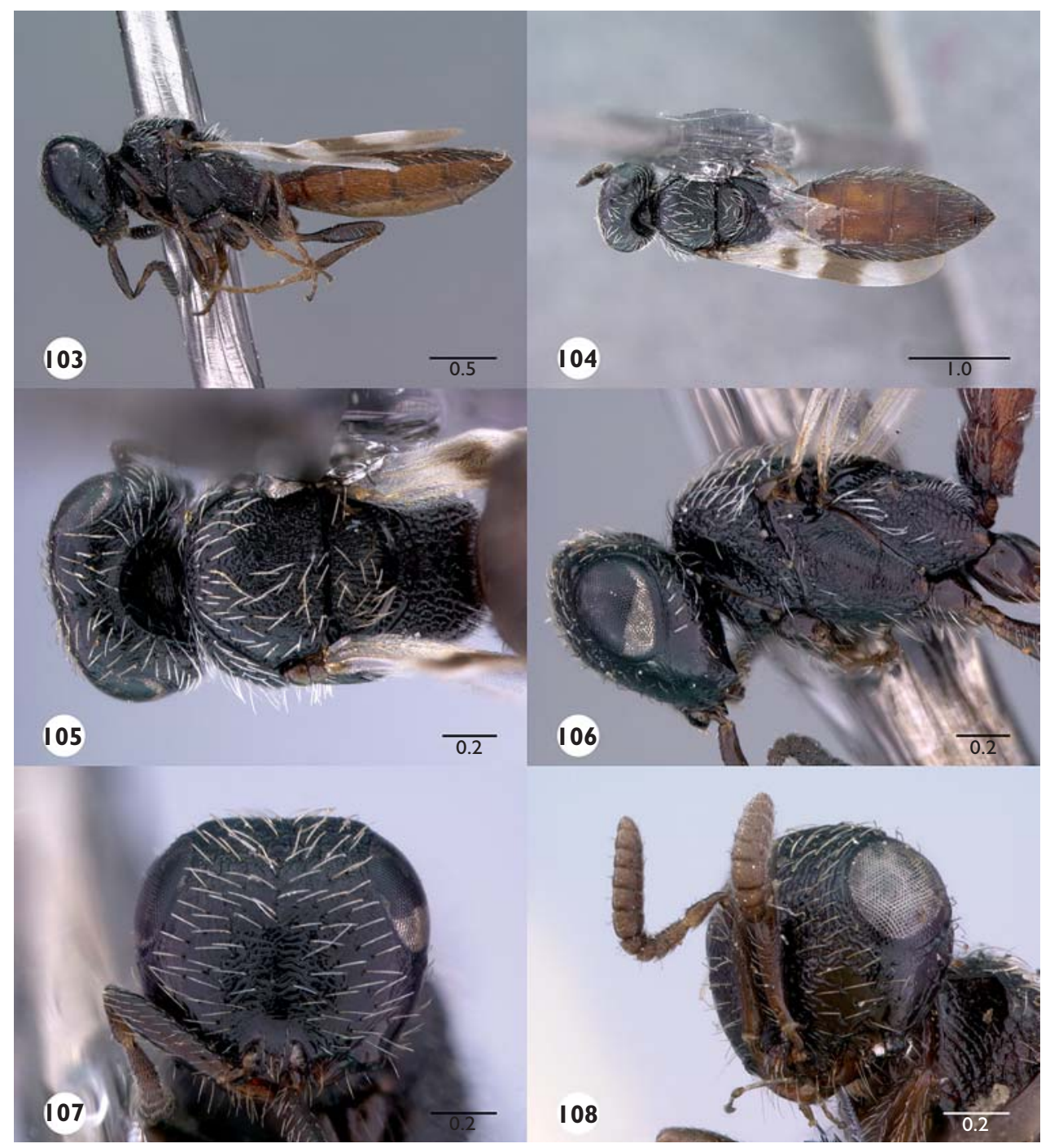

Figures 103-108.66 Scelio pulchripennis Brues, females. 103 Habitus, dorsal view (OSUC 213798) 104 Habitus, lateral view (OSUC 213799) I 05 Head and mesosoma, dorsal view (OSUC 213800) I 06 Head and mesosoma, lateral view (OSUC 213800) 107 Head, anterior view (OSUC 213800) 108 Head, anterolateral view (lectotype). Scale bars in millimeters. 
anterior margin with slightly lighter smaller patch, posterior margin even fainter (less contrasting), broadly divided medially by coloration that gradually fades to apex of fore wing.

Sculpture of dorsal T1 in female: longitudinally striate, with few to no transverse divisions or reticulations, interstices smooth or with very slight irregular microsculpture. Sculpture of dorsal T2 in female: fine parallel to slightly reticulate striae with minutely colliculate to transverse sculpture within interstices. Sculpture of anterior T2 through anterior depression in female: interrupted with by a smooth strip, majority of sculpture not contiguous with that of posterior T2. Sculpture of dorsal T3 in female: fine parallel to irregular longitudinal striae, with reticulation absent to moderately present. Medial sculpture of T4 in female: present. Medial sculpture of T5 in female: present. Sculpture of T2-T5 curved transition from dorsal to lateral terga in female: sculptured. Profile of female metasoma in lateral view: dorsal and ventral surfaces more or less evenly convex. Sculpture of lateral T2-T6 in female: fine irregular longitudinal striae throughout. Pilosity of laterotergites in female: present on T1-T4.

Diagnosis. Similar to those non-metallic species that have the mesoscutum sculptured throughout (without lateral smooth patches), including S. leipo, S. baoli, and S. parapulchripennis. Scelio pulchripennis is most similar to S. leipo which shares the absence of the transverse pronotal carina; it differs from $S$. leipo by the presence of a well-developed apical fascia on the fore wing.

Link to distribution map. [http://osuc.biosci.ohio-state.edu/HymOnline/maplarge.html?id=5311]

Material examined. Lectotype female (present designation): SOUTH AFRICA: Algoa Bay, Capland, 22.I.1896, H. Brauns, MCZ 31020 (MCZC). Other material: SOUTH AFRICA: 9 females, OSUC 254429-254433, 254435 (BMNH); OSUC 213798-213800 (INHS).

Comments. The concept of Scelio pulchripennis presented here is greatly narrowed from past use. As currently delimited S. pulchripennis is not known from Madagascar. However, specimens from there previously have been identified as $S$. pulchripennis. The metasoma is particularly thin in lateral view. The pronotal nucha is relatively smooth. Umbilicate sculpture is clearly evident on the lateral frons (Fig. 3, laf). If the color of the metasoma is not an artifact of the age of the specimens (lighter overall, somewhat orange-brown dorsobasally to brown apically) then it may be useful in diagnosing this species against other closely related non-metallic species.

Brues (1906) based his description on a series of five female specimens from Algoa Bay. Masner (1965b) mistakenly interpreted the single specimen in the MCZC as the unique holotype of this species. Noonan (1984) reported that three additional syntype specimens are deposited in the Milwaukee Public Museum; we have not examined these specimens. We have designated the single female in the MCZC as the lectotype. 


\section{Scelio tria Yoder \& Masner, sp. n.}

urn:lsid:zoobank.org:act:C5002E8B-B258-4264-9196-AF973157D1FB

urn:Isid:biosci.ohio-state.edu:osuc_concepts:238049

Figs 109-114; Morphbank ${ }^{27}$

Description. Female body length: $2.84-3.40 \mathrm{~mm}(\mathrm{n}=8)$. Male body length: $2.62-$ $3.22 \mathrm{~mm}(\mathrm{n}=20)$. Color of antenna in female: A1-A3 yellow to light brown, remaining brown. Color of head in female: black. Color of mesosoma in female: dark brown to black. Color of coxae in female: yellow to light brown. Color of leg past coxa in female: yellow to light brown. Color of metasoma in female: brown to dark brown.

Sculpture of lower frons in female: predominantly transverse to slightly arcuate striae. Sculpture of ventrolateral frons in female: minutely rugulose to obliterated, sculpture appearing slightly rough, without fine umbilicate sculpture. Form of malar sulcus in female: not percurrent, with some sections variously obliterated. Sculpture of upper frons of female: rugulose, above anterior ocellus smooth to slightly sculpture (shagreened). Sculpture of dorsal head between and posterior to lateral ocelli in female: predominantly obliterated, in some specimens with traces of rugulae medially. Mandible of female: upper tooth typically developed, lower tooth very short but clearly present, truncate to pointed.

Transverse pronotal carina in female: absent mesad, transition from dorsal shoulder to anterior pronotum not sharply delimited but rather slightly curved, if appearing slightly present then either obliterated medially or composed of adjacent subpolygonal sculpture. Sculpture of medial mesoscutum in female: anteriorly with small patch of irregular transverse striae, remaining surface divided by one or two straight carinae along median, sculpture in and surrounding carinae slightly irregular, surface otherwise smooth. Sculpture of notaular course in female: one or two straight longitudinal carinae, surface immediately adjacent carinae irregularly rugulose. Sculpture of lateral mesoscutum in female: absent, or with obliterated patch that covers at least $1 / 2$ of area. Sculpture of mesoscutellum in female: irregularly longitudinally striate, sparsely to moderately reticulate. Sculpture of lateral pronotum in female (excluding interstitial sculpture): with or without slight smooth patch below lateral epomial carina, otherwise loosely longitudinally carinate, with very few to no reticulate elements. Pronotal verricule in female: apparently absent, or base more or less unmodified, with tightly clumped clump of short to moderately elongate setae. Pronotal setal patch posteroventral to end of lateral epomial carina in female: dense (around 5 to many) small patch of appressed to slightly semi-decumbent setae. Sculpture of mesopleural depression in female: anterior $1 / 3$ to $1 / 2$ smooth, posterior longitudinally striate, with few to no reticulations. Pilosity of anteroventral metapleuron in female: dense patch of semidecumbent to erect setae. Dorsal surface of hind tibia in female: sparse, elongate, erect and slightly curved. Shape of hind femur in female: narrow, dorsal and ventral surfaces relatively symmetrical. Basal pigmented spot of fore wing in female: percurrent from submarginal vein to posterior margin, striplike (a band), divided only by hyaline course of $\mathrm{M}+\mathrm{Cu}$. Basal fascia of fore wing in female: subrectangular, strip-like, percur- 
rent from anterior to posterior margin. Apical fascia of fore wing in female: broad, hyaline, percurrent from anterior to posterior fore wing margin, apex of fore wing past fascia only slightly darker.

Sculpture of dorsal T1 in female: longitudinally striate, with few to no transverse divisions or reticulations, interstices smooth or with very slight irregular microsculpture. Sculpture of dorsal T2 in female: fine parallel to slightly reticulate striae with minutely colliculate to transverse sculpture within interstices. Sculpture of anterior T2 through anterior depression in female: interrupted with by a smooth strip, majority of sculpture

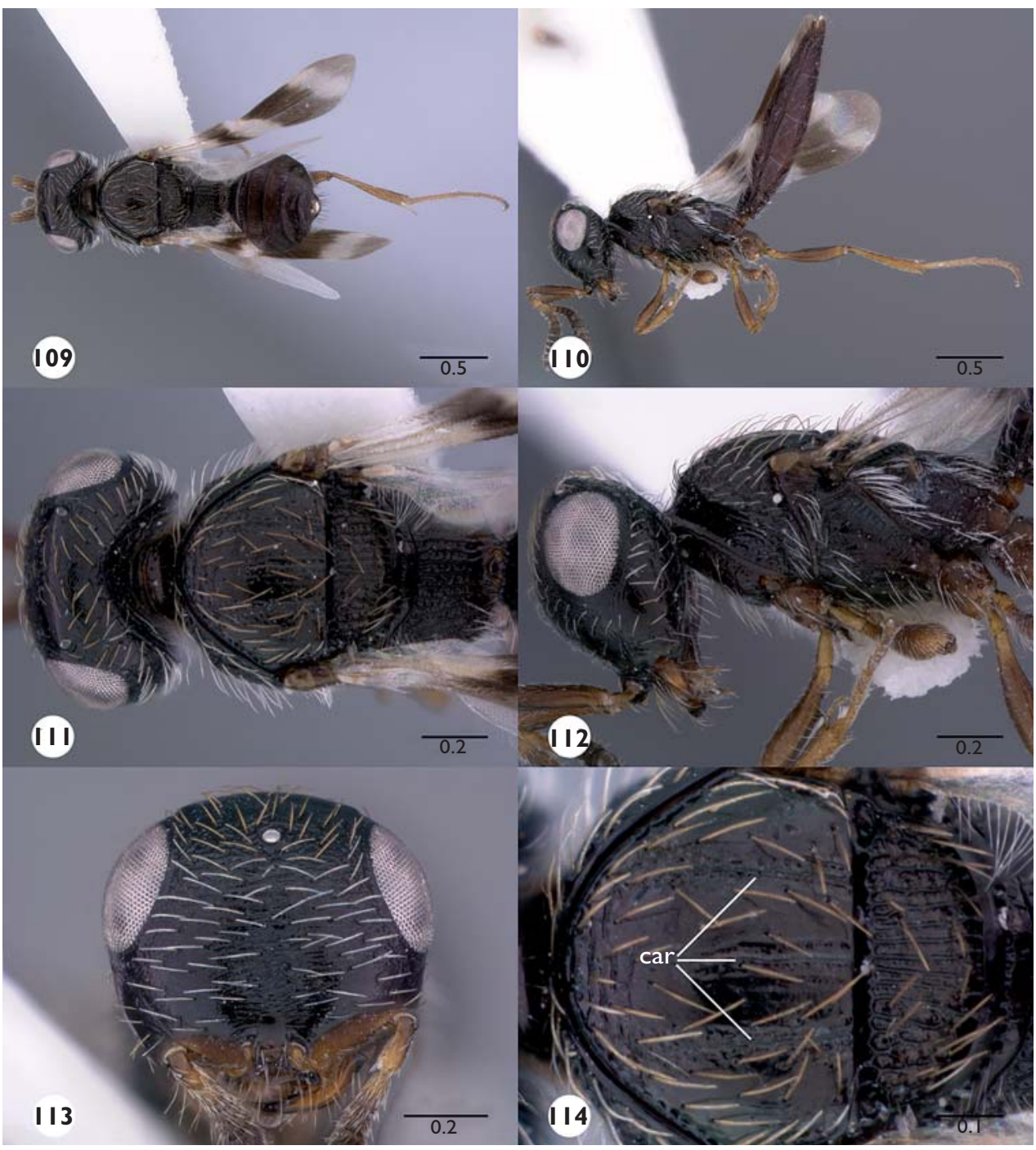

Figures I 09-I I 4. ${ }^{67}$ Scelio tria sp. n. (OSUC 235074). I 09 Habitus, dorsal view I I 0 Habitus, lateral view I I I Mesosoma, dorsal view I I 2 Mesosoma, lateral view I I 3 Head, anterior view I I 4 Mesonotum, dorsal view. Abbrieviation: car, carinae. Scale bars in millimeters. 
not contiguous with that of posterior T2. Sculpture of dorsal T3 in female: fine parallel to irregular longitudinal striae, with reticulation absent to moderately present, but not forming dense reticulations. Medial sculpture of T4 in female: obliterated to smooth. Medial sculpture of T5 in female: obliterated to smooth. Sculpture of T2-T5 curved transition from dorsal to lateral terga in female: obliterated to smooth. Profile of female metasoma in lateral view: dorsal and ventral surfaces more or less evenly convex. Sculpture of lateral T2-T6 in female: with some fine striae ventrally, particularly medially, dorsally smooth. Pilosity of laterotergites in female: present on T1-T2.

Diagnosis. Scelio tria differs from all non-metallic species by the three, sometimes paired, straight longitudinal carinae of the mesoscutum (Fig. 114).

Etymology. Latin for three, in reference to the three longitudinal markings on the mesoscutum.

Link to distribution map. [http://osuc.biosci.ohio-state.edu/HymOnline/maplarge.html?id=238049]

Material examined. Holotype female: INDIA: Delhi Union Terr., Indian Agricultural Research Institute (IARI), New Delhi, 300 m, 11.VII.1990, J. Heraty, OSUC 235083 (deposited in CNCI). Paratypes: INDIA: 8 females, 22 males, 1 unknown sex, OSUC 238937 (BMNH); OSUC 211543-211548, 211563-211564, 211590_ 211597, 234704-234710, 234712-234713, 235074-235075, 235084 (CNCI); UCRC ENT 110190 (UCRC); OSUC 253002 (USNM).

Comments. The sculpture of the dorsal metasoma is particularly fine, with obliterated areas relatively large, and transverse elements relatively reduced.

\section{Scelio turbidus Yoder, sp. n.}

urn:lsid:zoobank.org:act:30053E8F-C9AE-4356-89FB-7B6354F5164B urn:Isid:biosci.ohio-state.edu:osuc_concepts:238052

Figs 3,7,115-120; Morphbank ${ }^{28}$

Description. Female body length: 3.80-3.99 $\mathrm{mm}(\mathrm{n}=7)$. Color of antenna in female: concolorous, brown to dark brown throughout. Color of head in female: black. Color of mesosoma in female: dark brown to black. Color of coxae in female: brown to dark brown. Color of leg past coxa in female: brown to dark brown. Color of metasoma in female: brown to dark brown.

Sculpture of lower frons in female: slightly flattened irregular rugulae with no or only extremely slight transverse orientation, in some specimens rugulae tending to arcs. Sculpture of ventrolateral frons in female: slightly flattened rugulae often with some dorsoventral trend. Form of malar sulcus in female: sulcus percurrent, slit, groove or carina extremely narrow but course well defined. Sculpture of upper frons of female: rugulose, sculpture slightly flattened. Sculpture of dorsal head between and posterior to lateral ocelli in female: rugulose, obliterated in spots or not. Mandible of female: upper tooth typically developed, lower tooth very short but clearly present, truncate to pointed. 
Transverse pronotal carina in female: well developed, linear or with extremely slight deviations, contiguous with mesoscutum or interrupted by a single subpolygonal cell, anterior shoulder relatively abruptly transitioned to anterior pronotum. Sculpture of medial mesoscutum in female: flattened irregular longitudinal striae with many transverse divisions, roundly reticulate in parts, sculpture obliterated in two small bands just posterior to anterior margin, bands not reaching posterior margin of mesoscutum. Sculpture of notaular course in female: more or less undifferentiated to slightly more robust and coarse relative to medial sculpture. Sculpture of lateral mesoscutum in fe-

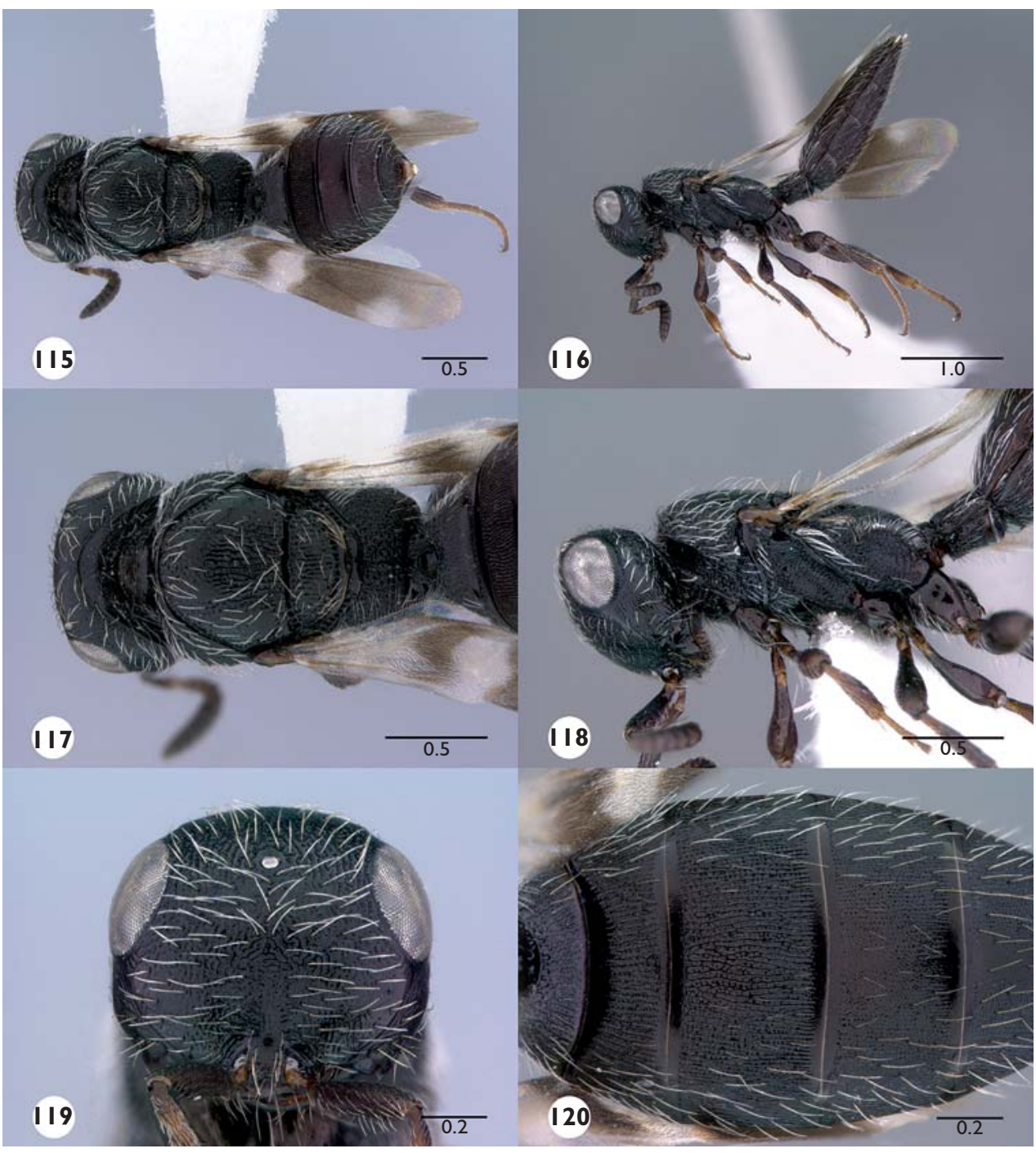

Figures II 5-I 20.68 Scelio turbidus sp. n. (OSUC 223095). I I5 Habitus, dorsal view II 6 Habitus, lateral view $\mathbf{I} \mathbf{1 7} \mathrm{Head}$ and mesosoma, dorsal view $\mathbf{I} \mathbf{8} \mathrm{Head}$ and mesosoma, lateral view $\mathbf{1} \mathbf{9}$ Head, anterior view 120 Medial metasoma, dorsal view. Scale bars in millimeters. 
male: absent, or with obliterated patch that covers at least $1 / 2$ of area. Sculpture of mesoscutellum in female: slightly flattened and polished longitudinal striae, with no to few reticulations. Sculpture of lateral pronotum in female (excluding interstitial sculpture): with smooth to obliterated patch immediately below lateral epomial carina, otherwise reticulate with few to moderate longitudinal elements. Pronotal verricule in female: apparently absent. Pronotal setal patch posteroventral to end of lateral epomial carina in female: dense (around 5 to many) small patch of appressed to slightly semi-decumbent setae. Sculpture of mesopleural depression in female: predominantly longitudinally striate. Pilosity of anteroventral metapleuron in female: glabrous, or sparsely setose. Dorsal surface of hind tibia in female: typical distribution and moderate length, setae appressed to loosely appressed, more or less straight. Shape of hind femur in female: wide, dorsal surface distinctly convex and more strongly arched than ventral. Basal pigmented spot of fore wing in female: percurrent from submarginal vein to posterior margin, striplike (a band), divided only by hyaline course of $\mathrm{M}+\mathrm{Cu}$. Basal fascia of fore wing in female: subrectangular, striplike, percurrent from anterior to posterior margin. Apical fascia of fore wing in female: broad, more or less semi-circular, only slightly lightened, without lighter patch posteriorly, gradually lighter to apex of fore wing.

Sculpture of dorsal T1 in female: polygonal-reticulate, interstices more or less smooth. Sculpture of dorsal T2 in female: fine parallel to slightly reticulate striae with minutely colliculate to transverse sculpture within interstices. Sculpture of anterior T2 through anterior depression in female: interrupted with by a smooth strip, majority of sculpture not contiguous with that of posterior T2. Sculpture of dorsal T3 in female: fine parallel to irregular longitudinal striae, with reticulation absent to moderately present, but not forming dense reticulations. Medial sculpture of T4 in female: present, obliterated to smooth. Medial sculpture of T5 in female: obliterated to smooth. Sculpture of T2-T5 curved transition from dorsal to lateral terga in female: sculptured. Profile of female metasoma in lateral view: dorsal and ventral surfaces more or less evenly convex. Sculpture of lateral T2-T6 in female: uniform longitudinal striae throughout. Pilosity of laterotergites in female: present on T1-T5.

Diagnosis. This species is most similar to $S$. habilis which shares the pattern of obliterated or smooth patches on the mesoscutum. Scelio turbidus is distinguished by the more or less striate sculpture of the mesoscutum (reticulate-rugulose in S. habilis). Scelio turbidus may be distinguished from all other non-metallic species by the combination of the enlarged hind femur and the slightly flattened rugulose sculpture of the frons.

Etymology. Latin for "confused" in reference to the irregular sculpture of the face.

Link to distribution map. [http://osuc.biosci.ohio-state.edu/HymOnline/maplarge.html?id=238052]

Material examined. Holotype female: BOTSWANA: Botswana, Serowe, Farmer's Brigade, IV-1989, Malaise trap, P. Forchhammer, OSUC 211627 (deposited in USNM). Paratypes: (6 females) BOTSWANA: 3 females, OSUC 211446-211447 (CNCI); OSUC 223095 (OSUC). SOUTH AFRICA: 3 females, OSUC 211445, 211455 (CNCI); OSUC 250709 (SANC). Other material: TANZANIA: 1 female, OSUC 250706 (SANC). 
Comments. Individuals of $S$. turbidus have a relatively well-developed vertical epomia, though it does not reach the anteroventral margin of the pronotum. Specimens are notably dorsoventrally flattened, and the propodeum is more or less perpendicular with the mesonotum. Specimens have whitish, semidecumbent setae (slightly more appressed than in S. habilis) on the mesoscutum. All specimens observed have a smooth and shining strip devoid of sculpture at the base of the pronotal nucha. A single specimen from Tanzania (OSUC 250706) is tentatively included here, though it may represent a new species. It is somewhat intermediate between $S$. turbidus and $S$. habilis, though it has more in common with the former. It differs from all other specimens of S. turbidus by the color of pilosity of the mesoscutum (darker, brown), the sculpture of the lower frons (striate, not rugulose), the sculpture of the base of the pronotal nucha (sculptured throughout).

\section{Scelio variegatus Kozlov \& Kononova}

urn:lsid:zoobank.org:act:94A7C307-6A43-4806-B7C0-C66A067AA187

urn:lsid:biosci.ohio-state.edu:osuc_concepts:5353

Figs 121-126; Morphbank ${ }^{29}$

Scelio variegatus Kozlov \& Kononova, 1990: 220, 223 (original description. keyed); Kononova \& Kozlov, 2008: 143 (as junior synonym of Scelio poecilopterus Priesner).

Description. Female body length: $2.68-2.96 \mathrm{~mm}(\mathrm{n}=4)$. Color of antenna in female: A1-A2 yellow to light brown, remaining brown. Color of head in female: black. Color of mesosoma in female: orange brown, rarely with darker patch on medial dorsal mesoscutum. Color of coxae in female: yellow to light brown, or amber-orange. Color of leg past coxa in female: amber-orange. Color of metasoma in female: amber-orange to orange at base (typically T1-T3) to brown to dark brown at apex.

Sculpture of lower frons in female: predominantly transverse to slightly arcuate striae. Sculpture of ventrolateral frons in female: very fine transverse striae with fine interstitial sculpture, appearing granular. Form of malar sulcus in female: sulcus percurrent, slit, groove or carina extremely narrow but course well defined. Sculpture of upper frons of female: very fine rugulae, almost granular in appearance. Sculpture of dorsal head between and posterior to lateral ocelli in female: obliterated to fine coriaceous sheen. Mandible of female: upper tooth slightly elongate, elongate-triangular, lower tooth absent to almost imperceptible, a slight extension of the inner-ventral margin.

Transverse pronotal carina in female: well developed, linear or with extremely slight deviations, contiguous with mesoscutum or interrupted by a single subpolygonal cell, anterior shoulder relatively abruptly transitioned to anterior pronotum. Sculpture of medial mesoscutum in female: parallel striae in posterior $2 / 3$, anterior third with sculpture reduced to absent. Sculpture of notaular course in female: more or less undifferentiated to slightly more robust and coarse relative to medial sculpture. Sculpture of 
lateral mesoscutum in female: absent, or with obliterated patch that covers at least $1 / 2$ of area. Sculpture of mesoscutellum in female: longitudinally striate, with few to no reticulations. Sculpture of lateral pronotum in female (excluding interstitial sculpture): with or without slight smooth patch below lateral epomial carina, otherwise loosely longitudinally carinate, with very few to no reticulate elements. Pronotal verricule in female: apparently absent, or base more or less unmodified, with tightly clumped clump of extremely short setae. Pronotal setal patch posteroventral to end of lateral epomial carina in female: sparse (around 2-5) scattered, shorter semidecumbent to erect setae.

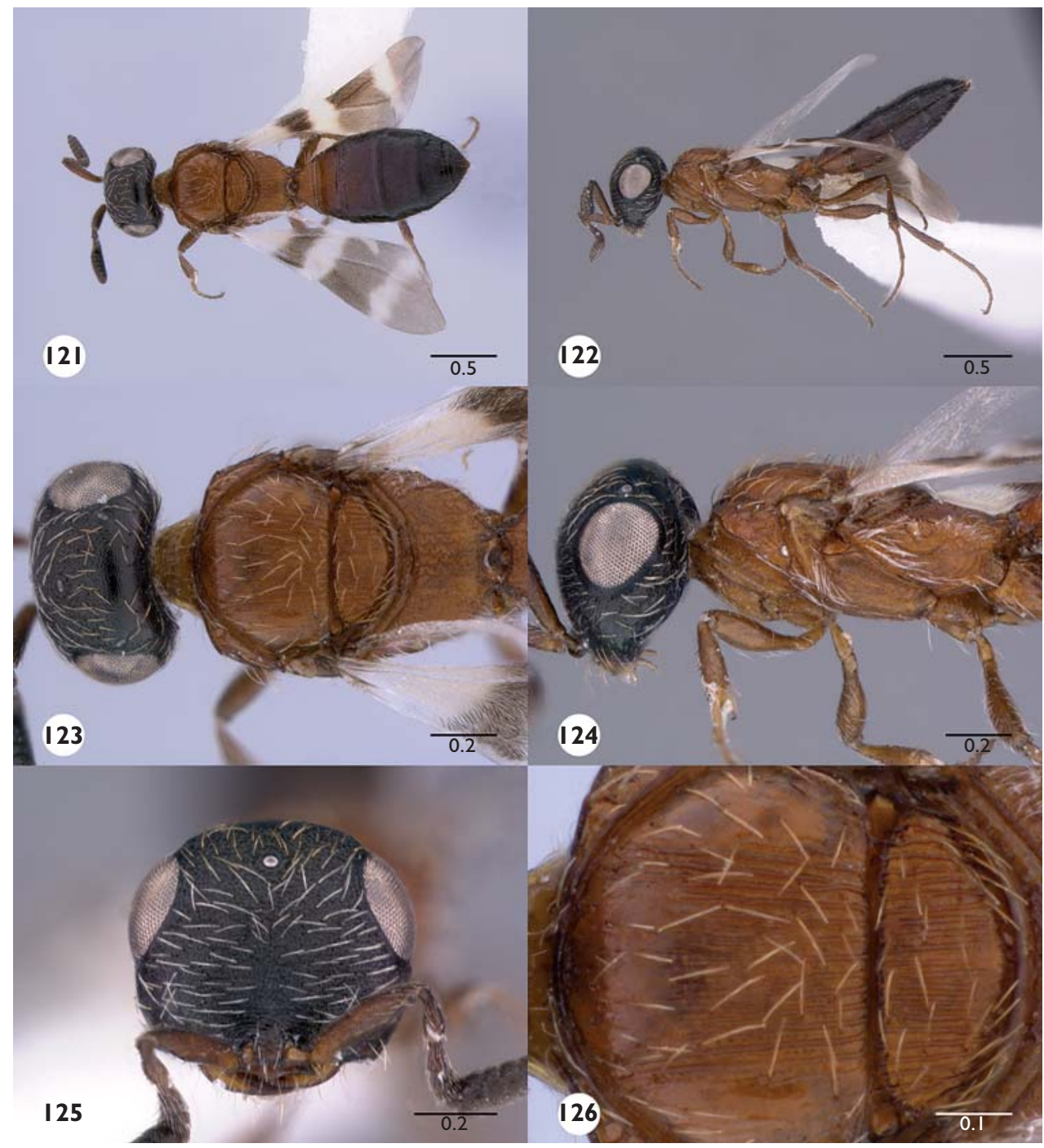

Figures I 2 I-I 26.69 Scelio variegatus Kozlov \& Kononova (OSUC 235091). I 2 I Habitus, dorsal view I 22 Habitus, lateral view I 23 Mesosoma, dorsal view 124 Mesosoma, lateral view I 25 Head, anterior view 126 Metanotum, dorsal view. Scale bars in millimeters. 
Sculpture of mesopleural depression in female: anterior $1 / 3$ to $1 / 2$ smooth, posterior longitudinally striate, with few to no reticulations. Pilosity of anteroventral metapleuron in female: glabrous, or sparsely setose. Dorsal surface of hind tibia in female: typical distribution and moderate length, setae appressed to loosely appressed, more or less straight. Shape of hind femur in female: narrow, dorsal and ventral surfaces relatively symmetrical. Basal pigmented spot of fore wing in female: percurrent from submarginal vein to posterior margin, striplike (a band), divided only by hyaline course of $\mathrm{M}+\mathrm{Cu}$. Basal fascia of fore wing in female: subrectangular, striplike, percurrent from anterior to posterior margin. Apical fascia of fore wing in female: broad, hyaline, percurrent from anterior to posterior fore wing margin, apex of fore wing past fascia only slightly darker.

Sculpture of dorsal T1 in female: longitudinally striate, with few to no transverse divisions or reticulations, interstices smooth or with very slight irregular microsculpture. Sculpture of dorsal T2 in female: appearing smooth, with extremely slight sculpture (shagreen) visible at oblique angles, fine parallel to slightly reticulate striae with minutely colliculate to transverse sculpture within interstices. Sculpture of anterior T2 through anterior depression in female: interrupted with by a smooth strip, majority of sculpture not contiguous with that of posterior T2. Sculpture of dorsal T3 in female: dense minute reticulations, with slight longitudinal elements absent to very sparse. Medial sculpture of T4 in female: obliterated to smooth. Medial sculpture of T5 in female: obliterated to smooth. Sculpture of T2-T5 curved transition from dorsal to lateral terga in female: obliterated to smooth. Profile of female metasoma in lateral view: dorsal and ventral surfaces more or less evenly convex. Sculpture of lateral T2-T6 in female: predominantly smooth, in some specimens with very small patch of striae to obliterated grooves ventrally. Pilosity of laterotergites in female: present on T1-T2.

Diagnosis. Scelio variegatus can be confused only with the larger $S$. poecilopterus with which it shares a similar body color. It differs from $S$. poecilopterus by the fine, almost granular sculpture throughout the head (sculpture absent dorsally in $S$. poecilopter$u s$ ), and the longer, more well-impressed, fine longitudinal striae of the medial mesoscutum (short, irregular, and present only along the posterior margin in S. poecilopterus).

Link to distribution map. [http://osuc.biosci.ohio-state.edu/HymOnline/maplarge.html?id=5353]

Material examined. Other material: ( 8 females) INDIA: 1 female, OSUC 235082 (CNCI). SAUDI ARABIA: 1 female, OSUC 211570 (CNCI). SPAIN (Canary Islands): 3 females, OSUC 254451-254453 (BMNH). UNITED ARAB EMIRATES: 2 females, OSUC 254454 (BMNH); OSUC 235091 (CNCI). YEMEN: 1 female, OSUC 211569 (CNCI).

Comments. The sculpture of the frons is particularly fine, and the interstices are densely sculptured as well resulting in an almost granular appearance. There is much less variation in the length and degree of impression of the longitudinal striae of the medial mesoscutum in $S$. variegatus than in S. poecilopterus.

We saw the holotype of the species prior to undertaking this study; we were subsequently unable to reexamine the specimen. However, based on the original description (largely repeated in Kononova and Kozlov 2008), we feel that our concept well 
matches that originally provided by Kozlov and Kononova (1990). Kononova and Kozlov (2008), apparently on the basis of Priesner's original description of S. poecilopterus, treated $S$. variegatus as a junior synonym of $S$. poecilopterus. We have no doubt that two very similar species exist in this small complex (see diagnoses), and the description of variegatus corresponds well to one of these. Therefore, we have elected to remove $S$. variegatus from synonymy and treat it as a valid species.

\section{Acknowledgments}

Thanks to: J. Cora who provided invaluable database, software, and specimen support; S. Hemly for specimen preparation; and E. Talamas, L. Musetti, C. Taekul for helpful comments and discussion. This work was made possible through the collection and curation of material from the museums listed in material and methods. This material is based upon work supported by the National Science Foundation under grant No. DEB-0614764 to N.F. Johnson and A.D. Austin.

\section{References}

Brues CT (1906) Descriptions of parasitic Hymenoptera from Cape Colony. Bulletin of the Wisconsin Natural History Society 4: 103-112. ${ }^{30}$

Dangerfield P, Austin A, Baker G (2001) Biology, ecology and systematics of Australian Scelio, wasp parasitoids of locust and grasshopper eggs. CSIRO, Collingwood, Victoria, 254 pp. ${ }^{31}$

Deans AR, Yoder MJ, Seltmann KC: Hymenoptera Glossary. http://purl.oclc.org/NET/hymontology [accessed 1.12.2008]

Ferrière C (1952) Deux nouveaux parasites des oeufs de Locusta migratoria migratorioides en Afrique. Bulletin de la Société Entomologique de France 56: 114-118. ${ }^{32}$

Johnson NF (1992) Catalog of world Proctotrupoidea excluding Platygastridae. Memoirs of the American Entomological Institute 51: 1-825.33

Johnson NF, Masner L, Musetti L, van Noort S, Rajmohana K, Darling DC, Guidotti A, Polaszek A (2008) Revision of world species of the genus Heptascelio Kieffer (Hymenoptera: Platygastroidea, Platygastridae). Zootaxa 1776: 1-51. ${ }^{34}$

Kieffer J-J (1910) Hymenoptera. Fam. Scelionidae. Addenda et corrigenda. Genera Insectorum 80: 61-112.35

Kieffer J-J (1926) Scelionidae. Das Tierreich. Vol. 48. Walter de Gruyter \& Co., Berlin, 885 pp. ${ }^{36}$ Kononova SV (1995) [Fam. Scelionidae.] In: Lehr PA [Key to insects of Russian Far East in six volume. vol. 4. Neuropteroidea, Mecoptera, Hymenoptera. Part 2. Hymenoptera], Dal'nauka, Vladivostok, 57-121.37

Kononova SV, Kozlov MA (2008) [Scelionids of the Palearctic (Hymenoptera, Scelionidae). Subfamily Scelioninae] Tovarishchestvo Nauchnykh Izdanii KMK, Saint Petersburg, 489 pp. ${ }^{38}$

Kozlov MA (1972) [On the fauna of Hymenoptera Proctotrupoidea of the Mongolian People's Republic. I. Heloridae, Proctotrupidae, Scelionidae.] [Insects of Mongolia] 1: 645-672.39 
Kozlov MA, Kononova, SV (1990) [Scelioninae of the Fauna of the USSR (Hymenoptera, Scelionidae, Scelioninae).] Nauka, Leningrad, 344 pp. $^{40}$

Masner L (1965a) The types of Proctotrupoidea (Hymenoptera) in the British Museum (Natural History) and in the Hope Department of Entomology, Oxford. Bulletin of the British Museum (Natural History) Entomology Supplement 1: 1-154. ${ }^{41}$

Masner L (1965b) The types of Proctotrupoidea (Hymenoptera) in the Charles T. Brues collection at the Museum of Comparative Zoology. Psyche 72: 295-304.42

Masner L (1976) Revisionary notes and keys to world genera of Scelionidae (Hymenoptera: Proctotrupoidea). Memoirs of the Entomological Society of Canada 97: 1-87.43

Nixon GEJ (1958) A synopsis of the African species of Scelio Latreille (Hymenoptera: Proctotrupoidea, Scelionidae). Transactions of the Royal Entomological Society of London 110: $303-318 .^{44}$

Noonan GR (1984) Type specimens in the insect collections of the Milwaukee Public Museum. Milwaukee Public Museum Contributions in Biology and Geology 58: 1-14. ${ }^{45}$

Priesner H (1951) New genera and species of Scelionidae (Hymenoptera, Proctotrupoidea) from Egypt. Bulletin de l'Institut Fouad I du Desert 1(2): 119-149. ${ }^{46}$

Risbec J (1950) Travaux du Laboratoire d'Entomologie du Secteur Soudanis de Recherches Agronomiques. Gouvernement Général de l'Afrique Occidentale Française, Paris, 639 pp. ${ }^{47}$

Yoder MJ, Valerio AA, Masner L, Johnson NF (2009) Identity and synonymy of Dicroscelio Kieffer and description of Axea, a new genus from tropical Africa and Asia (Hymenoptera: Platygastroidea, Platygastridae). Zootaxa 2003: 1-45.48 


\section{Endnotes}

2

3

4

5

6

7

8

9

http://biocol.org/urn:lsid:biocol.org:col:1009

http://biocol.org/urn:lsid:biocol.org:col:1011 http://biocol.org/urn:lsid:biocol.org:col:1012 http://biocol.org/urn:lsid:biocol.org:col:34797 http://biocol.org/urn:lsid:biocol.org:col:33791 http://biocol.org/urn:lsid:biocol.org:col:33864 http://biocol.org/urn:lsid:biocol.org:col:1014 http://biocol.org/urn:lsid:biocol.org:col:1018 http://biocol.org/urn:lsid:biocol.org:col:34248 http://biocol.org/urn:lsid:biocol.org:col:34336 http://biocol.org/urn:lsid:biocol.org:col:1019 http://www.morphbank.net/?id=464338 http://www.morphbank.net/?id=464340 http://www.morphbank.net/?id=464341 http://www.morphbank.net/?id=464344 http://www.morphbank.net/?id=464346 http://www.morphbank.net/?id=464348 http://www.morphbank.net/?id=464349 http://www.morphbank.net/?id=464363 http://www.morphbank.net/?id=464366 http://www.morphbank.net/?id=464367 http://www.morphbank.net/?id=464368 http://www.morphbank.net/?id=464370 http://www.morphbank.net/?id=464361 http://www.morphbank.net/?id=464372 http://www.morphbank.net/?id=464374 http://www.morphbank.net/?id=464377 http://www.morphbank.net/?id=464378 http://www.morphbank.net/?id=464380 http://lsid.tdwg.org/urn:lsid:biosci.ohio-state.edu:osuc_pubs:169 http://lsid.tdwg.org/urn:lsid:biosci.ohio-state.edu:osuc_pubs:9560 http://lsid.tdwg.org/urn:lsid:biosci.ohio-state.edu:osuc_pubs: 960 http://lsid.tdwg.org/urn:Isid:biosci.ohio-state.edu:osuc_pubs:229 http://lsid.tdwg.org/urn:lsid:biosci.ohio-state.edu:osuc_pubs:21725 http://lsid.tdwg.org/urn:lsid:biosci.ohio-state.edu:osuc_pubs:309 http://lsid.tdwg.org/urn:lsid:biosci.ohio-state.edu:osuc_pubs:310 http://lsid.tdwg.org/urn:lsid:biosci.ohio-state.edu:osuc_pubs:602 http://lsid.tdwg.org/urn:lsid:biosci.ohio-state.edu:osuc_pubs:22613 http://lsid.tdwg.org/urn:lsid:biosci.ohio-state.edu:osuc_pubs:482 http://lsid.tdwg.org/urn:lsid:biosci.ohio-state.edu:osuc_pubs:340 
http://lsid.tdwg.org/urn:lsid:biosci.ohio-state.edu:osuc_pubs:342 http://lsid.tdwg.org/urn:lsid:biosci.ohio-state.edu:osuc_pubs:536 http://lsid.tdwg.org/urn:lsid:biosci.ohio-state.edu:osuc_pubs:311 http://lsid.tdwg.org/urn:lsid:biosci.ohio-state.edu:osuc_pubs:585 http://lsid.tdwg.org/urn:lsid:biosci.ohio-state.edu:osuc_pubs:423 http://lsid.tdwg.org/urn:lsid:biosci.ohio-state.edu:osuc_pubs:345 http://lsid.tdwg.org/urn:lsid:biosci.ohio-state.edu:osuc_pubs:21214 http://lsid.tdwg.org/urn:lsid:biosci.ohio-state.edu:osuc_pubs:22482 http://www.morphbank.net/?id=464489 http://www.morphbank.net/?id=464490 http://www.morphbank.net/?id=464490 http://www.morphbank.net/?id=464490 http://www.morphbank.net/?id=464343 http://www.morphbank.net/?id=464345 http://www.morphbank.net/?id=464347 http://www.morphbank.net/?id=464348 http://www.morphbank.net/?id=464350 http://www.morphbank.net/?id=464364 http://www.morphbank.net/?id=464366 http://www.morphbank.net/?id=464367 http://www.morphbank.net/?id=464369 http://www.morphbank.net/?id=464371 http://www.morphbank.net/?id=464362 http://www. morphbank.net/?id=464373 http://www. morphbank.net/?id=464376 http://www. morphbank.net/?id=464375 http://www.morphbank.net/?id=464377 http://www.morphbank.net/?id=464379 http://www.morphbank.net/?id=464381 